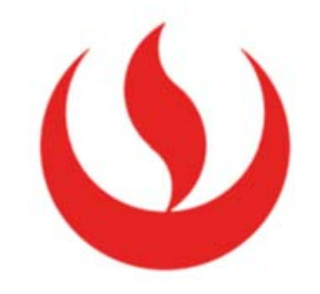

UNIVERSIDAD PERUANA DE CIENCIAS APLICADAS

Facultad de Ingeniería

Programa de Ciencias de la Computación

\title{
DESARROLLO DE APLICACIONES BIOMÉTRICAS Y COGNITIVAS PARA UN MODELO DE ESPEJO INTELIGENTE
}

\author{
TESIS \\ Para optar el título profesional de: Licenciado en Ciencias de la \\ Computación

\section{AUTORES} \\ Araujo García, Ivette Cristina (0000-0003-4775-6692) \\ Linares Salmón, Eduardo Rodrigo (0000-0003-4712-8012)
}

\section{ASESOR DE TESIS}

Burga Durango, Daniel Wilfredo (0000-0003-0312-727X) 
Este trabajo está dedicado a nuestras familias, quienes nos han apoyado a lo largo de toda nuestra carrera universitaria. 


\section{Resumen Ejecutivo}

En los últimos años el avance de las tecnologías de información y comunicación (TIC) han ayudado a mejorar la calidad de vida de las personas. El paradigma de internet de las cosas (IoT) plantea soluciones innovadoras que están cambiando nuestro estilo de vida, debido a esto se propone la implementación de un espejo inteligente, con el cual pretendemos optimizar el tiempo de las personas mientras se preparan para comenzar su día. Con el objetivo de proporcionar servicios de información como clima, información del tráfico, noticias, música y agenda; Ceccaroni implementó un prototipo de espejo inteligente llamado Magical Mirror ${ }^{1}$, en donde las personas podían interactuar con el espejo mediante comandos de voz. En base a esto se ha construido un dispositivo a partir de un vidrio reflejante, monitor LCD, placa Raspberry Pi, cámara y una plataforma IoT orientada a cloud computing, en donde se obtiene la información para mostrar en el espejo mediante servicios web, los cuales son personalizables gracias a una aplicación móvil, que a su vez permite obtener las fotos del usuario para acceder al espejo, mediante reconocimiento facial. Además, para brindarle al usuario una experiencia personalizada, el espejo inteligente incorpora un sistema de recomendación de noticias, implementado utilizando un modelo predictivo, que a su vez usa el algoritmo naive Bayes.

Palabras clave: Espejo inteligente, sistemas de recomendación, reconocimiento facial, internet de las cosas.

\footnotetext{
${ }^{1}$ Luigi Ceccaroni y Xavier Verdaguer (2004) proponen el desarrollo de un dispositivo innovador que incorpore servicios interactivos de ocio e información ofrecidos en I interfaz de un espejo.
} 


\begin{abstract}
In recent years, the advancement of information and communication technologies (ICT) has helped improve the quality of life of people. The paradigm of Internet of Things (IoT) raises innovative solutions that are changing our lifestyle, so we propose the implementation of an intelligent mirror, with which we intend to optimize people's time while preparing to start the day. With the aim of providing information services such as weather, traffic information or public transport, news, music, television and calendar; Ceccaroni implemented a prototype intelligent mirror called Magical Mirror ${ }^{2}$, where people could interact with the mirror using voice commands. Based on this, we have built a device from a reflective glass, an LCD monitor, a Raspberry Pi board, a camera and an IoT platform oriented to cloud computing, where the information displayed in the mirror is obtained through the consumption of web services. , which are customizable thanks to a mobile application, which in turn allows you to obtain the user's photos to access the mirror, by authenticating facial recognition and user information to predict the news that will be displayed according to their profile. In addition, as part of the idea of providing the user with a personalized experience, the intelligent mirror incorporates a news recommendation system, implemented using a predictive model, which in turn uses the Naive Bayes algorithm.
\end{abstract}

Keywords: Smart Mirror, Recommendation Systems, Face Recognition, Internet of Things.

\footnotetext{
${ }^{2}$ Ceccaroni Luigi Ceccaroni and Xavier Verdaguer (2004) propose the development of an innovative device that incorporates interactive leisure and information services offered in the interface of a mirror.
} 


\section{Tabla de contenido}

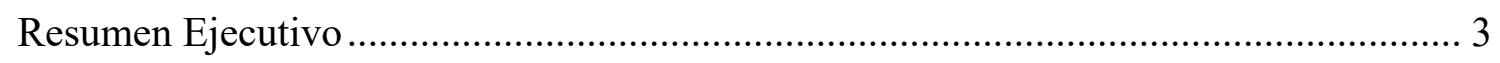

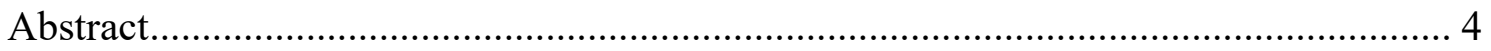

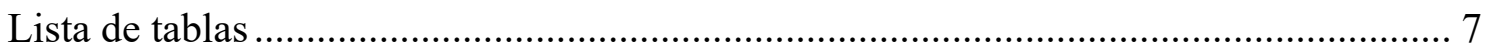

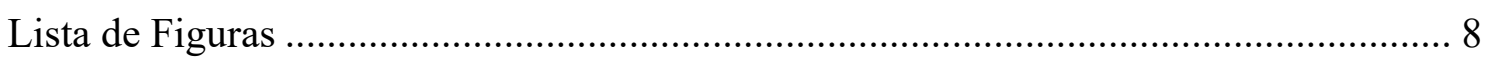

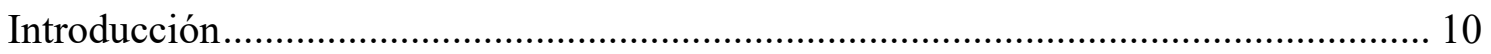

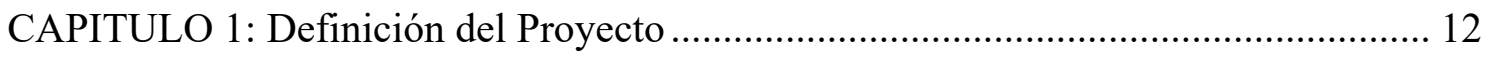

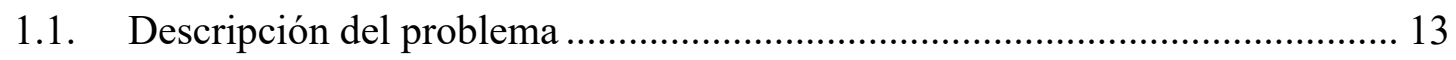

1.2. Objetivos de la Investigación...................................................................... 13

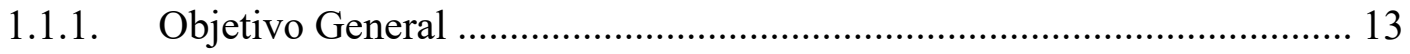

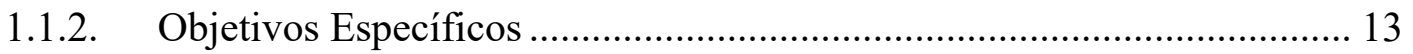

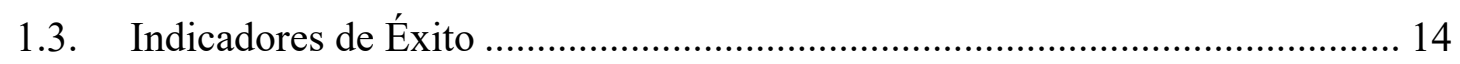

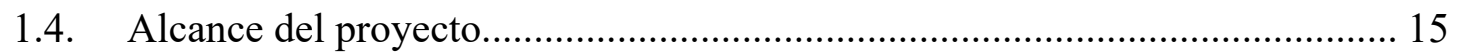

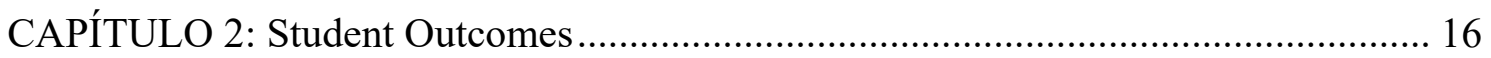

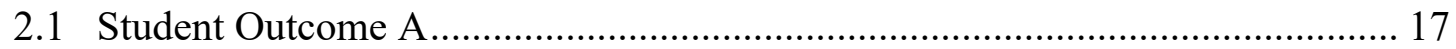

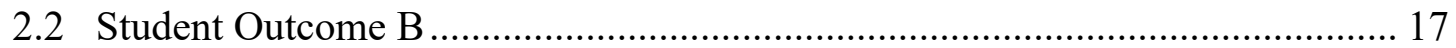

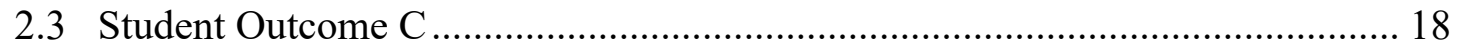

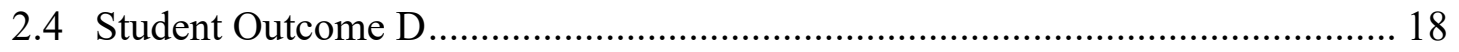

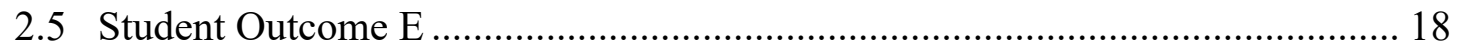

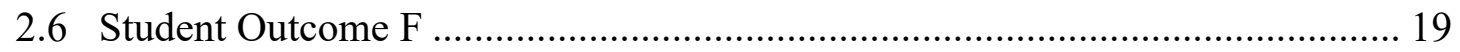

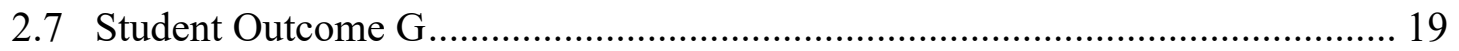

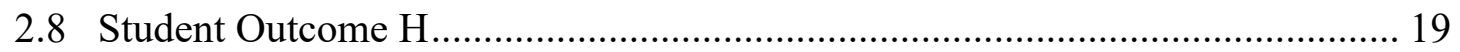

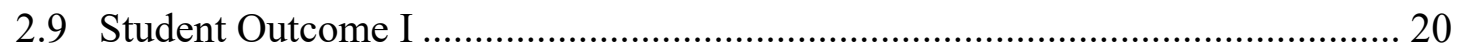

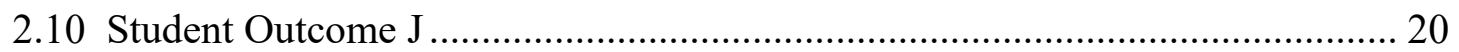

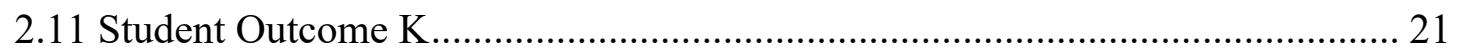

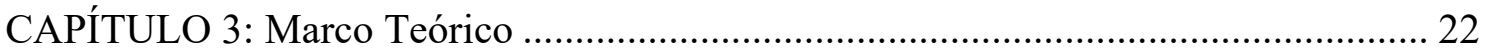

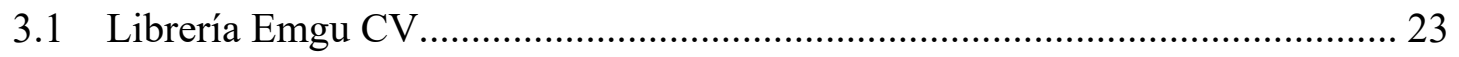

3.1.1 Algoritmos Implementados en EMGUCV …........................................ 23

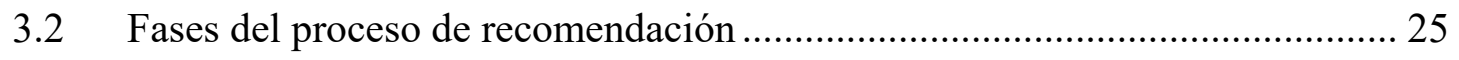

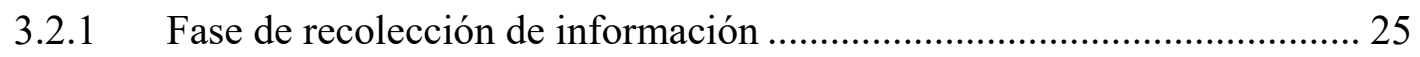

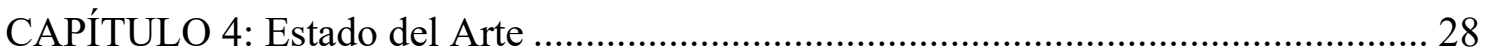

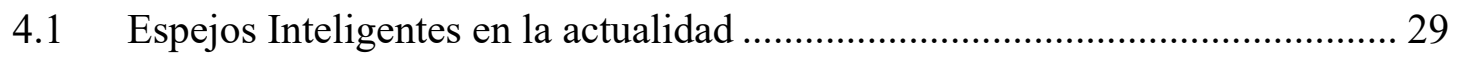

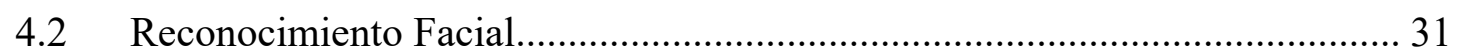

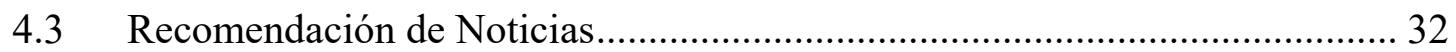




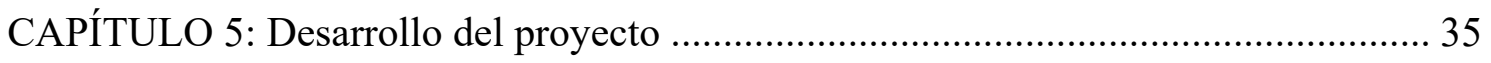

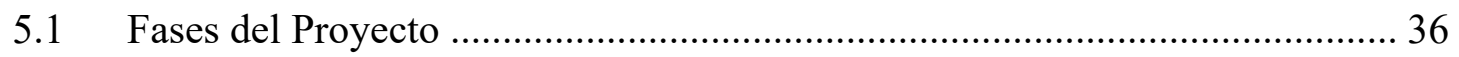

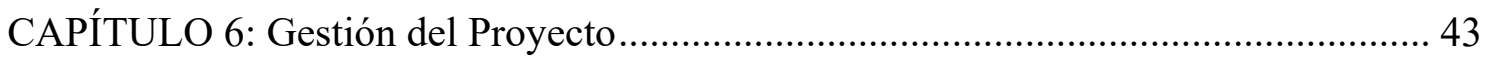

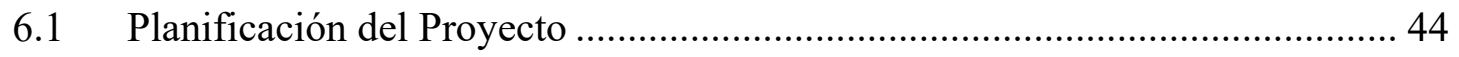

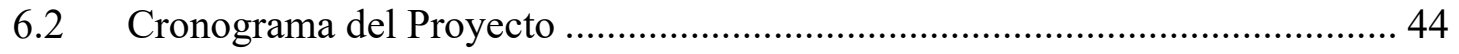

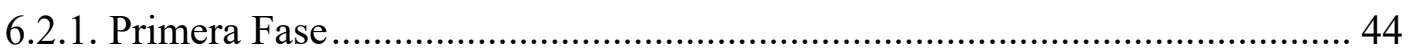

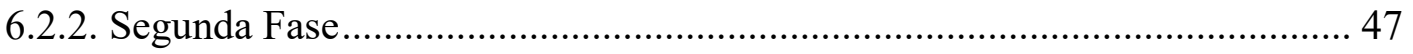

6.3 Gestión de los Recursos Humanos.................................................................. 49

6.4 Gestión de las Comunicaciones ....................................................................... 49

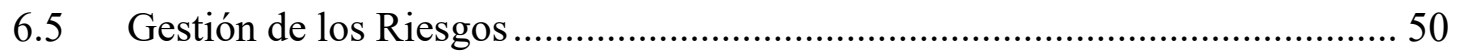

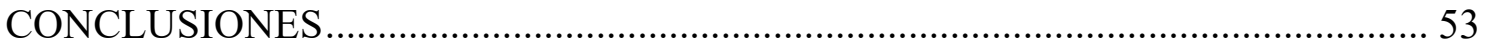

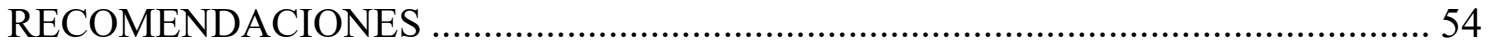

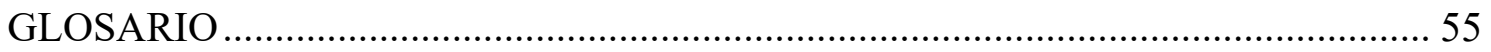

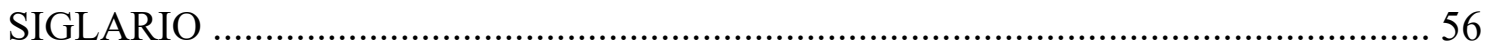

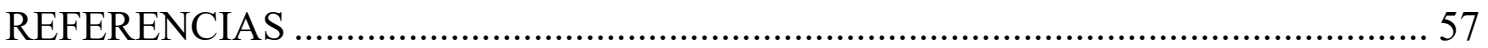

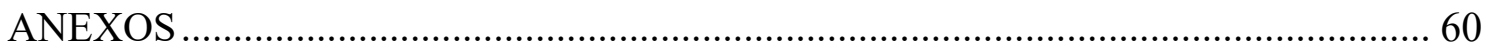

Anexo 1: Planos de construcción del Smart Mirror....................................................... 60

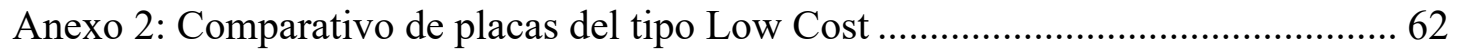

Anexo 3: Guía de Instalación - Prueba Concepto Raspberry Pi ................................. 63

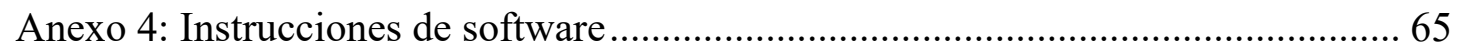

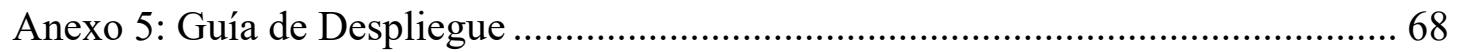

Anexo 6: Manual de Identidad Reflection .................................................................... 84

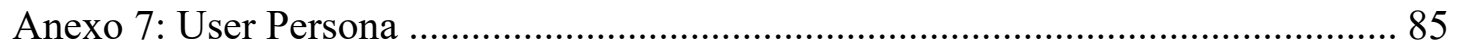

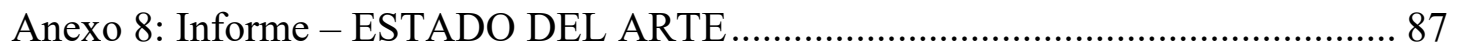

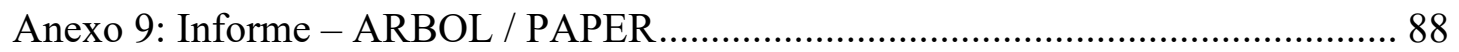

Anexo 10: Informe - ALGORITMO DE MACHINE LEARNING .......................... 89 


\section{Lista de tablas}

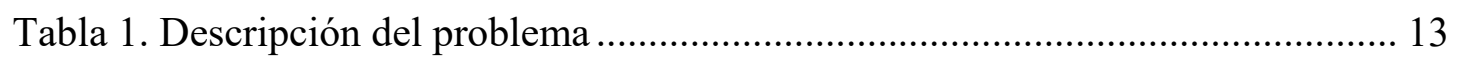

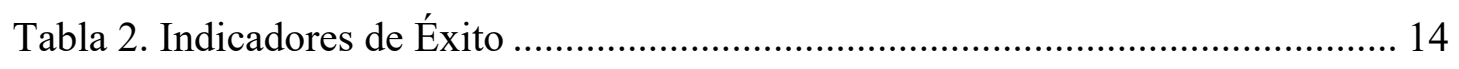

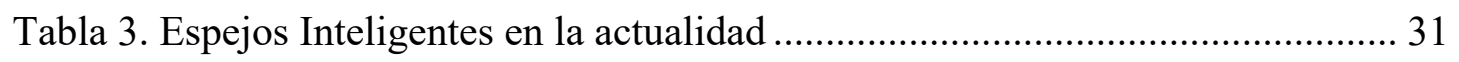

Tabla 4. Implementación de un Smart Mirror con Raspberry Pi 2016 - 02 ................ 46

Tabla 5.Implementación de un Smart Mirror con Raspberry Pi 2017 - 01 ................ 49

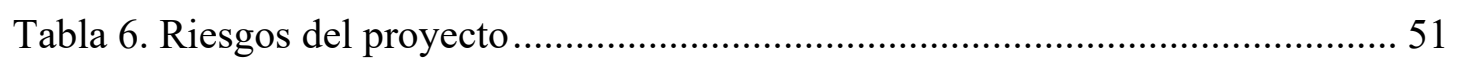

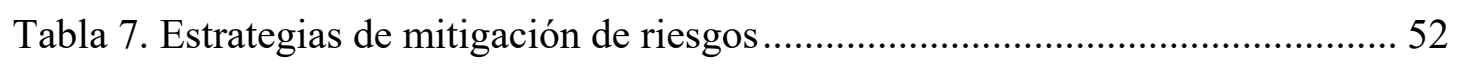

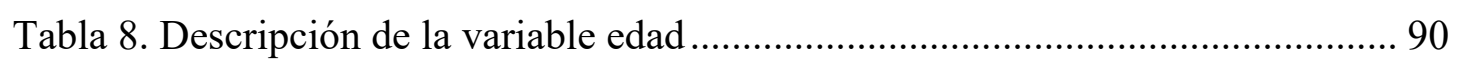

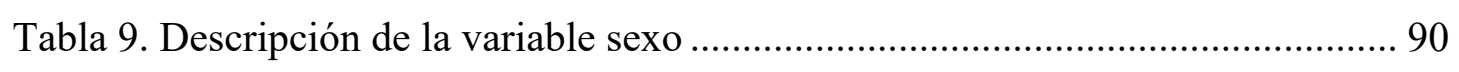

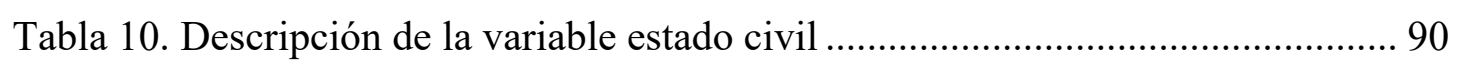

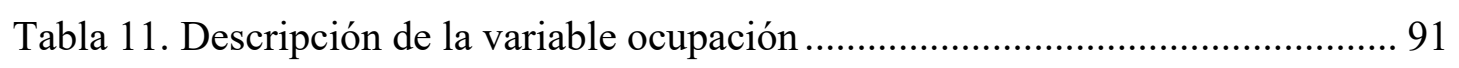

Tabla 12. Descripción de la variable residencia ........................................................ 91

Tabla 13. Descripción de la variable sector socioeconómico ................................... 91

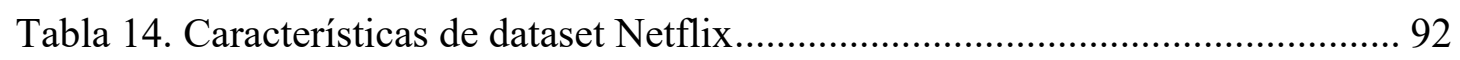

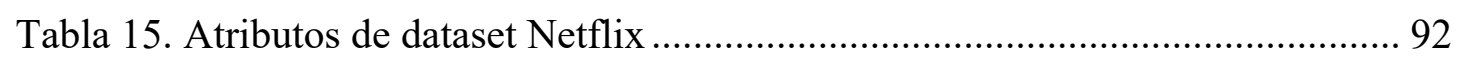

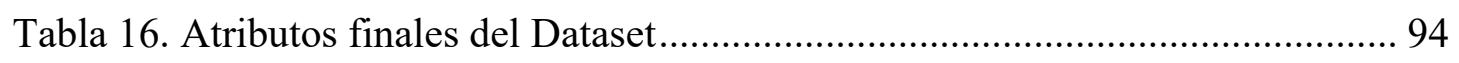

Tabla 17. Comparación de porcentajes de instancias correctamente clasificadas ...... 97 


\section{Lista de Figuras}

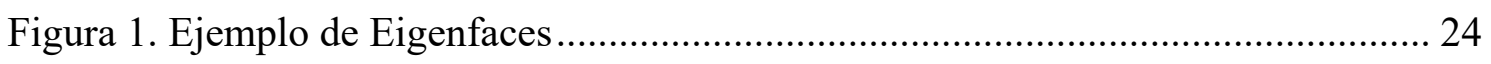

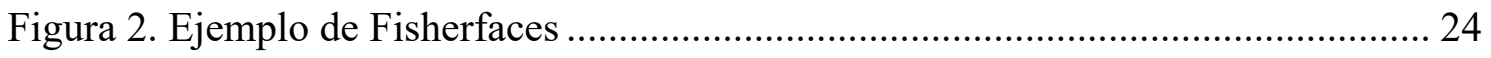

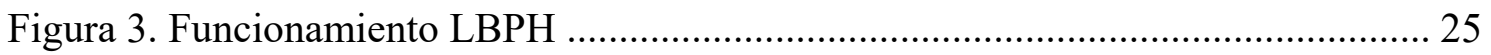

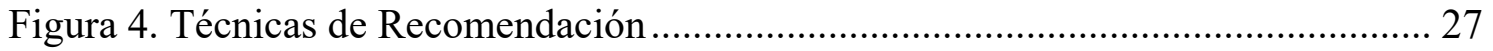

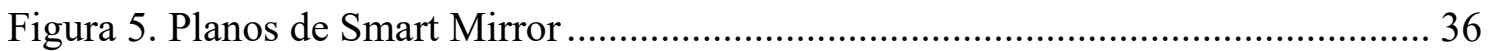

Figura 6. Prueba de concepto del Raspberry Pi con una pantalla LCD......................... 37

Figura 7. Diagrama de flujo del espejo y aplicación móvil.......................................... 37

Figura 8. Primera versión de la interfaz de Reflection ............................................... 38

Figura 9. Primera versión de la aplicación móvil.............................................................. 39

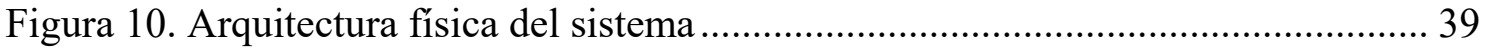

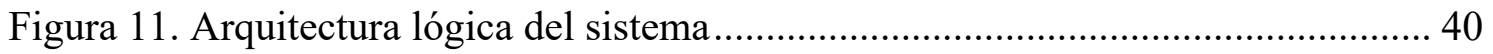

Figura 12. Última versión de la interfaz del espejo.................................................... 41

Figura 13.Diagrama de Flujo del algoritmo de recomendación de noticias .................. 42

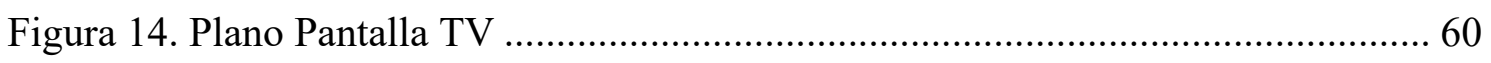

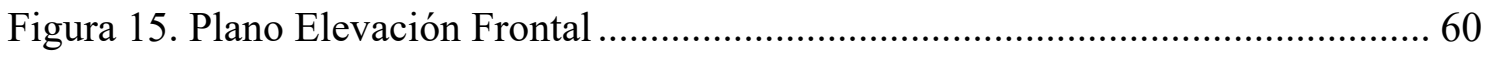

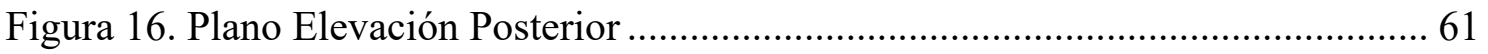

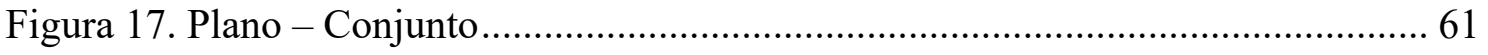

Figura 18. Comparativo de placas del tipo Low Cost ..................................................... 62

Figura 19. Guía de Instalación - Prueba Concepto Raspberry Pi 1 ................................ 63

Figura 20. Guía de Instalación - Prueba Concepto Raspberry Pi 2 ................................. 64

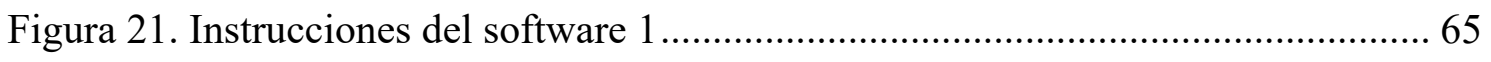

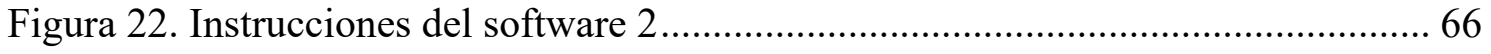

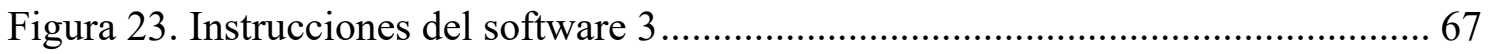

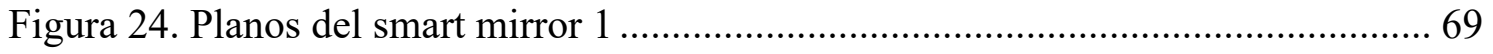

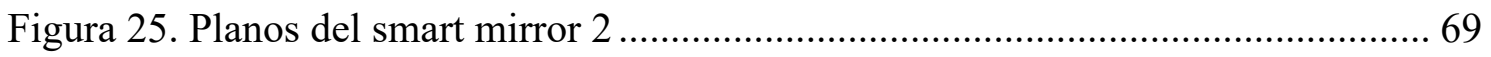

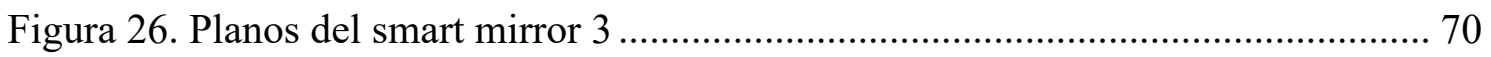

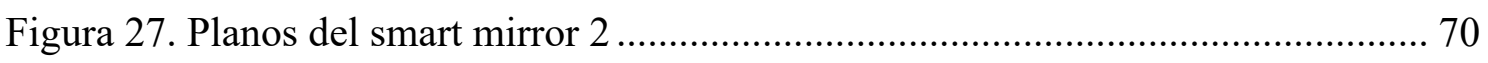

Figura 28. Configuración de Raspbian .................................................................. 71

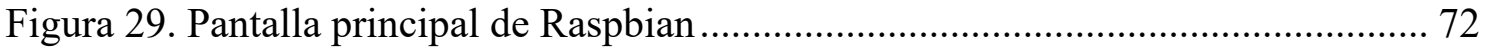

Figura 30. Dashboard Microsoft Azure ..................................................................... 73

Figura 31. Panel de creación de Microsot Azure............................................................. 74

Figura 32. Panel de creación de servidor SQL server ....................................................... 74 
Figura 33. Configuración de servidor SQL Server................................................. 75

Figura 34. Panel de creación de base de datos ........................................................... 75

Figura 35. Panel de configuración de base de datos.................................................... 76

Figura 36. Panel de base de datos reflection-upc Microsoft Azure ................................. 76

Figura 37. Pantalla de logueo de SQL Server ................................................................. 77

Figura 38. Ejecución de script en SQL Server ............................................................ 77

Figura 39. Dashboard Microsoft Azure .................................................................. 78

Figura 40. Creación de Nuevo servicio Microsoft Azure ............................................ 78

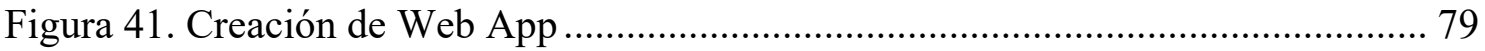

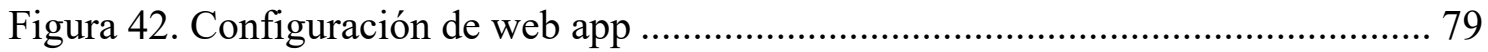

Figura 43. Modificación de cadena de conexión en Web.config ................................... 80

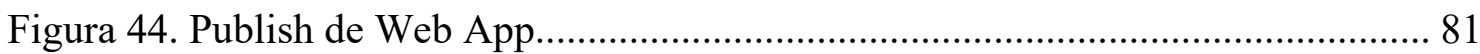

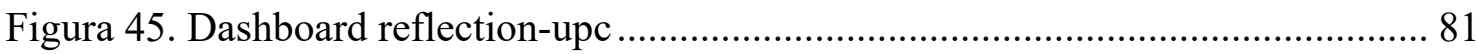

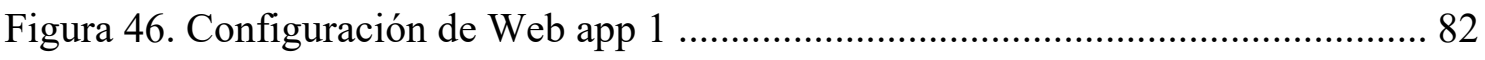

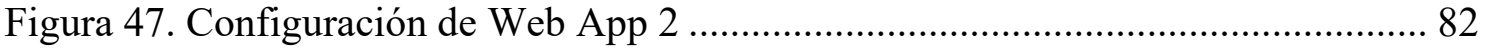

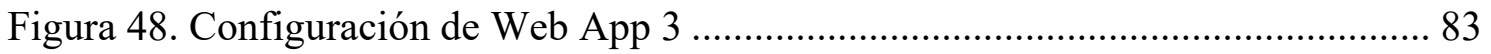

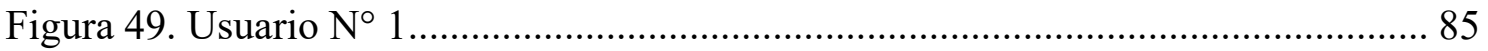

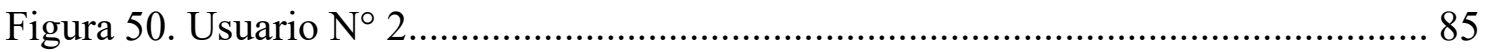

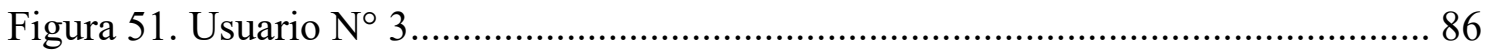

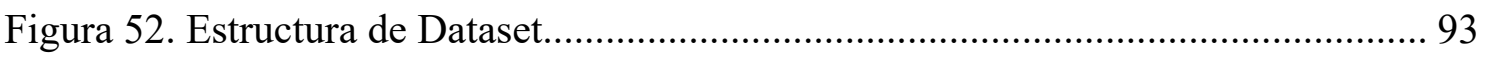

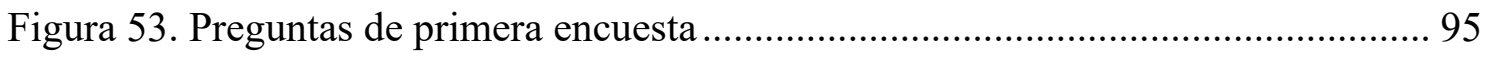

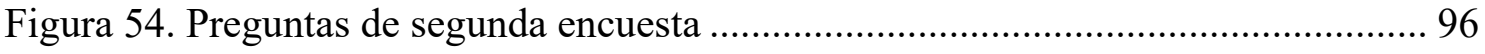

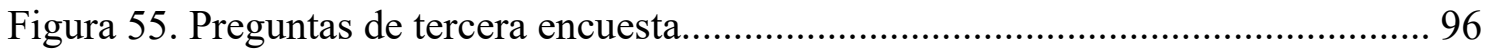

Figura 56. Matriz de confusión usando Naive Bayes con Cross Validation ................... 97

Figura 57. Matriz de confusión usando Naive Bayes con 70 Percentage Split.............. 98

Figura 58. Matriz de confusión usando Multilayer Perceptron con Cross Validation ... 98

Figura 59. Matriz de confusión usando Multilayer Perceptron, 70 Percentage Split..... 98

Figura 60. Matriz de confusión usando J48 con Cross Validation .................................. 99

Figura 61. Matriz de confusión usando J48, 70 Percentage Split ................................. 99

Figura 62. Comparación por área debajo de la curva de los algoritmos de clasificación y

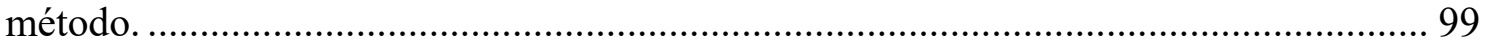

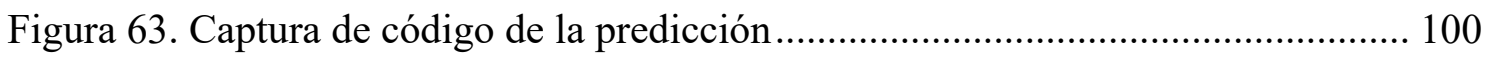




\section{Introducción}

Con los avances tecnológicos que se vienen dando en los últimos 4 años (2013 - 2017) podemos observar que casi todos los dispositivos están adaptando tecnologías Smart. Ejemplos de ello son televisores, teléfonos, sistemas de seguridad, reproductores de música, consolas de juego e incluso casas enteras. Asimismo, agrupando esta tecnología Smart con placas del tipo Low Cost Development Board se crean proyectos innovadores como el Smart Mirror, el cual es considerado un "espejo inteligente" que permite al usuario contar con información básica como el clima, calendario, hora, tareas o actividades, informes del tráfico, noticias y correo al comenzar su día ${ }^{3}$.

El presente proyecto consiste en desarrollar un espejo inteligente que permita ayudar a las personas a consultar información que le permita planificar su día sin la necesidad de estar manipulando varios dispositivos, permitiendo ahorrar tiempo. Esta herramienta se debe integrar con unas de las placas más utilizadas actualmente para proyectos personales: el Raspberry Pi. Esta placa ha sido incluida en diversos tipos de proyectos: desde servidores de archivos o correo, hasta centro de control para drones, vehículos teledirigidos y todo tipo de automatización.

Asimismo, el proyecto se divide en dos etapas: Primero, en la etapa de planificación se necesitará identificar las herramientas de desarrollo que mejor se adapten a la implementación del Smart Mirror junto con el Raspberry Pi. Luego de evaluar estas herramientas, se procederá a ejecutar el proyecto. Para ello, se necesitará consolidar la metodología necesaria para obtener y desarrollar el proyecto. Una vez que se finalice la elaboración e implementación del Smart Mirror, se procederá a realizar las pruebas para verificar que cumpla con las funcionalidades básicas como: visualizar la fecha y hora, clima, las noticias, etc. La interfaz del software será amigable y fácil de usar que no pierda la usabilidad de un espejo normal. Finalmente, al implementar el Smart Mirror con funcionalidades básicas se procederá a desarrollar el algoritmo de recomendación de noticias para que la información brindada al usuario sea más personalizada.

En el capítulo 1 se describe la problemática abordada, el planteamiento de la solución, se presentan los objetivos de investigación, así como los indicadores de éxito y el alcance

\footnotetext{
${ }^{3}$ Cfr. Slice Of Lime 2015
} 
del proyecto. En el capítulo 2, se detalla y explica el cumplimiento de todos los STUDENT OUTCOMES relacionados a la carrera de Ciencias de la Computación durante el desarrollo del proyecto. En el capítulo 3, se profundizará en las definiciones y contexto de los conceptos más importantes en el proyecto.

El capítulo 4 presenta y describe el estado actual de las herramientas y las tecnologías involucradas en el desarrollo del proyecto, como el reconocimiento facial y la recomendación de noticias. El capítulo 5 detalla las 2 fases con las que contó el desarrollo del proyecto: concepción e implementación. En la primera de ellas se elaboraron los planos para la construcción de la estructura del espejo, se realizaron pruebas de concepto con el Raspberry Pi y se definieron las funcionalidades con las que contaría el espejo y la aplicación móvil. Mientras que, en la fase de implementación, se desarrolló lo definido anteriormente, primero fue la aplicación móvil y posteriormente se implementaron las diversas funcionalidades del espejo. Finalmente, en el capítulo 6 se detallarán los planes definidos para la gestión del tiempo, recursos, comunicaciones, riesgos y producto final. 


\section{CAPITULO 1: Definición del Proyecto}

Este capítulo comprende siete puntos importantes, los cuales buscan tener una idea general del proyecto. Se enuncia qué se busca solucionar, cuál es el objetivo general, objetivos específicos, indicadores de éxito y alcance de la implementación del proyecto. 


\subsection{Descripción del problema}

El problema planteado y las causas siguientes:

\begin{tabular}{|l|l|}
\hline \multicolumn{1}{|l|}{ Problema } & Causas \\
\hline Dependencia de los usuarios a & Existencia de varios dispositivos que \\
múltiples dispositivos que & cumplen funciones de proporcionar \\
proporcionan sistemas & información. \\
interactivos de información no & El estilo de vida donde se exige la \\
seleccionada cuando se requiere & optimización el tiempo. \\
optimizar el tiempo y organizar & \\
tareas. &
\end{tabular}

Tabla 1. Descripción del problema

Nota: Elaboración Propia

\subsection{Objetivos de la Investigación}

Los objetivos que se encuentran ligados a los problemas en los cuales nos vamos a centrar son:

\subsubsection{Objetivo General}

Desarrollar aplicaciones cognitivas en un modelo de espejo inteligente con autenticación de reconocimiento facial cuya interacción a los servicios de información como fecha, hora, clima, agenda, correo se realice mediante el reconocimiento de voz y la integración de un algoritmo de clasificación de Naive Bayes para la personalización de noticias.

\subsubsection{Objetivos Específicos}

- OE1: Comparar algoritmos de clasificación que permita analizar los datos personales que se utilizan como patrones de comportamiento para el desarrollo de un modelo de predicción. 
- OE2: Analizar líneas de diseño y funcionalidades de espejos inteligentes en la actualidad.

- OE3: Desarrollar tecnologías cognitivas como: reconocimiento facial, interacción por comandos de voz y machine learning para elaborar un modelo de predicción de noticias que se mostrará en el espejo inteligente.

- OE4: Validar y verificar las tecnologías cognitivas en el espejo inteligente propuesto.

\subsection{Indicadores de Éxito}

Los indicadores que sustentarán el cumplimiento de cada uno de los objetivos planteados son:

I1 Acta de la investigación e implementación del algoritmo de

OE1 machine learning con la técnica de clasificación y tipo de aprendizaje supervisado para la extracción de patrones de comportamiento del usuario al utilizar el smart mirror aprobado por el revisor Luis Canaval

I2 Acta de aprobación de diseño de la arquitectura del OE2/OE3 dispositivo aprobada por Alfredo Barrientos

I3 Acta de aprobación de los requerimientos propuestas por el OE2 cliente aprobado por Alfredo Barrientos.

I4 Acta de pruebas de concepto a desarrollar aprobada por

Alfredo Barrientos

I5 Certificado de calidad por parte de la empresa QS

OE4

Tabla 2. Indicadores de Éxito

Nota: Elaboración Propia 


\subsection{Alcance del proyecto}

El proyecto será desarrollado durante los ciclos académicos 2016-2 y 2017-1 y el alcance abarcará los puntos a mencionar a continuación:

- Implementación y desarrollo de un espejo inteligente con la placa Raspberry Pi.

- Documentación de la investigación realizada con respecto al espejo inteligente implementado con la placa Raspberry Pi, manual de usuario y guía de desarrollo del espejo inteligente.

- Definición e implementación de la prueba de concepto que será la integración del reconocimiento facial del usuario quien se registrará por medio de una aplicación móvil que registra información del usuario en un servidor.

- Implementar pruebas de concepto del desarrollo de una aplicación móvil para la configuración y personalización del espejo.

- Implementar la prueba de concepto del uso de APIs Google para correo, agenda, Darksky API para la hora y el clima.

- Implementar la prueba de concepto visualización de noticias por medio del RSS del diario local Perú21.

- Definición e implementación la segunda prueba de concepto que será la integración de las funcionalidades del smart mirror con el algoritmo Naive Bayes de recomendación de noticias.

El proyecto no contemplará lo siguiente:

- Definir o realizar una prueba de concepto adicional a las establecidas.

- Definir funcionalidades que no se han establecido al inicio del proyecto. 


\section{CAPÍTULO 2: Student Outcomes}

En esta sección, se describe a detalle el cumplimiento de los STUDENT OUTCOMES

relacionados a la carrera de Ciencias de la Computación durante el desarrollo del proyecto. 


\subsection{Student Outcome A}

\section{Aplica conocimientos de computación y matemáticas a problemas propios de las ciencias de la computación de manera acertada}

Durante el proceso de desarrollo del proyecto fue necesario aplicar conocimientos de diversos ámbitos tales como matemática, estructuras de datos, procesamiento de imágenes, programación web y machine learning. Estos conceptos mencionados anteriormente, principalmente se aplicaron en dos partes importantes del proyecto como son el desarrollo de la aplicación móvil y la implementación del algoritmo de recomendación de noticias. También se implementó un algoritmo de recomendación de noticias, utilizando Weka y conceptos de machine learning. El proyecto demanda de creación de un sitio web que es con el cuál el usuario interactúa al utilizar el espejo y todas sus funcionalidades.

\subsection{Student Outcome B}

\section{Analiza un problema, identifica y define los requerimientos computacionales para la solución de manera apropiada}

Se identificó el problema de la dependencia de los usuarios a múltiples dispositivos que proporcionan sistemas interactivos de información no seleccionada cuando se requiere optimizar el tiempo y organizar tareas, a partir de ello se realizó un análisis de las posibles soluciones y se definió construir un espejo inteligente que consuma servicios web, utilice comandos de voz para la interacción con el usuario, visualización de información relevante y personalizada y un sistema de recomendación de noticias que le permita leer noticias de su interés. Para el desarrollo del Smart Mirror se utiliza un Raspberry Pi, el cuál al ser una computadora de bajo costo, no ofrece grandes prestaciones computacionales debido a ello se definió optimizar los todos los procesos y algoritmos desarrollados, para aprovechar eficientemente los recursos proporcionados por el Raspberry Pi. 


\subsection{Student Outcome C}

Diseña un sistema, componente o proceso e implementa un programa, para alcanzar las necesidades deseadas, considerando las restricciones que se presentan

Durante el proceso de desarrollo de proyecto, se desarrollaron diversas pruebas de concepto para validar funcionalidades que posteriormente serían utilizadas e integradas al mismo. Se desarrolló una aplicación móvil para sistema operativo Android, con IDE Android Studio, para que los usuarios puedan registrando utilizando autenticación con Facebook o Google. Además, se desarrolló un servidor el cuál se encarga de gestionar y procesar la información para mostrarla al usuario y almacenarla en la base de datos. Este servidor fue implementado con Visual Studio y consume servicios web para obtener la información que será mostrada posteriormente, desde un inicio estaba alojado en Winhost pero por problemas que se presentó en el desarrollo del proyecto se migró a Azure.

\subsection{Student Outcome D}

Trabaja en equipos multidisciplinarios y consigue objetivos comunes con acierto

En el proceso de desarrollo del Smart Mirror fue necesario contar con el apoyo de diseñadores que se encargaron de diseñar la interfaz que muestra el espejo, el logo del producto y el landing page. Asimismo, se contó con el apoyo de recursos de la empresa Software Factory quienes nos ayudaron en la implementación de algunas funcionalidades del espejo. Finalmente, contamos con el apoyo de la empresa QA quienes se encargaron en las pruebas de caja negra del proyecto.

\subsection{Student Outcome E}

Entiende la responsabilidad profesional, ética y legal en las soluciones de problemas de las ciencias de la computación de manera apropiada

Durante el desarrollo del algoritmo de Machine Learning para la recomendación de noticias del Smart Mirror, fue necesario la elaboración de nuestro propio 
Dataset pues necesitábamos datos que se adapten a nuestro modelo predictivo para lo cual realizamos encuestas y obtuvimos datos de diferentes usuarios. En el formulario fue necesario informar a los usuarios encuestados que la información brindada sería utilizada solamente con fines académicos.

\subsection{Student Outcome F}

\section{Se comunica a través de reportes orales y escritos de manera efectiva}

La comunicación se realizó por medio de correos electrónicos, elaboración de actas por cada reunión que se realizó entre los jefes de proyecto y el cliente, así mismo, también se elaboraron actas de reunión con el gerente de la empresa a la que pertenece el proyecto profesional. Asimismo, se realizaron actas de conformidad de cada una de las empresas por las cuales el proyecto tuvo que presentar algún entregable.

\subsection{Student Outcome G}

Analiza el impacto de las soluciones de ciencias de la computación en un contexto global, económico, medio ambiente y de sociedad con acierto

Nuestro proyecto busca crear un impacto social mediante la ayuda en la optimización del tiempo de las personas que tienen un ritmo acelerado en su día a día, busca brindar la información necesaria mientras se preparan para realizar sus actividades cotidianas. Asimismo, buscamos un impacto económico mediante la revalorización de monitores en desuso que puedan ser utilizados para la construcción personalizada del espejo.

\subsection{Student Outcome H}

Reconoce la necesidad de, y la habilidad para abordar un aprendizaje de por vida, de manera eficaz

Dado que nuestro proyecto utiliza varias tecnologías, hubo la necesidad de poner en práctica distintos lenguajes de programación como: .net, java y android. Asimismo, conocer las últimas tendencias tecnológicas como Internet de las 
cosas, domótica, metodologías, patrones de diseño como material design para la aplicación móvil, etc.

\subsection{Student Outcome I}

Usa técnicas y herramientas necesarias para la práctica de las ciencias de la computación, de manera eficaz

Durante el desarrollo del espejo se utilizaron diversas herramientas del tipo hardware como un Raspberry Pi, monitor; y software como: Visual Studio, para la programación de los servicios que consume el espejo; Android Studio para el desarrollo de la aplicación de configuración; Weka para comparar algoritmos de predicción y obtener el mejor valor de precisión de acuerdo al dataset que se elaboró. Para realizar pruebas de los servicios se utilizó Postman. Asimismo, la metodología que se utilizó para la gestión del proyecto fue SCRUM, la cual nos permitió tener un desarrollo ágil y modificar algunas fechas del cronograma impidiendo el corte de algunas funcionalidades ya establecidas. Para el desarrollo del proyecto se utilizó el patrón MVC pues como proyecto multidisciplinario fue necesario buscar un patrón que nos permita trabajar en el código independientemente sin sufrir algunos inconvenientes durante el desarrollo.

\subsection{Student Outcome J}

\section{Aplica fundamentos matemáticos, principios algorítmicos y teoría de ciencias de la computación en el modelamiento y diseño de sistemas basados en computador de manera que demuestre comprensión de las compensaciones involucradas en la selección del diseño}

Durante el desarrollo del smart mirror, se utilizó conceptos geométricos, para la elaboración del sistema de recomendación se utilizó técnicas estadísticas para la elaboración del dataset, asimismo se implementó el algoritmo Naive Bayes para la elaboración del modelo de predicción del sistema de recomendación. 


\title{
2.11 Student Outcome K
}

\begin{abstract}
Aplica el diseño y desarrolla principios en la construcción de sistemas de software de complejidad variada

El proyecto utiliza varias tecnologías desde aquellas que son fáciles de implementar hasta las difíciles en desarrollar. Por ejemplo, no tuvimos problemas en consumir APIs para mostrar información en el espejo, y como actividades difíciles fue el despliegue del servidor en Azure, implementación del algoritmo de reconocimiento facial y recomendación de noticias personalizadas.
\end{abstract}




\section{CAPÍTULO 3: Marco Teórico}

Este capítulo comprende definiciones, funcionalidades y características de las tecnologías y algoritmos que se utilizarán de referencia para el proyecto. 


\subsection{Librería Emgu CV}

Emgu CV es una librería cross platform desarrollado con .Net de para la biblioteca de procesamiento de imágenes de OpenCV. Permite que las funciones de OpenCV sean llamadas desde los lenguajes compatibles con .NET, tales como $C \#, V B, V C++$, IronPython, etc. El contenedor puede ser compilado por Visual Studio, Xamarin Studio y Unity, puede ejecutarse en Windows, Linux, Mac OS X, iOS, Android y Windows Phone. ${ }^{4}$

\subsubsection{Algoritmos Implementados en EMGUCV}

- Eigenfaces:

Los eigenfaces son vectores de datos, también denominados eigenvectors, en el que cada uno posee valores escalares conocidos como eigenvalues. Cada eigenface representa un rasgo característico de las imágenes faciales siguiendo un patrón obtenido del estudio de muchos rostros. El funcionamiento de este método es el siguiente: Por cada imagen del conjunto de entrenamiento se concatenan sus filas de pixeles, transformándola en un vector en el que cada valor le corresponde a cada píxel. Tras esto, obtenemos una matriz de vectores, siendo cada vector una imagen. A este vector se le aplica el método PCA para obtener los componentes principales y reducir la dimensionalidad. Se pasa a tener una matriz de $\mathrm{k}$ vectores (siendo $\mathrm{k}<\mathrm{M}$ ), a cada vector le corresponde un eigenface y se calcula el eigenface promedio. A partir de estos eigenfaces, cada imagen del dataset de entrenamiento se puede reconstruir de una forma muy aproximada combinándolos en mayor o menor medida. Este método es muy aceptado debido a su fácil implementación y a que utilizado en condiciones buenas, tiene un buen porcentaje de aciertos. Por el contrario, uno de los inconvenientes con los que cuenta es que no solo se maximiza la dispersión entre clases (personas), siendo información útil para la clasificación, sino que también se maximiza la dispersión entre clases, producido en mayor parte por las condiciones de iluminación y por la expresión facial, lo cual dificulta la clasificación.

\footnotetext{
${ }^{4}$ Cfr. EMGUCV, 2017
} 


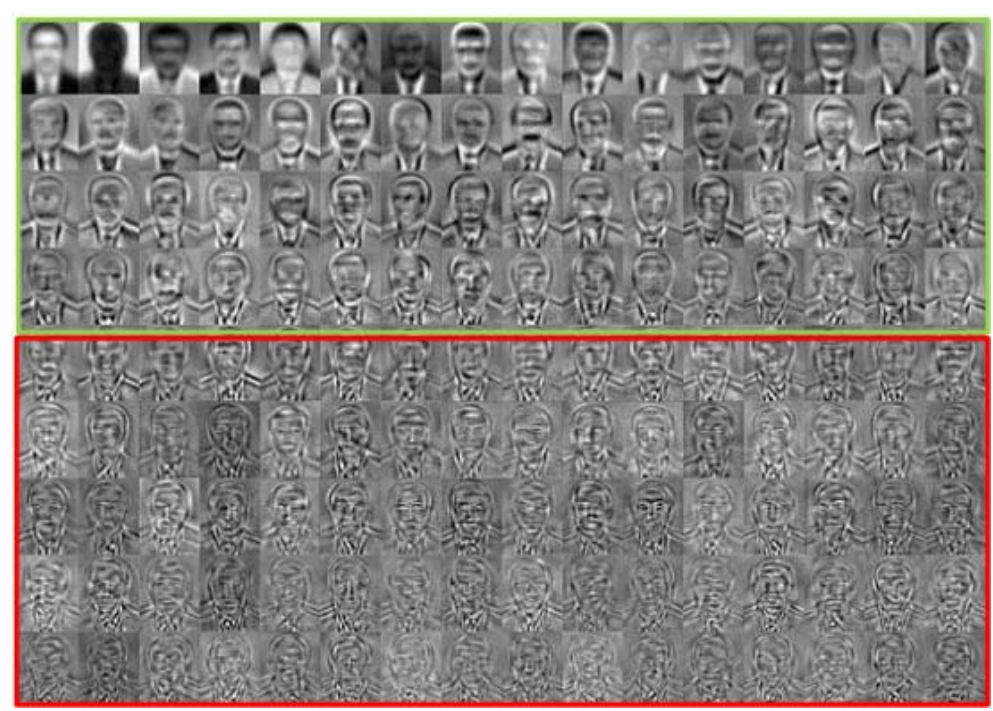

Figura 1. Ejemplo de Eigenfaces

Fuente: Autenticación biométrica en redes sociales: diseño e implementación de reconocimiento facial mediante EmguCV para autenticación en redes sociales

\section{- Fisherfaces}

El funcionamiento de este método es similar al de Eigenfaces, diferenciándose en que primero se aplica PCA para la reducción de la dimensionalidad y posteriormente se aplica LDA.

Para ello, y ayudándose del hecho de que las imágenes cuentan con el nombre de la persona a la que pertenece, permite reducir la problemática de la dispersión entre clases. En este caso se busca que las mismas clases se agrupen muy cercanas, mientras que diferentes clases deben estar lo más alejadas posibles la una de la otra para mejorar la clasificación.

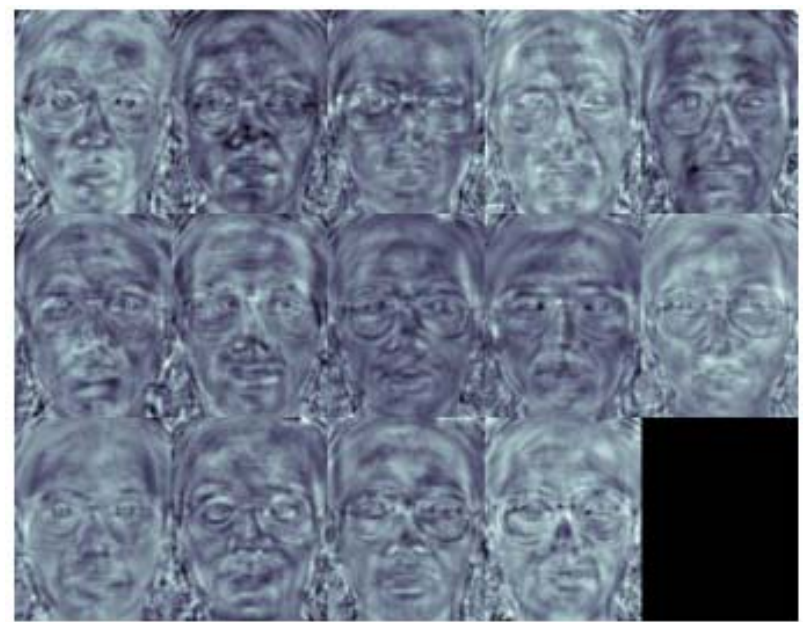

Figura 2. Ejemplo de Fisherfaces

Fuente: Autenticación biométrica en redes sociales: diseño e implementación de reconocimiento facial mediante EmguCV para autenticación en redes sociales

- Local Binary Pattern Histogram 
En los algoritmos Eigenfaces y Fisherfaces se trata la imagen como un vector de datos en un espacio de muy alta dimensionalidad. Pero en LBPH se pretenden describir las características locales de cada rostro. De esta manera, las características extraídas tendrán dimensionalidad baja, evitando así el hecho de tener que usar algoritmos adicionales para tratar este problema. E1 LBPH se basa en ir tomando pixeles "vecinos" respecto de un pixel central, el cual establece un valor de umbral. Si el valor del pixel central es menor, se le asigna con un uno, y si es mayor se asigna cero como valor. Estos valores obtenidos se concatenan para formar un número binario, que posteriormente se convierte en decimal, que finalmente se convertirá en el nuevo valor del pixel. Por cada región se obtiene un histograma, que luego será concatenado para obtener una representación del rostro. ${ }^{5}$
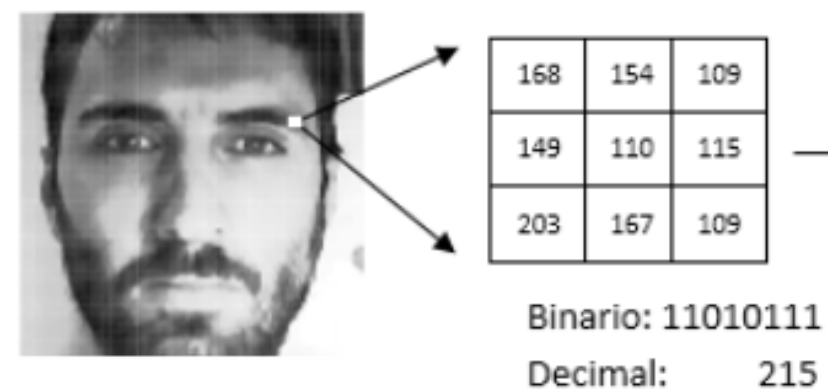

Figura 3. Funcionamiento LBPH

Fuente: Autenticación biométrica en redes sociales: diseño e implementación de Reconocimiento facial mediante EmguCV para autenticación en redes sociales

\subsection{Fases del proceso de recomendación}

\subsubsection{Fase de recolección de información}

En esta fase se recoge información relevante de los usuarios para generar un perfil o modelo de usuario para las tareas de predicción incluyendo el atributo del usuario, los comportamientos o el contenido de los recursos a los que el usuario accede. Un agente de recomendación no puede funcionar con precisión hasta que el perfil de usuario no haya sido bien construido. El sistema necesita saber tanto como sea posible del usuario para proporcionar una recomendación razonable desde el principio. Los sistemas de recomendación se basan en diferentes tipos de

${ }^{5}$ Cfr. Vásquez 2014 
información, como la retroalimentación explícita de alta calidad más conveniente, que incluye la información explícita de los usuarios sobre su interés en el elemento o la retroalimentación implícita al inferir indirectamente las preferencias del usuario mediante la observación del comportamiento del usuario. La retroalimentación híbrida también puede obtenerse mediante la combinación de retroalimentación explícita e implícita. El perfil de usuario se utiliza normalmente para recuperar la información necesaria para crear un modelo del usuario. Por lo tanto, un perfil de usuario describe un modelo de usuario simple. El éxito de cualquier sistema de recomendación depende en gran parte de su capacidad para representar los intereses actuales del usuario. Los modelos precisos son indispensables para obtener recomendaciones pertinentes y precisas de cualquier técnica de predicción.

\subsubsection{Feedback explícito}

El sistema normalmente solicita al usuario a través de la interfaz del sistema que proporcione clasificaciones de elementos para construir y mejorar su modelo. La precisión de la recomendación depende de la cantidad de valoraciones proporcionadas por el usuario. El único inconveniente de este método es que requiere esfuerzo de los usuarios y también, los usuarios no siempre están dispuestos a proporcionar suficiente información. A pesar de que la retroalimentación explícita requiere más esfuerzo del usuario, todavía se considera que proporciona datos más confiables, ya que no implica la extracción de preferencias de las acciones, y también proporciona transparencia en el proceso de recomendación que da como resultado una calidad de recomendación percibida ligeramente superior Y más confianza en las recomendaciones

\subsubsection{Feedback implícito}

El sistema infiere automáticamente las preferencias del usuario mediante el seguimiento de las diferentes acciones de los usuarios, como el historial de compras, el historial de navegación y el tiempo dedicado a algunas páginas web, los vínculos seguidos por el usuario, el contenido del correo electrónico y los clics de botón, entre otros. La retroalimentación implícita reduce la carga sobre los usuarios al inferir las preferencias de sus usuarios 
de su comportamiento con el sistema. Sin embargo, el método no requiere esfuerzo del usuario, pero es menos preciso. También se ha argumentado que los datos de preferencia implícita podrían en realidad ser más objetivos, ya que no hay sesgos derivados de que los usuarios respondan de una manera socialmente deseable y no hay problemas de autoimagen o cualquier necesidad de mantener una imagen para otros.

\subsubsection{Feedback híbrido}

Las fortalezas de la retroalimentación implícita y explícita se pueden combinar en un sistema híbrido con el fin de minimizar sus debilidades y obtener un sistema de mejor desempeño. Esto puede lograrse utilizando un dato implícito como una comprobación de la calificación explícita o permitiendo al usuario dar una retroalimentación explícita sólo cuando elige expresar interés explícito. ${ }^{6}$

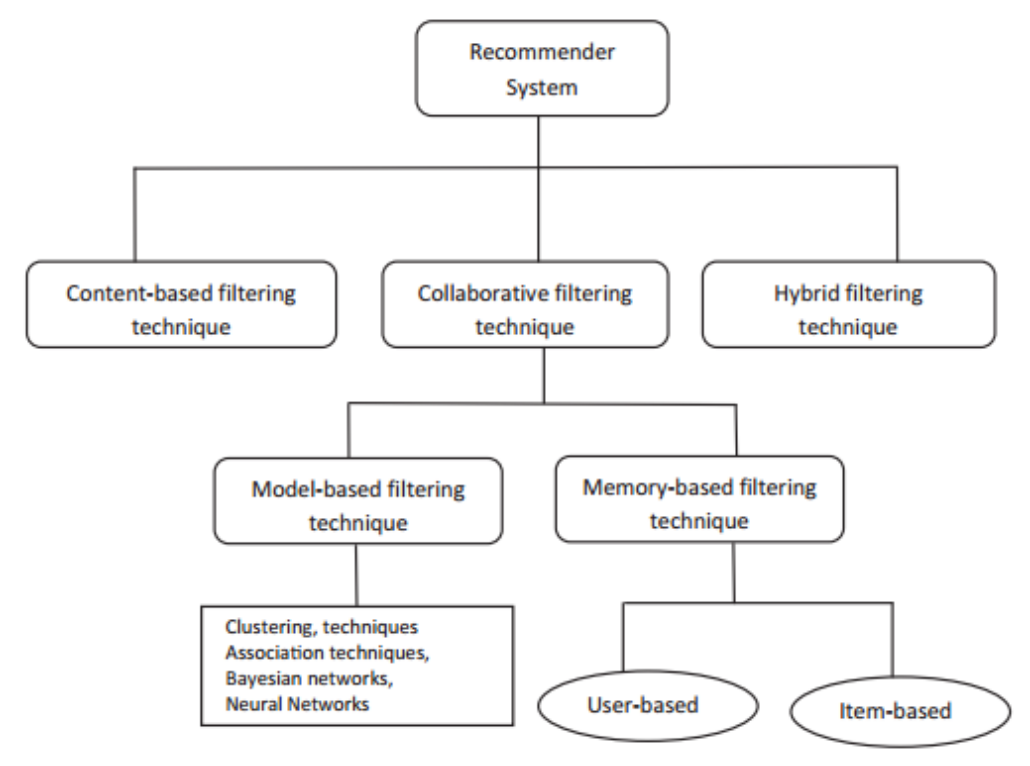

Figura 4. Técnicas de Recomendación

Fuente: Recommendation systems: Principles, methods and evaluation

${ }^{6}$ Cfr. Isinkaye, Folajimi y Ojokoh 2015 


\section{CAPÍTULO 4: Estado del Arte}

En este capítulo se presentará y describirá los conceptos, el estado actual de las herramientas y las tecnologías involucradas en el desarrollo del proyecto. 


\subsection{Espejos Inteligentes en la actualidad}

\begin{tabular}{|c|c|c|c|c|}
\hline Descripción & Empresa & Funcionalidades & Input & Output \\
\hline $\begin{array}{l}\text { Magic } \\
\text { Mirror }\end{array}$ & Microsoft & $\begin{array}{l}\text { Fecha y hora, clima, datos } \\
\text { de las bolsas de valores más } \\
\text { importantes y la situación } \\
\text { del tráfico de camino al } \\
\text { trabajo, indicando el } \\
\text { tiempo de recorrido y en } \\
\text { que vías principales hay } \\
\text { más tráfico. } \\
\text { Reconocimiento facial para } \\
\text { configurar diferentes } \\
\text { perfiles. }\end{array}$ & $\begin{array}{l}\text { Reconocimiento } \\
\text { facial mediante } \\
\text { una cámara } \\
\text { detrás del espejo }\end{array}$ & $\begin{array}{l}\text { Información } \\
\text { personalizada } \\
\text { para comenzar el } \\
\text { día }\end{array}$ \\
\hline $\begin{array}{l}\text { Smart } \\
\text { Mirror }\end{array}$ & Lenovo & $\begin{array}{l}\text { Interfaz gestual que } \\
\text { permite revisar } \\
\text { información acerca de tus } \\
\text { músculos, huesos, etc. }\end{array}$ & $\begin{array}{l}\text { Peso recibido a } \\
\text { través de una } \\
\text { balanza, gestos, } \\
\text { body recognition }\end{array}$ & $\begin{array}{l}\text { Información } \\
\text { acerca de la salud } \\
\text { de tu cuerpo }\end{array}$ \\
\hline $\begin{array}{l}\text { Oak Fitting } \\
\text { Room }\end{array}$ & Oak Labs Inc. & $\begin{array}{lr}\text { Reconocimiento } & \text { de } \\
\text { productos dentro de la } \\
\text { habitación, cambio de } \\
\text { luces, selección de } \\
\text { lenguajes, selección de } \\
\text { tallas y colores, integración } \\
\text { con app para empleados, } \\
\text { recomendaciones }\end{array}$ & $\begin{array}{l}\text { Selección de } \\
\text { opciones } \\
\text { mediante interfaz } \\
\text { touch }\end{array}$ & $\begin{array}{l}\text { Compras más } \\
\text { sencillas, } \\
\text { eliminación de la } \\
\text { necesidad de ir a } \\
\text { buscar una prenda } \\
\text { de otra talla }\end{array}$ \\
\hline $\begin{array}{l}\text { Magic } \\
\text { Mirror }\end{array}$ & New York Times & $\begin{array}{l}\text { Mostrar el clima, noticias } \\
\text { para llevar (NFC), } \\
\text { seguimiento de } \\
\text { movimiento durante el día, } \\
\text { integración } \\
\text { medicamentos. }\end{array}$ & $\begin{array}{l}\text { Comandos } \\
\text { voz, gestos }\end{array}$ & $\begin{array}{l}\text { Información } \\
\text { personalizada } \\
\text { para comenzar el } \\
\text { día }\end{array}$ \\
\hline
\end{tabular}




\begin{tabular}{|c|c|c|c|c|}
\hline $\begin{array}{l}\text { Smart Fitting } \\
\text { Room }\end{array}$ & Rebecca Minkoff & $\begin{array}{ll}\text { Reconocimiento de } \\
\text { productos dentro de la } \\
\text { habitación, cambio de } \\
\text { luces, selección de } \\
\text { lenguajes, selección de } \\
\text { tallas y colores, integración } \\
\text { con app para empleados, } \\
\text { recomendaciones }\end{array}$ & $\begin{array}{lr}\text { Interfaz touch, } \\
\text { selección de } \\
\text { prendas }\end{array}$ & $\begin{array}{l}\text { Compras más } \\
\text { sencillas, } \\
\text { eliminación de la } \\
\text { necesidad de ir a } \\
\text { buscar una prenda } \\
\text { de otra talla }\end{array}$ \\
\hline $\begin{array}{l}\text { Touchscreen } \\
\text { Smart } \\
\text { Mirror }\end{array}$ & Ryan Nelwan & $\begin{array}{l}\text { Funcionalidades } \\
\text { aplicaciones de un } \\
\text { smartphone, llevadas a un } \\
\text { espejo (wrapper de } \\
\text { iPhone/iPad) }\end{array}$ & $\begin{array}{l}\text { Interfaz touch, } \\
\text { ingreso de texto }\end{array}$ & $\begin{array}{l}\text { Aplicaciones } \\
\text { como Reddit, } \\
\text { Spotify, iTunes } \\
\text { adaptadas a un } \\
\text { espejo }\end{array}$ \\
\hline $\begin{array}{l}\text { Mirrored } \\
\text { Multi- } \\
\text { Display }\end{array}$ & Toshiba & $\begin{array}{l}\text { Multi-Display, Recetas de } \\
\text { cocina, hora, clima, notas } \\
\text { adhesivas }\end{array}$ & Gestos & $\begin{array}{l}\text { Información } \\
\text { personalizada, } \\
\text { como recetas o } \\
\text { películas/videos }\end{array}$ \\
\hline LG Mirror & $L G$ & $\begin{array}{l}\text { Recordatorios, calendario, } \\
\text { compra de entradas para el } \\
\text { cine, compra de artículos } \\
\text { de casa, mapas, } \\
\text { visualización de fotos }\end{array}$ & Touch & $\begin{array}{l}\text { Compras más } \\
\text { rápidas } \\
\text { sencillas, } \\
\text { evitando colas. }\end{array}$ \\
\hline $\begin{array}{l}L G \\
\text { Transparent } \\
\text { Display }\end{array}$ & $L G$ & $\begin{array}{l}\text { Publicidad, visualización } \\
\text { de modelos } 3 \mathrm{D} \text { mediante } \\
\text { una interfaz touch, e- } \\
\text { commerce que va de la } \\
\text { mano con los modelos }\end{array}$ & Touch & $\begin{array}{l}\text { Compras más } \\
\text { rápidas y } \\
\text { sencillas, } \\
\text { evitando colas. }\end{array}$ \\
\hline $\begin{array}{l}\text { UniQlo } \\
\text { Magic } \\
\text { Mirror }\end{array}$ & $\begin{array}{l}\text { Dai Nippon } \\
\text { Printing }\end{array}$ & $\begin{array}{l}\text { Permite probarse una } \\
\text { prenda y cambiarle el color } \\
\text { digitalmente }\end{array}$ & $\begin{array}{l}\text { Touch, Color } \\
\text { Recognition }\end{array}$ & $\begin{array}{l}\text { Una forma más } \\
\text { fácil de probarse } \\
\text { prendas, sin estar } \\
\text { buscando }\end{array}$ \\
\hline
\end{tabular}




\begin{tabular}{|c|c|c|c|c|}
\hline & & & & $\begin{array}{l}\text { cambios de color } \\
\text { o diseños }\end{array}$ \\
\hline FitMirror & $\begin{array}{l}\text { Besserer Daniel, } \\
\text { Baurle } \\
\text { Johannes, Nikic } \\
\text { Alexander, } \\
\text { Honold Frank, } \\
\text { Schussel Felix, } \\
\text { Weber Michael. }\end{array}$ & $\begin{array}{l}\text { Muestra información como } \\
\text { el peso y otros datos de } \\
\text { salud así como el } \\
\text { reconocimiento de } \\
\text { ejercicios que beneficien al } \\
\text { usuario y así motivarlos. }\end{array}$ & Gestos & $\begin{array}{l}\text { Datos } \\
\text { personales, } \\
\text { de sugerencia } \\
\text { personalizados. }\end{array}$ \\
\hline
\end{tabular}

Tabla 3. Espejos Inteligentes en la actualidad Fuente: Elaboración Propia

Philips HomeLab es un banco de pruebas para la creación e innovación de tecnologías en un entorno doméstico. Entre sus proyectos esta la creación de un espejo interactivo en el baño que proporcione servicios personalizados de acuerdo a las preferencias del usuario. Por ejemplo: los niños pueden ver sus dibujos animados favoritos mientras se cepillan los dientes, proporcionar canales de televisión, comprobar la información del tráfico, etc. Es dispositivo se construye a partir de una pantalla LCD combinada con un superficie reflejante y conectada a un procesador central que proporcione los servicios mencionados. $^{7}$

La empresa The Fung Group, realizó una investigación sobre los espejos inteligentes que se enfoque al sector retail o comercialización de prendas de vestir. Siendo uno de los destacados el Memomi's Memory Mirror, espejo inteligente cuya funcionalidad es similar a un probador de ropa virtual, pues permite a los clientes cambiar tamaños, colores y estilos de los outfits en tiempo real y, por supuesto, compartirlos a través de correo o redes sociales Cuenta con una cámara y sensores en la parte superior con la que se sigue los movimientos en tiempo real puede grabar vídeos que ofrecen imágenes de 360 grados cuando la persona se encuentre frente al espejo probando prendas a través de este. ${ }^{8}$

\subsection{Reconocimiento Facial}

Hitoshi Carlos, demuestra la detección del rostro humano sobre la interfaz de un espejo digital. Este sistema utiliza un detector robusto de múltiples caras y un rastreador basado

\footnotetext{
${ }^{7}$ Cfr. Philips Homelab, 2004

${ }^{8}$ Cfr. The Fung Group, 2015
} 
en la iluminación infrarroja activa (IR), y desarrollo un modelo facial basado en la física para generar resultados realistas para luego probar la integración de ambos módulos usando una aplicación de contacto visual que cambia aleatoriamente las expresiones faciales. ${ }^{9}$

El proceso del reconocimiento de rostros empieza con la captura de la imagen por medio de una cámara, esta imagen necesita ser pre procesado para mejorar el contraste. Generalmente, una imagen es una colección de pixeles, cuyo valor se da según la intensidad que se analiza desde el pixel superior izquierdo hasta el pixel inferior derecho. El valor de la intensidad se distribuye sobre toda la imagen utilizando técnica de ecualización del histograma. El primer paso del reconocimiento facial, es la detección de rostros. El sistema utiliza el algoritmo Viola y Jones para la detección de rostros en la que consiste procesar la imagen en función de rasgos similares a los clasificadores haar y no de pixeles. El segundo paso es reconocer a quien le pertenece este rostro. La imagen detectada previamente es recortada y redimensionada para el procesamiento posterior, el cual utiliza un enfoque geométrico basado en rasgos. ${ }^{10}$

\subsection{Recomendación de Noticias}

Se han desarrollado varios enfoques para crear sistemas de recomendación, que pueden utilizar filtrado colaborativo, filtrado basado en contenido o filtrado híbrido. La técnica de filtrado colaborativo es la más madura y la más comúnmente implementada. El filtrado colaborativo recomienda artículos identificando a otros usuarios con gusto similar; Utiliza su opinión para recomendar artículos al usuario activo. Se han implementado sistemas de recomendación colaborativa en diferentes áreas de aplicación. Group Lens es una arquitectura basada en noticias que emplea métodos colaborativos para ayudar a los usuarios a localizar artículos de la base masiva de noticias. Ringo es un sistema de filtrado de información social en línea que utiliza el filtrado colaborativo para crear un perfil de usuarios basado en sus calificaciones en álbumes de música. Amazon utiliza algoritmos de diversificación de temas para mejorar su recomendación. Este sistema utiliza el método de filtrado colaborativo para superar el problema de escalabilidad generando una tabla de elementos similares fuera de línea mediante el uso de matriz de elemento a elemento. Por otro lado, las técnicas basadas en contenido coinciden con los recursos de contenido con

\footnotetext{
${ }^{9}$ Cfr. Hitoshi Carlos, 2001

${ }^{10}$ Cfr. Chidambaram Sethukkarasi y otros, 2012
} 
las características del usuario. Las técnicas de filtradas basadas en el contenido normalmente basan sus predicciones en la información del usuario e ignoran las contribuciones de otros usuarios como en el caso de las técnicas colaborativas. Entre otros sistemas que utilizan el filtrado basado en contenido para ayudar a los usuarios a encontrar información en Internet encontramos a Letizia. El sistema hace uso de una interfaz de usuario que ayuda a los usuarios a navegar por Internet; es capaz de realizar un seguimiento del patrón de navegación de un usuario para predecir las páginas que pueden estar interesados. Pazzani diseñó un agente inteligente que intenta predecir qué páginas web le interesará a un usuario mediante el clasificador Naive Bayes. El agente permite que un usuario proporcione instancias de entrenamiento calificando diferentes páginas como buenas o malas de acuerdo a sus intereses. Andrew Jennings y Hideyuki Higuchi describen una red neuronal que modela los intereses de un usuario en un entorno de noticias. A pesar del éxito de estas dos técnicas de filtrado, se han identificado varias limitaciones. Algunos de los problemas asociados con las técnicas de filtrado basado en contenido son análisis de contenido limitado, la sobre especialización y la escasez de datos. Además, los enfoques colaborativos presentan problemas de arranque en frío, escasez y escalabilidad. Estos problemas generalmente reducen la calidad de las recomendaciones. Con el fin de mitigar algunos de los problemas identificados, el filtrado híbrido, que combina dos o más técnicas de filtrado de diferentes maneras con el fin de aumentar la precisión y el rendimiento de recomendar sistemas se ha propuesto. Estas técnicas combinan dos o más enfoques de filtrado con el fin de aprovechar sus fortalezas, e intentan reducir sus debilidades. Pueden clasificarse en función de sus operaciones en híbridos ponderados, híbridos mixtos, híbridos de conmutación, híbridos de combinación de características, híbridos en cascada, híbridos con características mejoradas e híbridos de meta-niveles. ${ }^{11}$

Los sistemas de recomendación de artículos de noticias a los lectores, tiene una serie de características únicas en comparación de los sistemas de recomendación de películas o productos en donde el perfil del usuario se construye a partir de la acción de calificar el artículo o el registro del historial de preferencias que se obtiene mediante interacción que realiza en la página. En el dominio de las noticias, no suele ser común disponer de una lista de interacción de los usuarios pues no es necesario que inicien sesión o crear perfiles. También, es poco común que el usuario proporcione un comentario sobre cada noticia

\footnotetext{
${ }^{11}$ Cfr. Isinkaye, Folajimi y Ojokoh 2015
} 
que lean. La única información disponible está implícita en los registros de los patrones de clic de los usuarios con el cual se puede utilizar métodos de filtrado colaborativo que se basan en opiniones de usuarios similares para generar recomendaciones. ${ }^{12}$

${ }^{12}$ Cfr. Ilievski, I. y Roy, S. 2013 


\section{CAPÍTULO 5: Desarrollo del proyecto}

En el presente capítulo se detalla todo el proceso de concepción, desarrollo e implementación de las funcionalidades del Smart Mirror. 


\subsection{Fases del Proyecto}

De acuerdo a la investigación realizada acerca de las funcionalidades de espejos inteligentes ya existentes se establecieron las funcionalidades de nuestro proyecto con el fin de que proporcionen información personalizada al usuario ofreciéndole una interacción lo más natural posible por medio del reconocimiento facial, recomendación de noticias y reconocimiento de comandos de voz. El proceso de construcción de nuestro Smart Mirror se divide en dos etapas: concepción e implementación.

\subsubsection{Fase 1 - Concepción}

En la primera etapa se realizaron planos del diseño de la estructura a utilizar para mantener unido el espejo con el monitor.

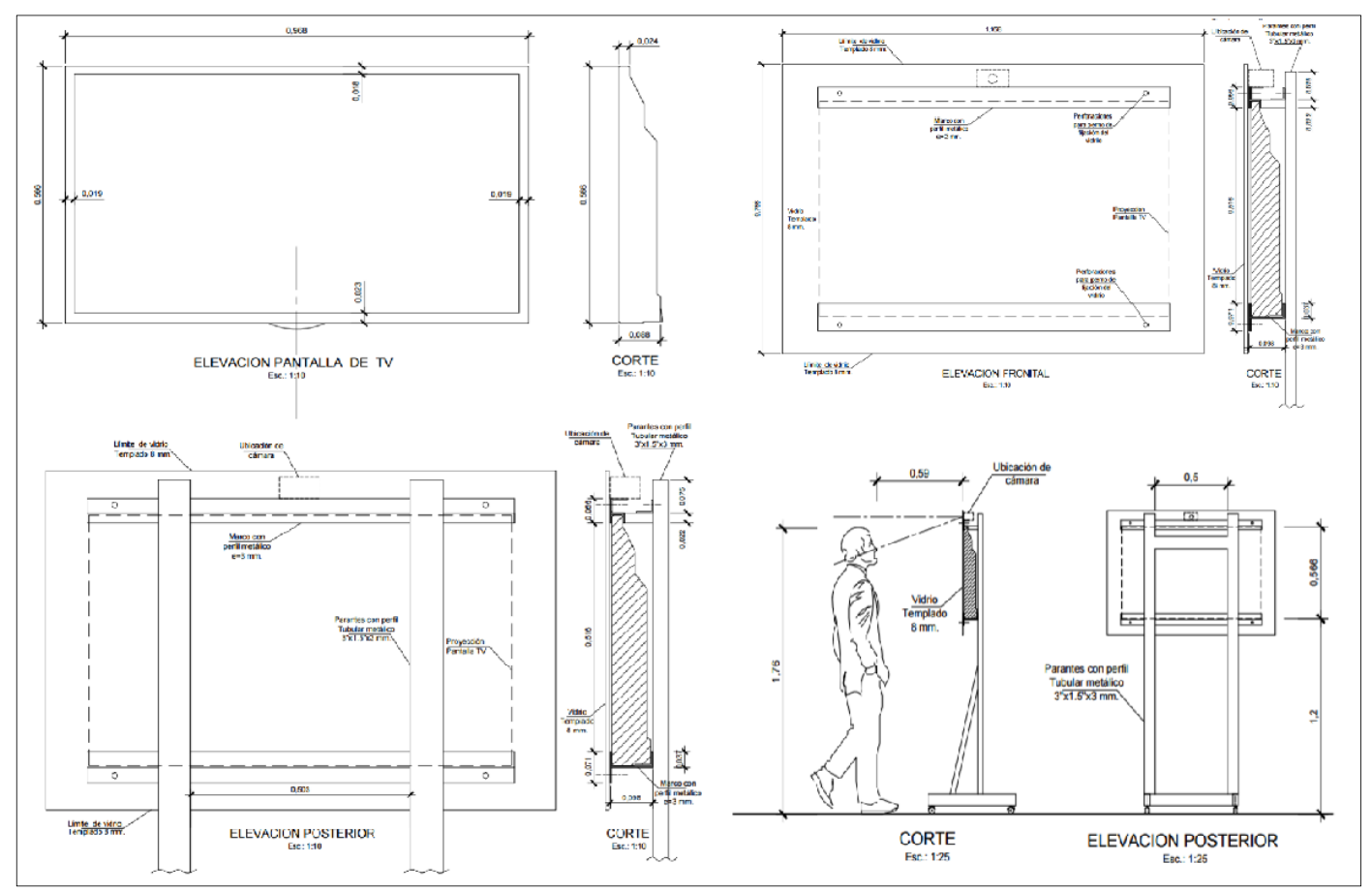

Figura 5. Planos de Smart Mirror Fuente: Elaboración propia

Asimismo, se definió el entorno del trabajo que funciona con conexión HDMI a la placa Raspberry Pi, pequeño ordenador con sistema operativo Raspbian que está basado en Linux, la información se muestra al conectarse a Internet por medio de conectividad de Wi-Fi del Raspberry Pi que muestra la interfaz del espejo por medio del navegador Chromium en modo kiosko, para ello se realizó una prueba de concepto con un simple "Hello World". 


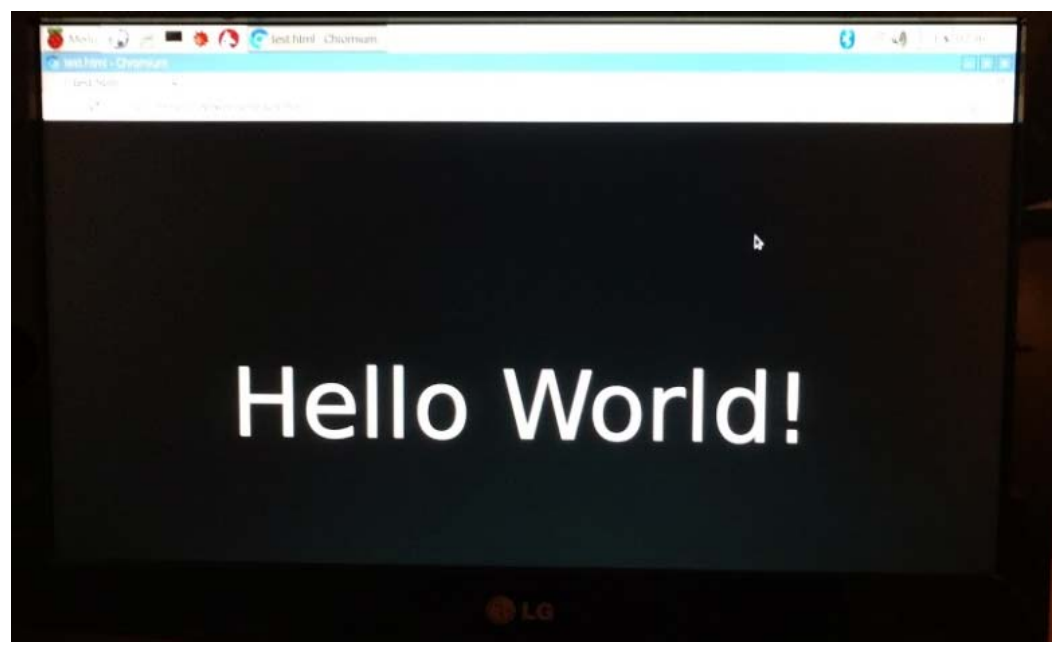

Figura 6. Prueba de concepto del Raspberry Pi con una pantalla LCD Fuente: Elaboración propia

Posteriormente se definió las funcionalidades que se van a implementar y el flujo completo que el usuario debería realizar para poder usar el espejo, el cual se describe en el siguiente diagrama de flujo:

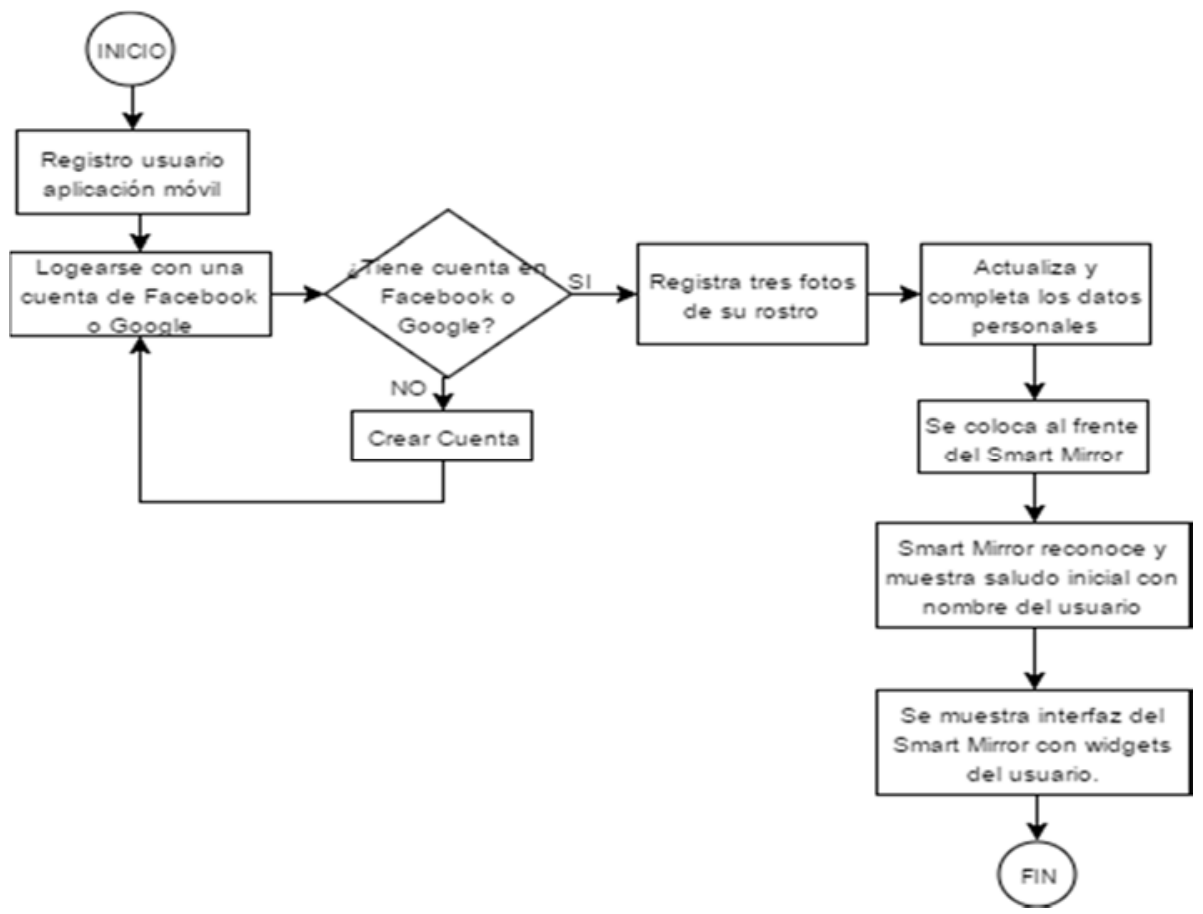

Figura 7. Diagrama de flujo del espejo y aplicación móvil Fuente: Elaboración propia

Por último, con toda esta información se procede a elaborar la primera versión del diseño de la pantalla del espejo (Fig. 4) junto con la diagramación del flujo de funcionamiento. 


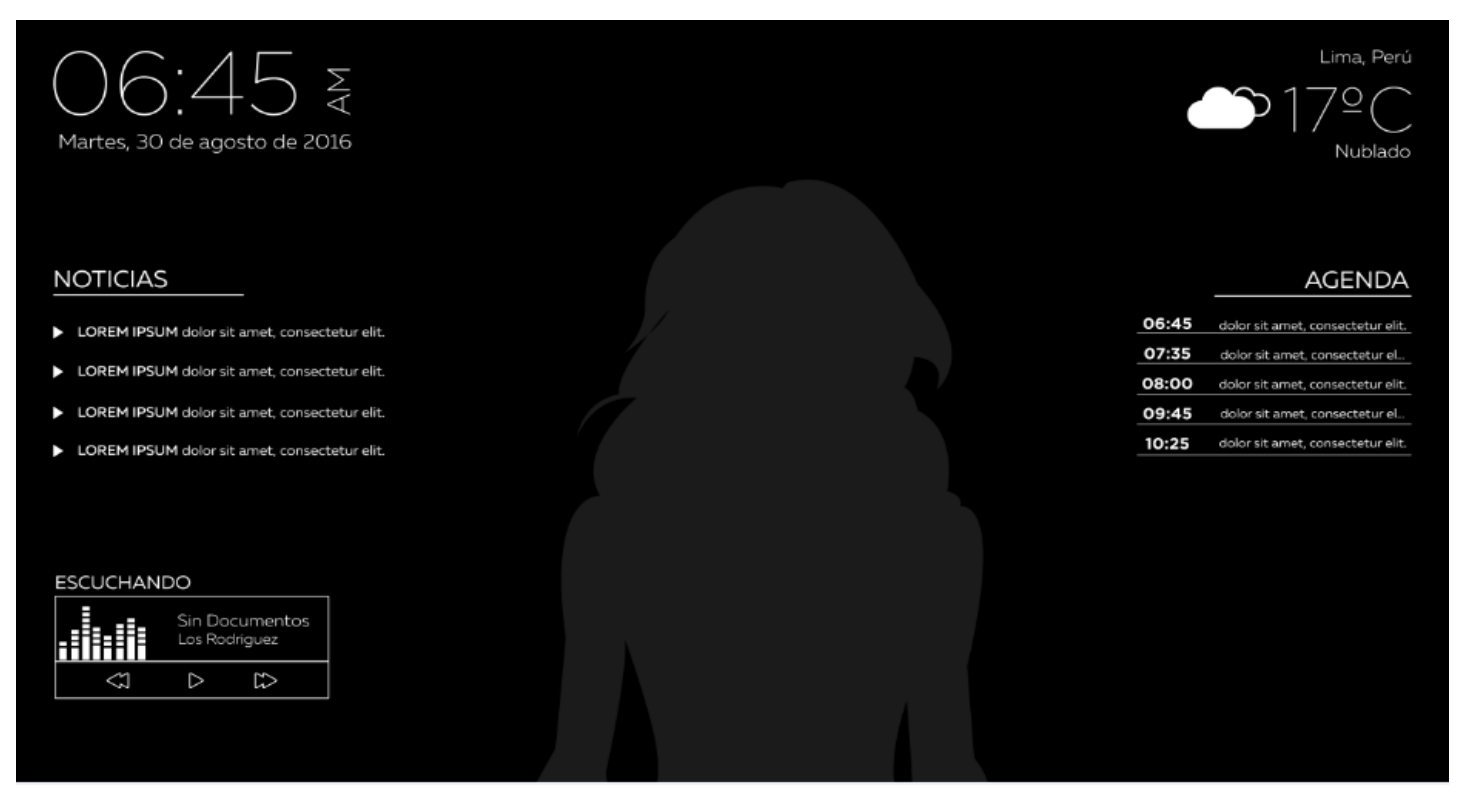

Figura 8. Primera versión de la interfaz de Reflection Fuente: Elaboración propia

\subsubsection{Fase 2 - Implementación}

En la segunda etapa, se procedió a organizar la arquitectura y las tecnologías que usaríamos en el proyecto. Buscamos un método que nos permita utilizar en el espejo una autenticación segura para ello implementamos una tecnología del tipo biométrica como es el reconocimiento facial, el cual se asemeje a Windows Hello $^{13}$, pues la autenticación la realiza de forma instantánea y brinda al usuario una experiencia automatizada.

Para desarrollar el reconocimiento facial se es necesario identificar y registrar al usuario, por lo que surgió el desarrollo de una aplicación móvil para celulares con plataforma Android, utilizando el IDE Android Studio, mediante la cual el usuario podrá registrarse de dos maneras: vía Facebook o vía Google.

Posteriormente la aplicación pide al usuario tomar fotos frontales del rostro para luego ser registrados en el servidor como un tipo de banco de imágenes y el espejo pueda utilizarlas para el reconocimiento facial. Asimismo, dicha aplicación permite actualizar y completar información del usuario para que esta pueda ser utilizada en el algoritmo de recomendación de noticias y también configurar los widgets que desea que se muestren en el espejo (Fig.5).

\footnotetext{
${ }^{13}$ Windows Hello, autenticación biométrica que utiliza las características biométricas de los usuarios para identificarlos en lugar de utilizar una contraseña que permite el acceso instantáneo a dispositivos con Windows 10. (https://blogs.windows.com/latam/2015/03/17/windows-10-mas-personal-y-mas-segurocon-windows-hello/)
} 


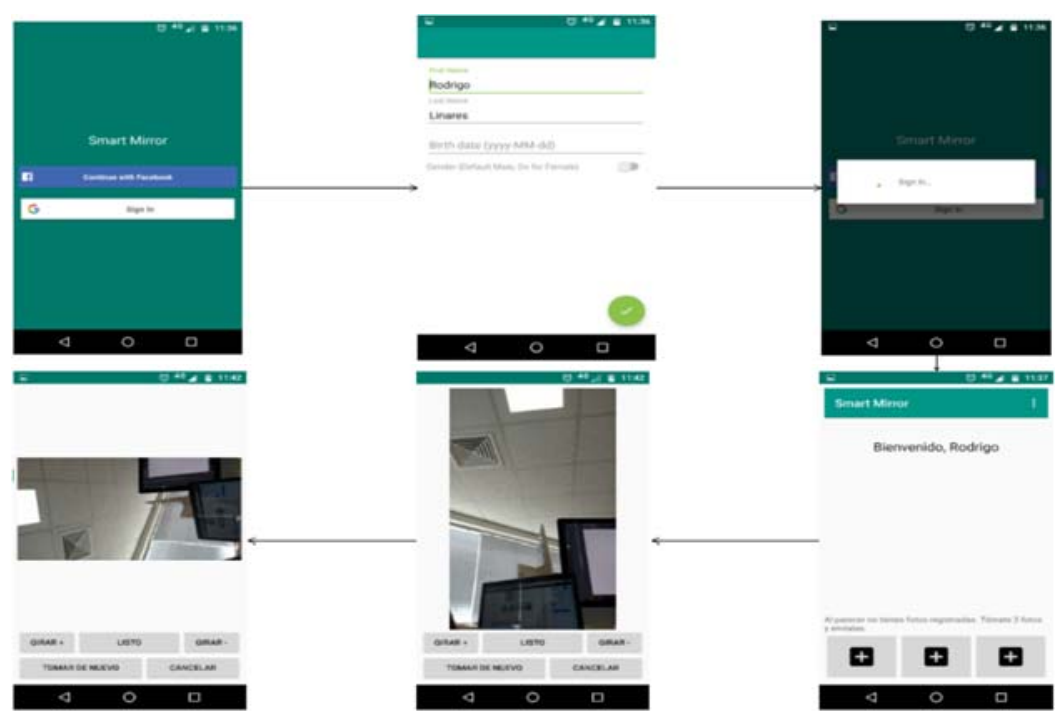

Figura 9. Primera versión de la aplicación móvil Fuente: Elaboración propia

El espejo al utilizar diversos servicios web, necesita de diversas integraciones que permitan obtener la información requerida las cuales son alojadas en un servidor REST programado en el lenguaje de C\# en Visual Studio 2015, en la cual se realiza el intercambio de datos de la aplicación móvil al servidor enviados con el formato JSON. Al inicio, el servidor estuvo alojado en Winhost, posteriormente se migró a Azure del paquete Imagine Premium que nos brinda la universidad, teniendo como arquitectura ffísica del espejo tres componentes: El dispositivo móvil con sistema operativo Android, Servidor Azure y el Smart Mirror, tal y como se muestra en la siguiente figura.

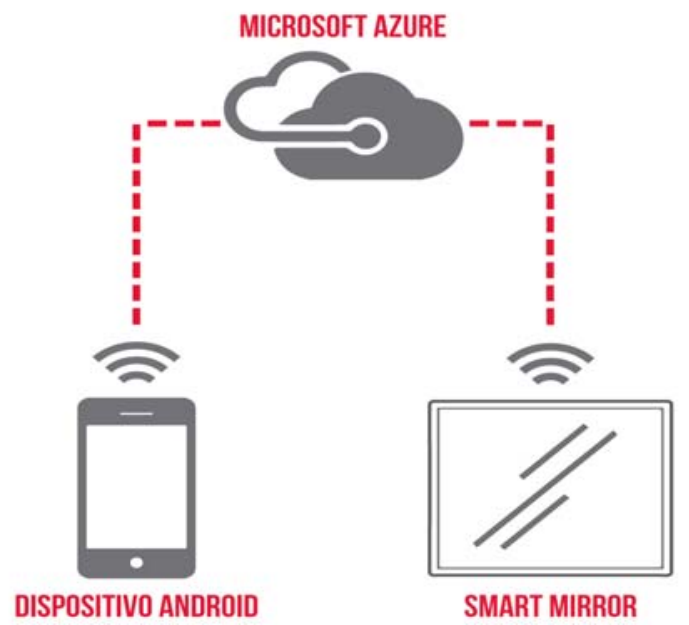

Figura 10. Arquitectura física del sistema Fuente: Elaboración propia 
Para la funcionalidad del reconocimiento facial se hace uso de librerías de EmguCV3. Al realizar las pruebas nos dimos cuenta que 3 fotos no son suficientes para garantizar el reconocimiento facial, sino se tomaría como mínimo 10 fotos del usuario para que el algoritmo sea eficiente. Asimismo, para los servicios como correo y calendarios se utilizó OAuth 2.0 para poder acceder desde la aplicación y guardar estos accesos para que el servidor y la interfaz no se vean afectados por la ventana de confirmación de acceso al servicio. En el reconocimiento de voz, se utilizó Annyang, librería de JavaScript que permite a los usuarios controlar las funcionalidades del Smart Mirror por medio de comandos de voz. Se consumió API's como Dark Sky, RSS del diario Perú 21, Google Calendar y Mail para brindar información del clima, noticias, eventos y correo del usuario respectivamente. Añadimos la funcionalidad de SPEAK utilizando la librería Responsive Voice para que el espejo pueda leer al usuario las noticia, correos o eventos que se muestra en el espejo. De tal forma se diseñó la arquitectura lógica del sistema según todos los componentes descritos, tal y como se muestra en la siguiente figura.

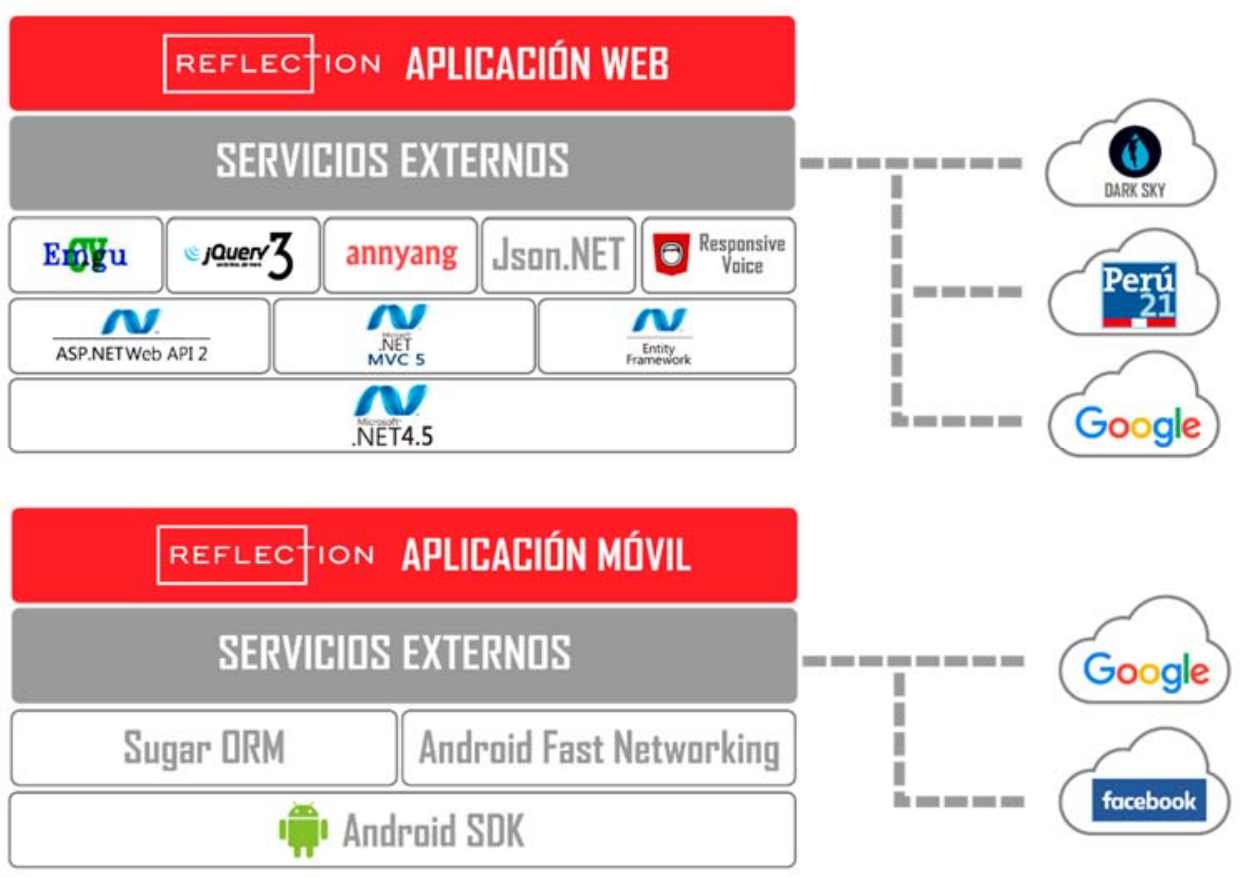

Figura 11. Arquitectura lógica del sistema Fuente: Elaboración propia

La interfaz de usuario que el espejo muestra se desarrolló con componentes de CSS, HTML y JavaScript, se reorganizó el diseño y distribución de los widgets con el objetivo de aprovechar cada espacio del espejo considerando los nuevos 
servicios que mostrará el Smart Mirror sin dejar de lado la función principal de un espejo común.

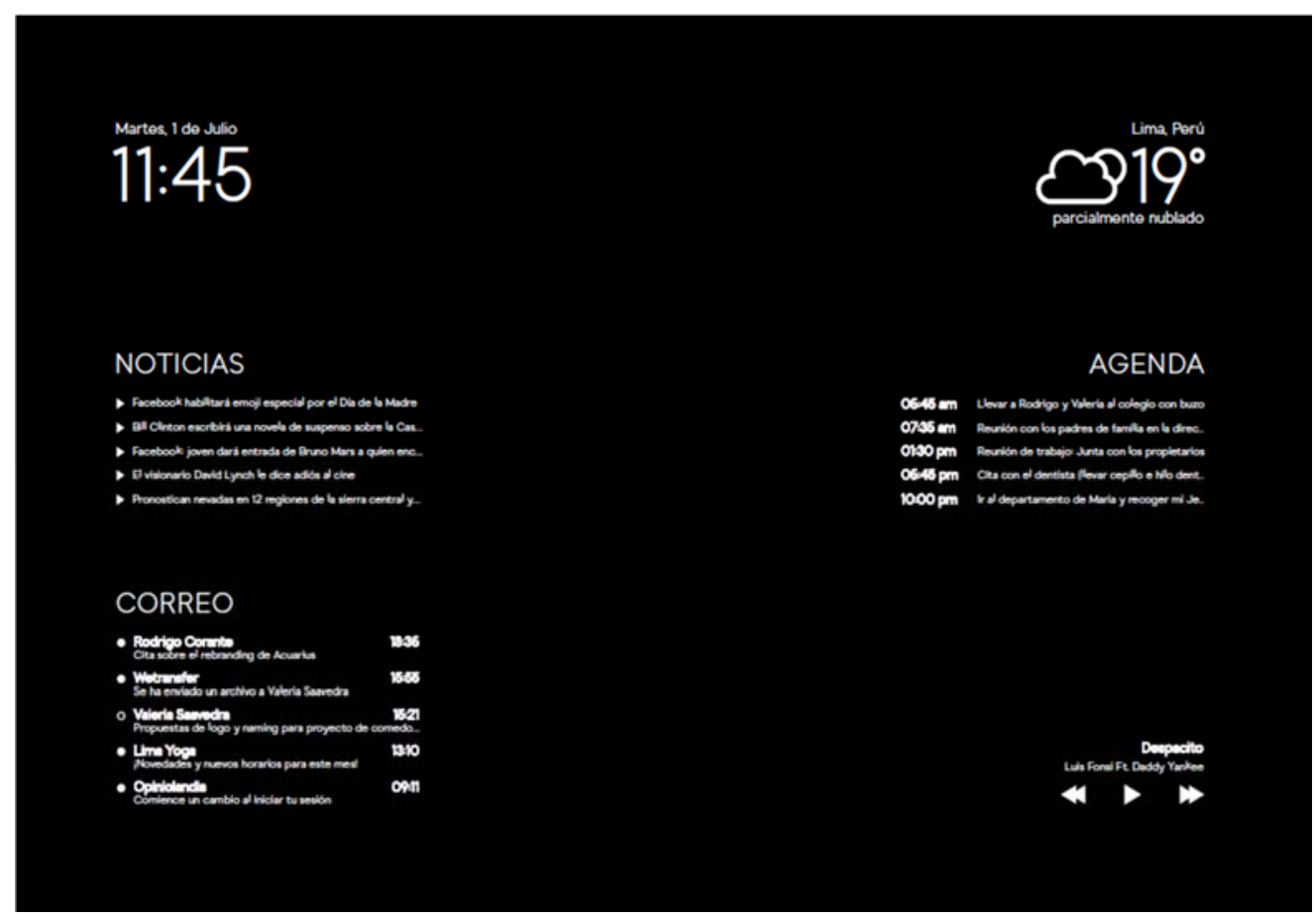

Figura 12. Última versión de la interfaz del espejo Fuente: Elaboración propia

Por último, para la construcción del algoritmo de machine learning se construyó un dataset a partir de una encuesta. Los datos resultantes de la encuesta se llenaron en un archivo de extensión. arff, luego se realizó la prueba de precisión en el programa Weka entre tres algoritmos de clasificación Multilayer Perceptron, Naive Bayes y J48, se realizó la comparación de los resultados obteniendo como mejor porcentaje de precisión para el algoritmo de Naive Bayes. Posteriormente, se desarrolló del modelo predictivo a partir de nuestro dataset el cual tiene como input el registro de nuevos datos y la salida sea la clasificación de ese dato según los patrones detectados en el entrenamiento, según el flujo que se muestra en la Fig.13 


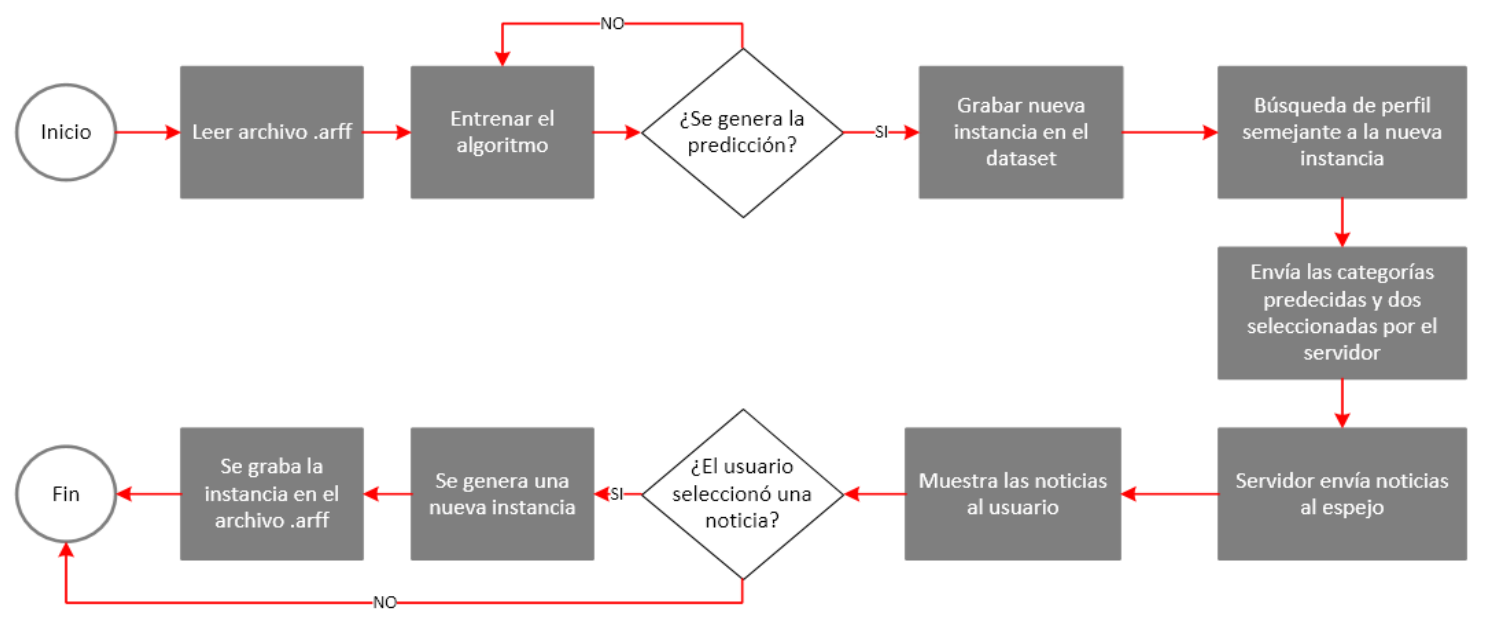

Figura 13.Diagrama de Flujo del algoritmo de recomendación de noticias Fuente: Elaboración propia 


\section{CAPÍTULO 6: Gestión del Proyecto}

En este capítulo, se describe la planificación del proyecto con respecto al tiempo, comunicación, recursos humanos y riesgos. 


\subsection{Planificación del Proyecto}

Un "espejo inteligente" es un espejo con características y funcionalidades añadidas, con el propósito de brindarle al usuario un "dispositivo" en el que pueda revisar el clima, su correo o incluso escuchar música; sin la necesidad de utilizar un pc. Este espejo permite la autenticación del usuario basada en el reconocimiento facial. El objetivo del diseño del espejo es proporcionar una interfaz natural en el ambiente doméstico para acceder a diversos servicios de información como música, noticias, clima, hora, etc.

\subsection{Cronograma del Proyecto}

Nuestro cronograma de proyecto se divide en dos fases, la primera se efectuó en el ciclo 2016-2 y la segunda en el ciclo 2017-1

\subsubsection{Primera Fase}

\section{ID EDT} 1

1.1

1.1.1

1.1.1.1

1.2

1.2.1

1.2.1.1

1.2.1.2

1.2.1.3

1.2.1.4

1.2.2

1.2.2.1

1.2.2.2

1.2.2.3

1.2.2.4

1.2.2.5

1.2.2.6

1.2.2.7

1.2.2.8

1.2.2.9

1.2.2.10

1.2.2.11

1.2.2.12

1.2.2.13
TAREA

Implementación de un Smart Mirror con Raspberry Pi 2016 - 02

\section{Inicio}

\section{Semana 1}

\section{Elaboración de Project Charter}

Planificación

\section{Semana 2}

Elaborar el Plan de Gestión del Alcance

Reunión con el cliente y profesor Gerente

Planificación y desarrollo del smart mirror a nivel de UI

Documentación de las herramientas a utilizar

\section{Semana 3}

Elaborar el Diccionario del EDT

Elaborar Matriz RAM

Elaborar plan de Gestión de Riesgos

Elaborar Matriz de Riesgos

Elaborar Plan de Gestión de RRHH

Elaborar Plan de Gestión de Comunicaciones

Elaborar Registro de Interesados

Elaborar Plan de Gestión del Cronograma

Elaborar Cronograma del Proyecto

Elaborar plan de Gestión de Calidad

Elaborar documento de Descripción de Roles y Responsabilidades

Elaborar Matriz de Trazabilidad de Requerimientos

Reunión con el Cliente 
1.2.2.14

1.2.2.15

1.3

1.3.1

1.3.1.1

1.3.1.2

1.3.1.3

1.3.1.4

1.3.1.5

1.3.2

1.3.2.1

1.3.2.2

1.3.2.3

1.3 .4

1.3.2.5

1.3.2.5.1

1.3.2.6

1.3.3

1.3.3.1

1.3.3.1.1

1.3.3.2

1.3.3.3

1.3.3.4

1.3.3.5

1.3.3.6

1.3.3.7

1.3.4

1.3.4.1

1.3.4.2

1.3.4.3

1.3.4.4

1.3.4.4.1

1.3.4.5

1.3.4.6

1.3.4.7

1.3.5

1.3.5.1

1.3.5.2
Reunión con el profesor gerente

Pruebas de Integración del Raspberry Pi con el Smart TV LG

\section{Ejecución}

Semana 4

Corrección de los documentos de Gestión

Elaboración del Manual de Instalación

Avance del Primer Capítulo de la Memoria

Reunión con el profesor gerente

Reunión con el cliente

\section{Semana 5}

Reunión con el profesor gerente

Desarrollo de la presentación para la primera exposición con el comité

Elaboración de las Historias de Usuario y Product Backlog

Exposición con el comité

\section{Prueba de Concepto 1}

Investigación e implementación del algoritmo de reconocimiento facial en el servidor

Reunión con el cliente

Semana 6

\section{Prueba de Concepto 2}

Desarrollo de la prueba de concepto para capturar imagen y creación de perfil de usuario desde una app

Investigación de algoritmos de Machine Learning

Actualización del Cronograma de Trabajo

Reunión con el profesor revisor para la aprobación del primer capítulo de la memoria

Corrección del primer capítulo de la memoria

Reunión con el profesor gerente

Reunión con el cliente

Semana 7

Avance del capítulo 3 de la memoria

Construcción del Smart Mirror

Desarrollo del Login de la aplicación

\section{Prueba de Concepto 3}

Primera parte del desarrollo de la prueba de concepto para la captura del rostro y envío al servidor

Reunión con el profesor Revisor para las correcciones del capítulo 3 de la memoria

Reunión con el profesor gerente

Reunión con el profesor cliente

Semana 9

Desarrollo de la primera parte de la interfaz del Smart Mirror

Prueba de Concepto 4 


\begin{tabular}{|c|c|}
\hline 1.3.5.2.1 & $\begin{array}{l}\text { Integración del smart mirror con los algoritmos de } \\
\text { reconocimiento facial }\end{array}$ \\
\hline 1.3.5.3 & Reunión con el profesor Gerente \\
\hline 1.3.5.4 & Reunión con el cliente \\
\hline 1.3.5.5 & Avance del capítulo 4 de la memoria \\
\hline 1.3.6 & Semana 10 \\
\hline 1.3.6.1 & $\begin{array}{l}\text { Reunión con el profesor revisor para la aprobación del cuarto } \\
\text { capítulo de la memoria }\end{array}$ \\
\hline 1.3.6.2 & Corregir el cuarto capítulo de la memoria \\
\hline 1.3.6.3 & Reunión y coordinación con el asesor de Machine Learning \\
\hline 1.3.6.4 & Reunión con el profesor Cliente \\
\hline 1.3.7 & Semana 11 \\
\hline 1.3.7.1 & Avance del capítulo 6 de la memoria \\
\hline 1.3.7.2 & Desarrollo del algoritmo de machine learning \\
\hline 1.3.7.3 & $\begin{array}{l}\text { Reunión con el profesor Revisor para las correcciones del capítulo } \\
6 \text { de la memoria }\end{array}$ \\
\hline 1.3.7.4 & Reunión con el profesor Cliente \\
\hline 1.3.8 & Semana 12 \\
\hline 1.3.8.1 & Solicitud de servicios de QS \\
\hline 1.3.8.2 & Corrección de los documentos de Gestión revisados por QS \\
\hline 1.3.8.3 & Integración de las funcionalidad de Hora y clima \\
\hline 1.3.8.4 & Reunión con el profesor Cliente \\
\hline 1.3.8.5 & Reunión con el profesor Gerente \\
\hline
\end{tabular}

\subsection{9}

1.3.9.1 Semana 13

memoria

1.3.9.2 Diseñar la interfaz de usuario para la aplicación del smart mirror

1.3.9.3 Reunión con el Cliente

1.3.9.4 memoria

Reunión con el Revisor para la aprobación del sexto capítulo de la

\subsubsection{Semana 14}

1.3.10.1 Desarrollo de la interfaz de usuario para la aplicación móvil

1.3.10.2 Integración de las funcionalidades del smart mirror

\begin{tabular}{l|l} 
1.3.10.3 Reunión con el cliente & Rema
\end{tabular}

1.3.11 Semana 15

\begin{tabular}{l|l} 
1.3.11.1 & Pruebas de Funcionalidad
\end{tabular}

1.3.11.2 Reunión con el cliente

1.3.11.3 Preparación de los documentos para la sustentación

\section{$1.4 \quad$ Cierre}

1.4.1 Semana 16

1.4.1.1 Exposición con el comité

Tabla 4. Implementación de un Smart Mirror con Raspberry Pi 2016 - 02

Fuente: Elaboración propia 


\subsubsection{Segunda Fase}

ID EDT TAREA

1 Implementación de un Smart Mirror con Raspberry Pi 2017 - 01

\section{3 Ejecución}

1.3.12

Semana 1

1.3.12.1

Prueba de Concepto 5 - Integración correo Google

1.3.12.2

Prueba de Concepto 6 - Integración agenda Google

1.3.12.3

Modificar la cantidad de registro de fotos

1.3.12.4

1.3.12.5

Inicio Prueba de Concepto 7 - Integración WEKA con IDE Java

1.3.13

Reunión con el cliente

1.3.13.1 Pruebas de Concepto 8 - Integración de annyang para reconocimiento de voz

1.3.13.2

1.3.13.3

Pruebas del cambio de la cantidad de registro de fotos

1.3.13.4 corpus

Elaboración del esquema del data set para la elaboración del

1.3.13.5

Revisión de las fuentes de información del paper de investigación.

1.3.14

Reunión con el cliente

1.3.14.1

Semana 3

1.3.14.2

Prueba de Concepto 9 - Integración de música en el Smart Mirror

1.3.14.3

Agregar formulario para modificar datos del usuario

1.3.14.4

Elaboración de la encuesta para el corpus del algoritmo de machine learning

1.3.14.6

1.3.14.7

Elaboración del capítulo 2 de la Memoria

1.3.15

Reunión con el profesor gerente

Reunión con el cliente

1.3.15.1

Semana 4

1.3.15.2

Pruebas de funcionalidad de las pruebas de concepto 5 y 6

1.3.15.3

Pruebas de las nuevas funcionalidades de la aplicación móvil.

1.3 .15 .4

Selección de atributos según los resultados de la encuesta

1.3.15.5

Pruebas de efectividad del modelo predictivo en base al dataset

1.3.15.6

Corrección del capítulo 2 de la Memoria

1.3.15.7

Reunión con el profesor gerente

1.3.16

Reunión con el profesor cliente

1.3.16.1

Semana 5

1.3.16.2

Pruebas de la funcionalidad de la prueba de concepto 7

Elaboración de la segunda versión de la encuesta para el corpus

del algoritmo de machine learning

1.3.16.3

Pruebas de login de Facebook y Google en la aplicación del móvil.

1.3.16.4 Reunión con el profesor Gerente

1.3.16.5

1.3.17

Reunión con el cliente

1.3.17.1

Semana 6

Selección de atributos según los resultados de la encuesta 


\begin{tabular}{|l|c|}
\hline 1.3.17.2 & $\begin{array}{c}\text { Pruebas de efectividad del modelo predictivo en base al nuevo } \\
\text { dataset }\end{array}$ \\
\hline $\begin{array}{l}\text { 1.3.17.3 } \\
\text { 1.3.17.4 }\end{array}$ & $\begin{array}{l}\text { Pruebas de la funcionalidad de modificar datos del usuario en la } \\
\text { aplicación móvil }\end{array}$ \\
\hline & Reunión con el profesor Cliente \\
\hline
\end{tabular}

\subsubsection{Semana 7}

1.3.18.1 Elaboración de la tercera versión de la encuesta para el corpus del algoritmo de machine learning

1.3.18.2 Prueba de la funcionalidad de la prueba de concepto 8

1.3.18.3 Avance de la introducción y desarrollo del paper de investigación

1.3.18.4 Reunión con el profesor Cliente

\subsubsection{Semana 9}

1.3.19.1 Selección de atributos según los resultados de la encuesta

1.3.19.2 Pruebas de efectividad del modelo predictivo en base al nuevo

\begin{tabular}{l|l} 
1.3.19.2 & dataset \\
\hline 1.3 .19 .3 & Modificación de la nueva interfaz del Smart Mirror
\end{tabular}

1.3.19.4 Elaboración de la presentación parcial del proyecto

1.3.19.5 Reunión con el profesor Gerente

1.3.20 Semana 10

1.3.20.1 Construcción del modelo predictivo con nuestro dataset

1.3.20.2 Cambiar diseño de la interfaz de usuario del Smart Mirror

1.3.20.3 Reunión con el Cliente

1.3.20.4 Reunión con el Gerente sobre el estado del proyecto

\subsubsection{Semana 11}

1.3.21.1 Agregar el formulario de configuración de gadgets en la

aplicación móvil

1.3.21.2 Integración de las pruebas de concepto en el Smart Mirror

1.3.21.3 Cambiar diseño de la interfaz de la aplicación móvil

1.3.21.4 Revisión del cierre del paper de investigación

1.3.21.5 Elaboración del capítulo 5 de la memoria

1.3.21.6 Reunión con el cliente

1.3.22 Semana 12

1.3.22.1 $\quad$ Pirror

1.3.22.2 Pruebas de las funcionalidades integradas en el Smart Mirror

1.3.22.3 Preparación de los documentos para la sustentación

1.3.22.4 Elaboración del contenido del poster

1.3.22.5 Corregir el capítulo 5 de la memoria

\subsubsection{Semana 13}

1.3.23.1 Pruebas de caja negra con la empresa virtual QS.

1.3.23.2 Entrega de los capítulos de la memoria finalizada.

1.3.23.3 Integración del algoritmo de machine learning en el servidor.

1.3.23.4 Entrega del paper de investigación

\subsubsection{Semana 14}

1.3.24.1 Impresión del poster 


\begin{tabular}{|c|c|}
\hline 1.3.24.2 & Pruebas de funcionalidad del Smart Mirror. \\
\hline 1.3.24.3 & Culminación de paper \\
\hline \multirow{4}{*}{ 1.3.25 } & Semana 15 \\
\hline & Culminar con las observaciones del cliente \\
\hline & Corregir documentos de gestión \\
\hline & Preparación de la diapositiva de presentación \\
\hline 1.4 & Cierre \\
\hline 1.4.1 & Semana 16 \\
\hline 1.4.1.1 & Exposición con el comité \\
\hline
\end{tabular}

Tabla 5.Implementación de un Smart Mirror con Raspberry Pi 2017 - 01

Fuente: Elaboración Propia

\subsection{Gestión de los Recursos Humanos}

El comité lo conforman Rosario Villalta, Pedro Shiguihara, Jimmy Armas y Victor Parasi. El proyecto pertenece a la empresa Innova TI, el Gerente General es Daniel Burga y el Gerente Alumno Henry Paulett. El cliente y profesor asesor fue Alfredo Barrientos.

La gestión de recursos humanos necesarios para el proyecto se realizó mediante solicitud a las empresas de apoyo Software Factory y QS. Con la primera de las empresas mencionadas, se solicitaron 4 recursos. El primero de ellos, con conocimientos en desarrollo para plataforma Android y servicios Web; para el desarrollo de una aplicación que permita proveer de información de los usuarios que luego se mostrará en el espejo. Los otros 3 recursos solicitados a Software Factory debían contar con conocimientos en C\#, Javascript y diseño web. Para desarrollar la interfaz web que mostrará el espejo. Adicionalmente, el proyecto demandó de dos recursos de QS para la revisión de los documentos de gestión.

El proyecto también necesita de recursos externos a las empresas mencionadas anteriormente, en especial se requirió alumnos de la escuela de Diseño. En este caso, participaron en el proyecto alumnos de las carreras de diseño gráfico y diseño de modas.

\subsection{Gestión de las Comunicaciones}

Inicialmente se definió el alcance del proyecto para lo cual se realizó una reunión en la que participaron el jefe del proyecto, la jefa de desarrollo y el cliente. Además, semanalmente se realizaron reuniones para revisar los avances del proyecto. Las coordinaciones adicionales se realizaron mediante correo. Luego de cada una de las 
reuniones se registró en actas los temas tratados, las personas que participaron en estas, los acuerdos que se llegaron y la firma de cada uno de los que participaron de la reunión para asegurar la veracidad del contenido del acta.

La conversación se mantuvo fluida durante el transcurso del ciclo 2016-02 entre los miembros del proyecto haciendo uso de chats, correos electrónicos, reuniones físicas, reuniones virtuales o llamadas telefónicas. En caso de necesitar contactarse con algún Stakeholder o miembro del comité, el medio de comunicación fue el correo electrónico.

\subsubsection{Reuniones}

Se siguió las indicaciones planteadas al inicio del proyecto para realizar las reuniones, evitando los retrasos y con el fin primordial de maximizar la efectividad de las reuniones. Cada una de las reuniones tuvo como resultado un acta en la que los asistentes firmó, dando fe de que los acuerdos serán cumplidos.

\subsubsection{Comunicación con el Equipo}

La comunicación con el equipo de proyecto se realizó de forma horizontal y fluida, delegando actividades y reportando el avance e inconvenientes. El compromiso por parte de todo el equipo se evidenció ante la presencia de incidencias de alto impacto y urgencia, por lo cual se agilizó la comunicación mediante el uso de celulares y chats.

\subsection{Gestión de los Riesgos}

Luego de que el alcance del proyecto se haya definido por completo, se pasó a identificar los riesgos que podrían surgir durante el desarrollo del mismo.

A partir de este proceso, se identificaron 9 riesgos, que se presentan a continuación:

\begin{tabular}{|c|c|}
\hline Cód. Riesgo & Descripción del Riesgo \\
\hline [ISM]-R001 & $\begin{array}{c}\text { Cancelación de las reuniones con el cliente o profesor } \\
\text { gerente }\end{array}$ \\
\hline [ISM]-R002 & Cambio del alcance del proyecto por necesidades del cliente \\
\hline
\end{tabular}




\begin{tabular}{|c|c|}
\hline [ISM]-R003 & Incumplimiento de los entregables por parte del equipo \\
\hline [ISM]-R004 & Insuficiente información brindada por el recurso \\
\hline$[\mathrm{ISM}]-\mathrm{R} 005$ & Costo alto de las principales fuentes de información \\
\hline [ISM]-R006 & $\begin{array}{l}\text { Disconformidad en la entrega de los informes ya } \\
\text { desarrollados }\end{array}$ \\
\hline [ISM]-R007 & $\begin{array}{l}\text { La estimación del tiempo del proyecto es optimista, en vez } \\
\text { de ser realista }\end{array}$ \\
\hline [ISM]-R008 & Existe conflictos entre los recursos del equipo del proyecto \\
\hline [ISM]-R009 & $\begin{array}{c}\text { Peligro de robo o deterioro de los equipos a causa de la } \\
\text { inseguridad de Lima. }\end{array}$ \\
\hline
\end{tabular}

Tabla 6. Riesgos del proyecto

Fuente: Elaboración Propia

A cada uno de ellos, se le asignó un grado de probabilidad de que ocurran, y el posible impacto que tendrían en el proyecto de suceder.

Luego de haber identificado cada uno de los riesgos, se procedió a plantear estrategias en caso se presenten durante el proyecto. A continuación, se describen:

\begin{tabular}{|c|c|c|}
\hline Cód. Riesgo & $\begin{array}{c}\text { Tipo de } \\
\text { Estrategia }\end{array}$ & $\begin{array}{c}\text { Descripción de la estrategia } \\
\text { planteada }\end{array}$ \\
\hline$[$ ISM]-R001 & Evitar & $\begin{array}{c}\text { Cancelación de las reuniones } \\
\text { con el cliente o profesor } \\
\text { gerente }\end{array}$ \\
\hline$[$ ISM]-R002 & Evitar & $\begin{array}{c}\text { Cambio del alcance del } \\
\text { proyecto por necesidades del } \\
\text { cliente }\end{array}$ \\
\hline$[$ ISM]-R003 & Evitar & $\begin{array}{c}\text { Incumplimiento de los } \\
\text { entregables por parte del } \\
\text { equipo }\end{array}$ \\
\hline$[$ ISM]-R004 & Mitigar & $\begin{array}{c}\text { Insuficiente información } \\
\text { brindada por el recurso }\end{array}$ \\
\hline$[$ ISM]-R005 & Aceptar - & $\begin{array}{c}\text { Costo alto de las principales } \\
\text { fuentes de información }\end{array}$ \\
\hline Pasivamente & Mitigar & $\begin{array}{c}\text { Disconformidad en la entrega } \\
\text { de los informes ya } \\
\text { desarrollados }\end{array}$ \\
\hline
\end{tabular}




\begin{tabular}{|c|c|c|}
\hline [ISM]-R007 & Mitigar & $\begin{array}{c}\text { La estimación del tiempo del } \\
\text { proyecto es optimista, en vez } \\
\text { de ser realista }\end{array}$ \\
\hline [ISM]-R008 & Evitar & $\begin{array}{c}\text { Existe conflictos entre los } \\
\text { recursos del equipo del } \\
\text { proyecto }\end{array}$ \\
\hline [ISM]-R009 & Mitigar & $\begin{array}{c}\text { Peligro de robo o deterioro de } \\
\text { los equipos a causa de la } \\
\text { inseguridad de Lima. }\end{array}$ \\
\hline
\end{tabular}

Tabla 7. Estrategias de mitigación de riesgos

Fuente: Elaboración Propia 


\section{CONCLUSIONES}

Los espejos inteligentes tienen un gran potencial para ayudar a los usuarios a acceder e interactuar con la información necesaria sin esfuerzo. Generalmente, la construcción de un espejo inteligente tiene dos pilares fundamentales: el diseño de la estructura y la definición de funcionalidades. El primero de ellos es un proceso clave, pues de acuerdo a la definición de la estructura y el tamaño con el que contará el espejo se podrá orientar a diferentes segmentos comerciales. La definición de las funcionalidades cuenta con especial importancia debido a que estas, en la mayoría de los casos, requieren del consumo de diversos servicios web que le permitan obtener la información que posteriormente mostrará.

Las investigaciones previas realizadas nos permitieron conocer y analizar los diversos espejos existentes y próximos a ser lanzados en el mercado, así como las funcionalidades con las que cuentan y el precio con el que se proyectan a ser ofrecidos. A partir de este análisis se adoptaron las funcionalidades más relevantes identificadas en los diferentes espejos ya existentes, y se agregaron algunas otras para darle un valor agregado al nuestro, como la autenticación con reconocimiento facial, los comandos de voz y el sistema de recomendación de noticias personalizadas.

Como resultado de las investigaciones sobre dispositivos con la superficie de un espejo, se ha diseñado un espejo inteligente que permite al usuario acceder e interactuar con la información, mejorando la experiencia de este mediante la personalización por medio de un sistema de recomendación de noticias. Además, con el fin de mejorar la experiencia de usuario que brinda nuestro espejo también se implementó la funcionalidad de reconocimiento de comandos de voz para mejorar la interacción del espejo y esta lea la información que presenta en su interfaz.

Durante la implementación del sistema de recomendación de noticias fue necesario la creación de un propio dataset, que se adapte al modelo a implementar. Para lo cual se realizó una encuesta a los alumnos de la Universidad Peruana de Ciencias Aplicadas pertenecientes a la sede Monterrico. Conforme recopilamos información de las encuestas, descartamos atributos que no aportaban información relevante al dataset, quedando finalmente los atributos de edad, sexo, ocupación, área y como clase se tiene la categoría de noticia a predecir. Finalmente, se implementó el algoritmo de clasificación Naive Bayes con el método de evaluación de Cross Validation. 


\section{RECOMENDACIONES}

- Obtener más instancias en el dataset para mejorar la precisión de la predicción de las noticias.

- Se recomienda trabajar con una webcam HD que incorpore micrófono.

- En un equipo multidisciplinario se recomienda contar con un repositorio para no retrasar o depender de los avances de otra persona

- Dado que la solución se encuentra en la nube se debe contar con un backup y guía de despliegue del proyecto por seguridad en caso de que se tenga problemas técnicos en el servidor actual. 


\section{GLOSARIO}

- Dimensionalidad: Tamaño que se obtiene de multiplicar la cantidad de píxeles de ancho y cantidad de píxeles de alto de una imagen.

- Sistemas de recomendación: Sistema que tiene por finalidad generar recomendaciones significativas a usuarios de artículos o productos que podrían interesarles.

- Estado del Arte: Conjunto de estudios anteriores realizados acerca del tema llevado a cabo en un Proyecto Profesional.

- Investigación Tecnológica: Metodología de investigación consistente en la demostración del funcionamiento de una nueva tecnología.

- IT Expert: Empresa virtual encargada de desarrollo de proyectos de automatización de procesos y de Tecnología de Información en general.

- Project Charter: Documento o Acta de Conformación del Proyecto, en el cual se delimitará el alcance y objetivos a realizar.

- Scrum: Marco de trabajo para proyectos de desarrollo de software, consistente en desarrollo por iteraciones en equipos pequeños.

- Software Factory: Empresa virtual encargada de proveer recursos desarrolladores a los Proyectos Profesionales.

- Autores Seminales: Son los autores que brindar por primera vez en la historia la definición a un tema en particular.

- Android: Sistema operativo de los teléfonos móviles fabricados por la empresa Google. 


\section{SIGLARIO}

- PMBOK: Project Management Body of Knowledge

- QA: Quality Assurance

- IE: Indicador de Éxito

- OE: Objetivo Específico

- IOT: Internet of Things

- SM: Smart Mirror 


\section{REFERENCIAS}

ANWAR Hossain, M., Atrey, P. K., \& El Saddik, a. (2007). Smart mirror for ambient home environment. 3rd IET International Conference on Intelligent Environments (IE 07), 2007, 589-596. https://doi.org/10.1049/cp:20070431

ASANOV, D. (2011). Algorithms and Methods in Recommender Systems. Other Conferences. Retrieved de http://www.uic.edu.hk/ alex/Algorithms and Methods in Recommender Systems.pdf

BARTH, A., JACKSON, C., \& REIS, C. (2008). The Security Architecture of the Chromium Browser. Proceedings of WWW 2009.

BESSERER, Daniel et al. (2016). FitMirror: A Smart Mirror For Positive Affect in Everyday User Morning Routines. Germany.

CECCARONI, Luigi y VERDAGUER, Xavier (2004). Magical Mirror: multimedia, interactive services in home automation. pp. 10-21. En: Proceedings of the Workshop on Environments for Personalized Information Access - Working Conference Advanced Visual Interfaces (AVI 2004), New York, NY, USA, 2004. ACM Press.

CHIDAMBARAM, Sethukkarasi y otros (2012) Design and Development of Interactive Mirror for Aware Home. National Ubiquitous Computing Research Centre Centre for Development of Advanced Computing Chennai, India 2012.

GARTNER. (11 de Abril de 2012). Surface Computers - Gartner IT Glossary. Recuperado el 23 de Agosto de 2016, de http://www.gartner.com/itglossary/surface-computers

DELGADO, Christian (29 de Septiembre de 2015). ¿Qué es Chromium y dónde descargar Chromium?. Recuperado el 29 de Agosto de 2016, de http://www.christiandve.com/2015/09/que-es-donde- descargar-chromiumdiferencias-chromium-google-chrome/ 
definición y características según el sistema operativo, arquitectura y codigo fuente. (Consultado 19 de Setiembre de 2016)

Fujinami, K., Kanwar F. y Nakajia T. (2005). AwareMirror: A Personalized Display Using a Mirror. Third International Conference on Pervasive Computing, pp.31-332.

Gold, D.y Sollinger D. (2016). SmartReflect: A Modular Smart Mirror Application Platform. Other Conferences. Retrieved from http://www.uic.edu.hk/ alex/Algorithms and Methods in Recommender Systems.pdf

HITOSHI, Carlos (2001) Interactive Digital Mirror. Departamento de Ci\&ncia da Computaqgo do IME-USP - Rua do MaGo 1010, Sho Paulo, SP 05508, Brazil.

ILIEVSKI, I., ROY, S. (2013). Personalized news recommendation based on implicit feedback. In: Proceedings of the 2013 International News Recommender Systems Workshop and Challenge.

Marqués, I. (2010). Face Recognition Algorithms Proyecto Fin de Carrera. Thesis. Retrieved from http://alweb.ehu.es/ccwintco/uploads/d/d2/PFC-IonMarqués.pdf

MICROSOFT ¿Qué es Windows Hello?
(https://support.microsoft.com/es-co/help/17215/windows-10-what-is-hello) (consulta: 28 de Junio de 2017)

PHILIPS HOMELAB

(http://www.research.philips.com/technologies/misc/homelab/ index.html) Sitio web oficial de las investigaciones que realiza la empresa Phillips para lanzar al mercado nuevas soluciones tecnológicas. (Consulta: 19 de setiembre del 2016) 
NOLAN Robert. The Evolution of Smart Mirrors. Recuperado el 29 de Agosto de 2016, de https://www.linkedin.com/pulse/evolution-smart-mirrors-robert-nolann-tech-research

O’Toole, A., PHILLIPS P., \& JIANG. et al., (2007). Face recognition algorithms surpass humans matching faces over changes in illumination. IEEE Transactions on Pattern Analysis and Machine Intelligence, 29(9), pp.1642-1646.

PEREZ, Javier. (2014) Autenticación biométrica en redes sociales: diseño e implementación de reconocimiento facial mediante EmguCV para autenticación en redes sociales. (Consultado 26 de Setiembre de 2016) (http://earchivo.uc3m.es/bitstream/handle/10016/22496/PFC_Javier_Perez_Miguez_201 4.pdf? sequence $=1 \&$ isAllowed $=y$ )

THE FUNG GROUP (2015) Global Retail Research \& Intelligence: Magic Mirror (http://www.actimirror.com/2015/02/17/fung-global-retail-researchintelligence/). Contiene información sobre espejos inteligentes que se han construido para el sector retail. (Consulta: 24 de Setiembre de 2016). 


\section{ANEXOS}

\section{Anexo 1: Planos de construcción del Smart Mirror}

1. Plano Pantalla TV

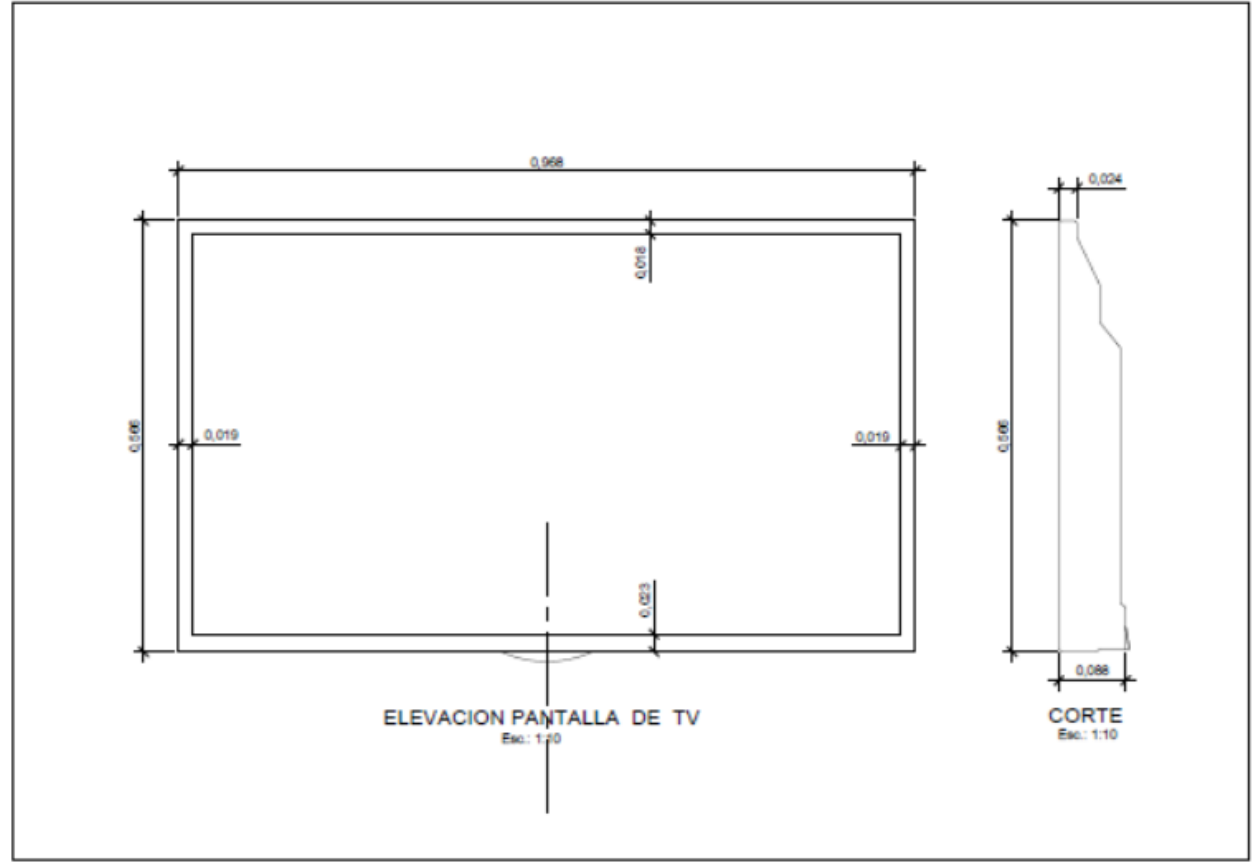

Figura 14. Plano Pantalla TV

Nota: Elaboración propia

2. Plano Elevación Frontal

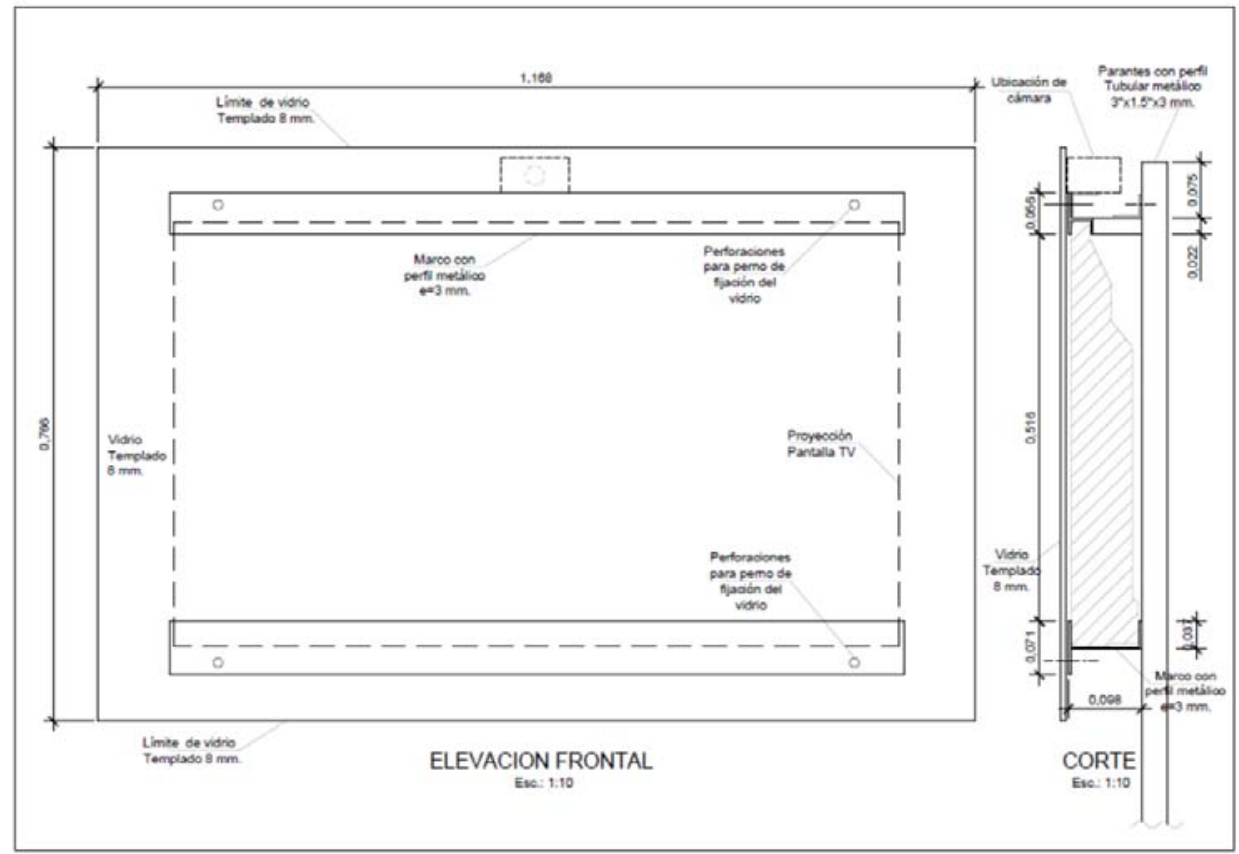

Figura 15. Plano Elevación Frontal Nota: Elaboración Propia 
3. Plano Elevación Posterior

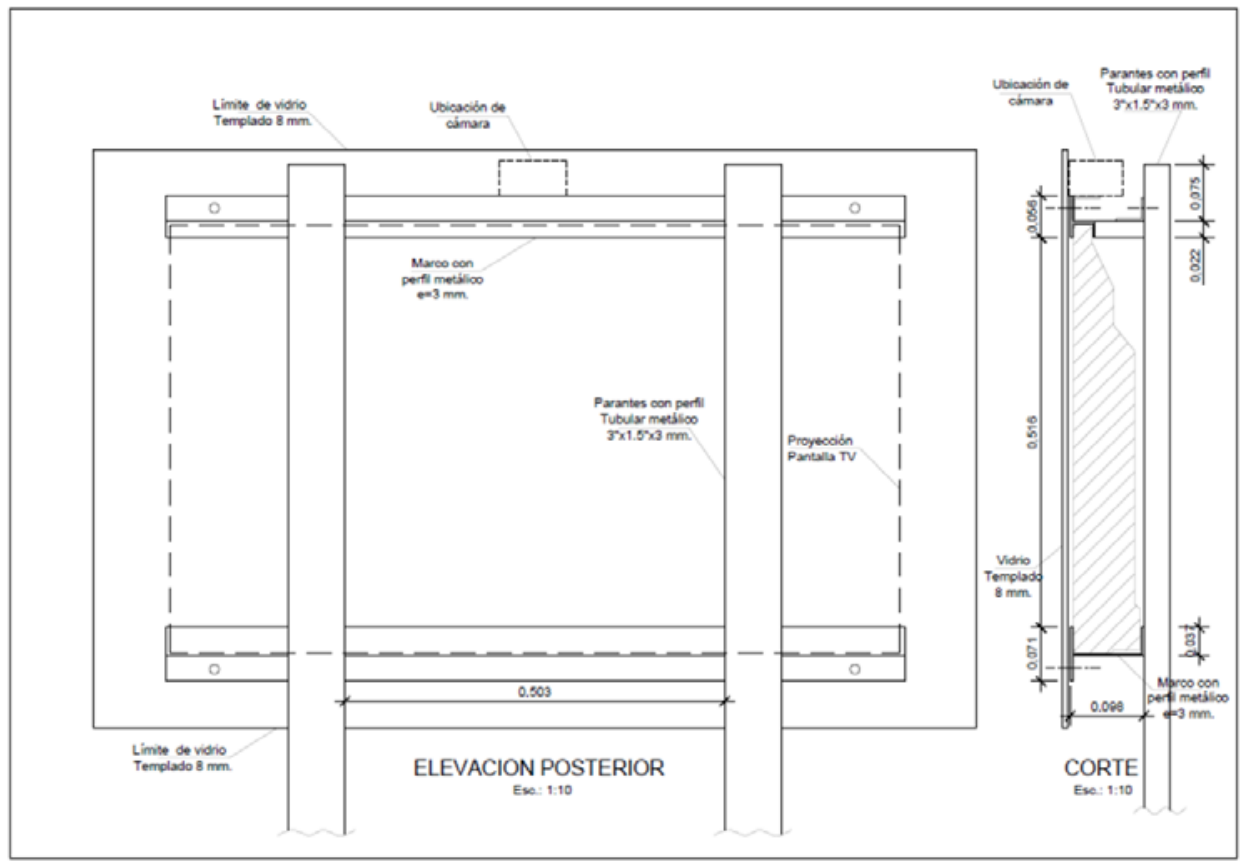

Figura 16. Plano Elevación Posterior Nota: Elaboración propia

4. Plano-Conjunto

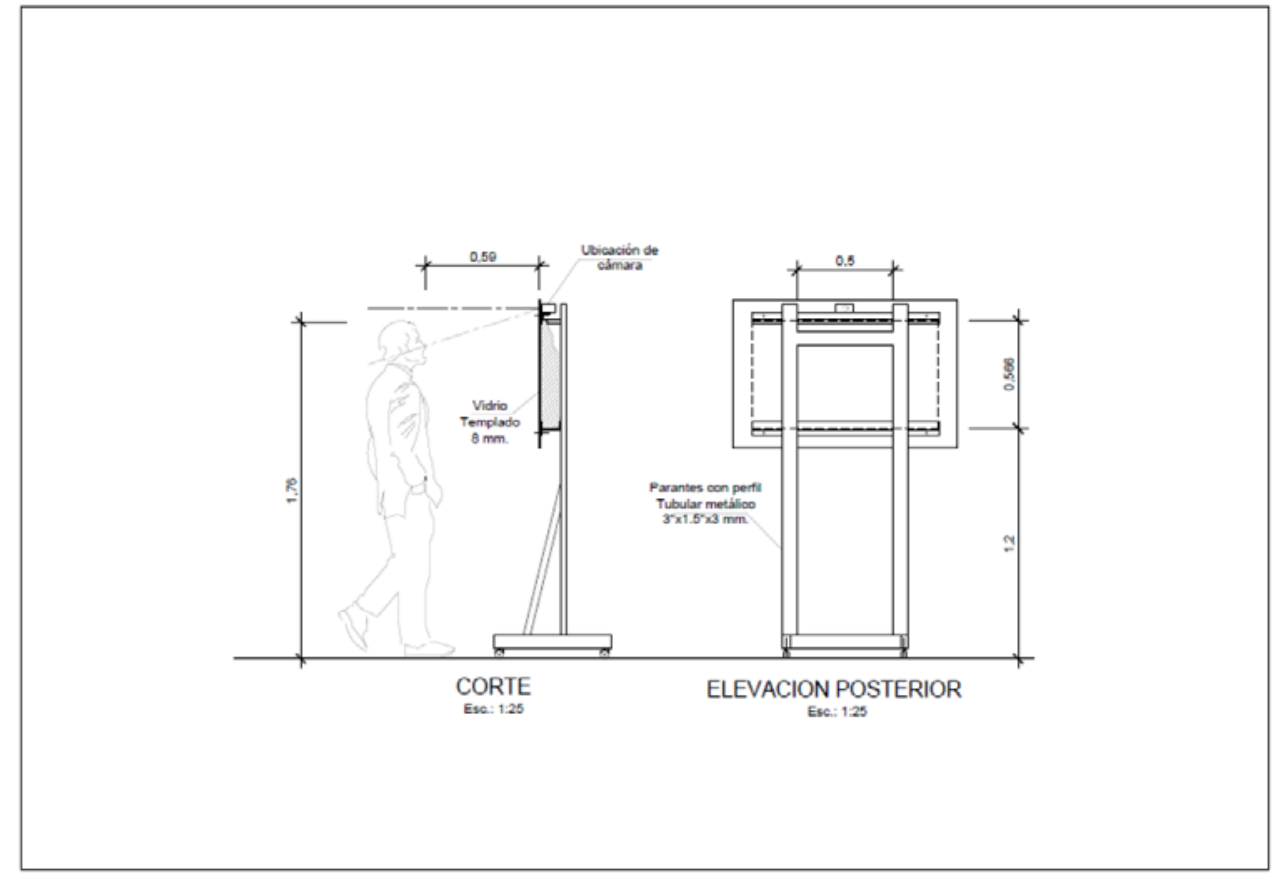

Figura 17. Plano - Conjunto

Nota: Elaboración Propia 


\section{Anexo 2: Comparativo de placas del tipo Low Cost}

\section{Comparación de Low Cost Development Boards}

Intel Galileo es una placa Arduino que cuenta con puertos I/O adicionales: un slot mini-PCI Express, un puerto de $100 \mathrm{Mb}$ de Ethernet, un slot Micro-SD, un puerto serial RS-232, un puerto USB Host y un puerto USB Client. También tiene una memoria de 8MB NOR flash, 512 KB SRAM, 256 MByte DRAM and un procesador de $400 \mathrm{MHz}$.

A comparación de eso un Arduino Uno tiene un CPU de $16 \mathrm{MHz}, 32 \mathrm{~KB}$ de memoria Flash y $2 \mathrm{~KB}$ de Sram. El Arduino Due tiene un $\mathrm{CPU}$ de $84 \mathrm{MHz}, 512 \mathrm{~K}$ de Flash and $96 \mathrm{~K}$ de SRAM.

Un Galileo es una placa mucho más rápida debido a sus mejores capacidades en cuanto a memoria e I/O, pero también cuenta con un costo mayor: $\$ 60$, en comparación con los Arduinos Uno y Due (\$25 y $\$ 50$ respectivamente).

Tanto el Arduino como el Galileo son micro-controladores y pueden correr el mismo software. Esto significa que no cuentan con un sistema operativo propio, por lo que uno debe instalar uno desde un USB o una tarjeta micro-SD.

Un Raspberry Pi es una máquina muy diferente. Es una computadora que cuenta con un sistema operativo optimizado para sus especificaciones: Raspbian, una variación de Debian. Al Raspberry Pi se le pueden conoctar, ratón, toclado, monitor y correr programas tales como exploradores de internet. Es mucho más rápido, pues cuenta con un procesador de $900 \mathrm{MHz}$ y $1 \mathrm{~GB}$ de memoria RAM. La desventaja es que en comparación al Arduino, demora un poco más en comenzar a trabajar. En cuanto a precio, es más barato que el Galileo, con un valor de $\$ 35$.

Debido a su poder y valor, el Raspberry Pi es la placa de bajo costo a elegir para el proyecto, brindandonos mayor poder que un Arduino o Galileo, a un menor costo y con una forma muy fácil de configurarse.

\section{Bibliografia}

Morris, Richard. (10 de Junio de 2015). What is a comparison between Arduino, Intel Galileo and the Raspberry Pi? Recuperado de: https://www.quora.com/ What-is-a-comparison-between-A rduino-Intel-Galiloo-and-the-Raspberry-Pi

1

Figura 18. Comparativo de placas del tipo Low Cost Nota: Fuente Propia 


\section{Anexo 3: Guía de Instalación - Prueba Concepto Raspberry}

Pi

\section{Guía de instalación y prueba de concepto con Raspberry Pi}

El objetivo de esta guía es hacer una prueba de concepto, la cual consiste en mostrar que tan bien se puede ver la interfaz del Smart Mirror.

Para esta guía se necesitará:

- Una computadora

- Una placa Raspberry Pi 3 Modelo B

- Una tarjeta miniSD

- Un mouse

- Un toclado

- Un cable HDMII

- Un monitor con puerto HDMI

\section{Paso 1}

Descargar el sistema operativo Raspbian de la siguiente página: httgs://www. raspberrypi.org/downloads/

\section{Paso 2}

Una vez descargado Raspbian se debe insertar la tarjeta miniSD a la computadora, ya sea por un USB o una lectora de la misma computadora, para poder cargar el Raspbian a la tarjeta. Se rocomienda utilizar Rufus (https://rufus.akoo.ie/) para hacer esto. Una vez iniciado Rufus se hace click al boton con el icono de unidad de disco para escoger la imagen de Raspbian previamente descargada. Una vez cargada la imagen hacer click en comenzar para iniciar a crear un Raspbian que se puoda inicializar desde la tarjeta miniSD.

1

Figura 19. Guía de Instalación - Prueba Concepto Raspberry Pi 1 Nota: Elaboración propia 


\section{Paso 3}

Una vez terminado el proceso de copiado en la tarjeta miniSD, se introduce la misma dentro del Raspberry. Antes de conectar la corriente del dispositivo se recomienda conoctar $\mathrm{el}$ mouse, el toclado y el monitor al Raspberry. Cuando todo este listo se conecta la corriente del Raspberry y se siguen las instrucciones que salen en pantalla.

\section{Paso 4}

Una vez instalado el sistema operativo podemos crear una carpeta con el nombre "tmp" en el escritorio, darle click derecho y hacer click a la opeion abrir en la terminal. Una vez en la terminal ejocutar el comando "nano" para iniciar una instancia del editor de texto en la terminal. Una vez ejecutado el comando, copiar cl siguiente código:

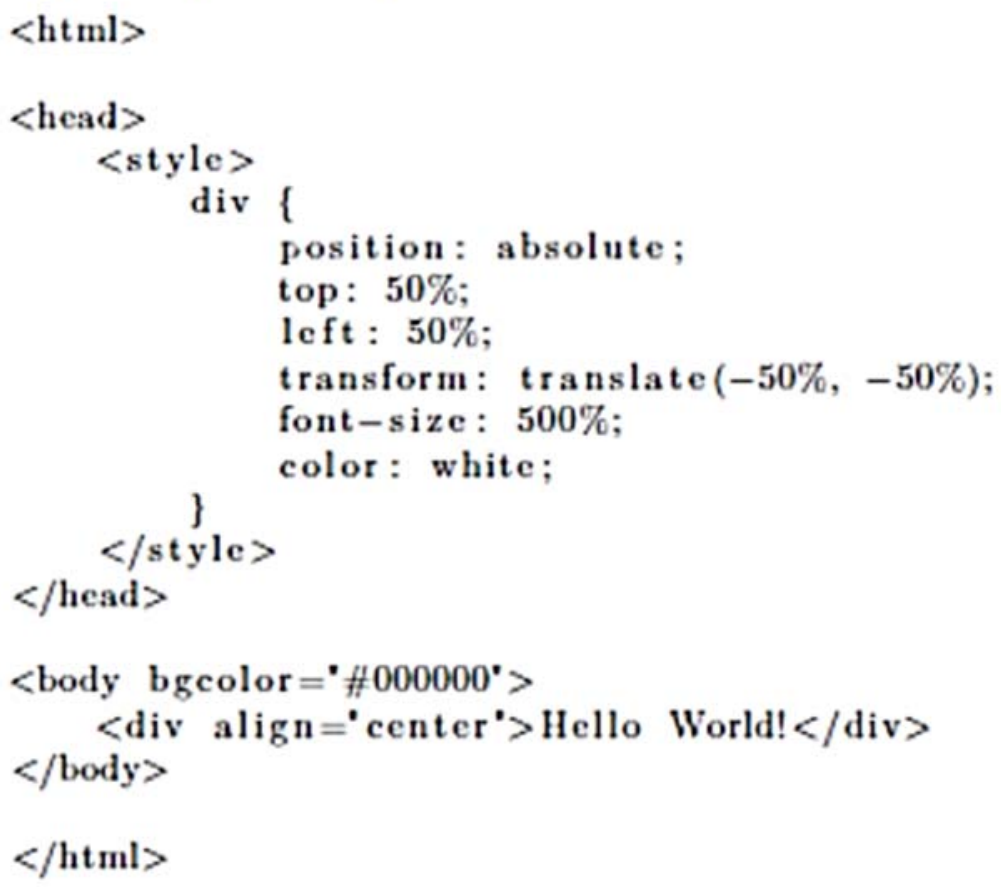

Lucgo de copiar el código oprimir la combinación de teclas "ctrl $+\bar{x}$ ", escribir el nombre "prueba.html" y luego oprimir la tecla "enter". Una vez hecho esto se deberia tener un archivo html en la carpeta previamente creada. Al hacerle doble click deberia mostrarse una instancia del navegador web con la frase: "Hello World!" al centro de la pantalla. Oprimir "F11" para poder visualizar como seria el modo kiosko del Raspberry.

Figura 20. Guía de Instalación - Prueba Concepto Raspberry Pi 2 Nota: Elaboración propia 


\section{Anexo 4: Instrucciones de software}

\section{Instrucciones del Software}

En este documento se da a conocer las instrucciones del software que utilizamos, sin embargo para poder probar se es necesario el hardware del proyecto.

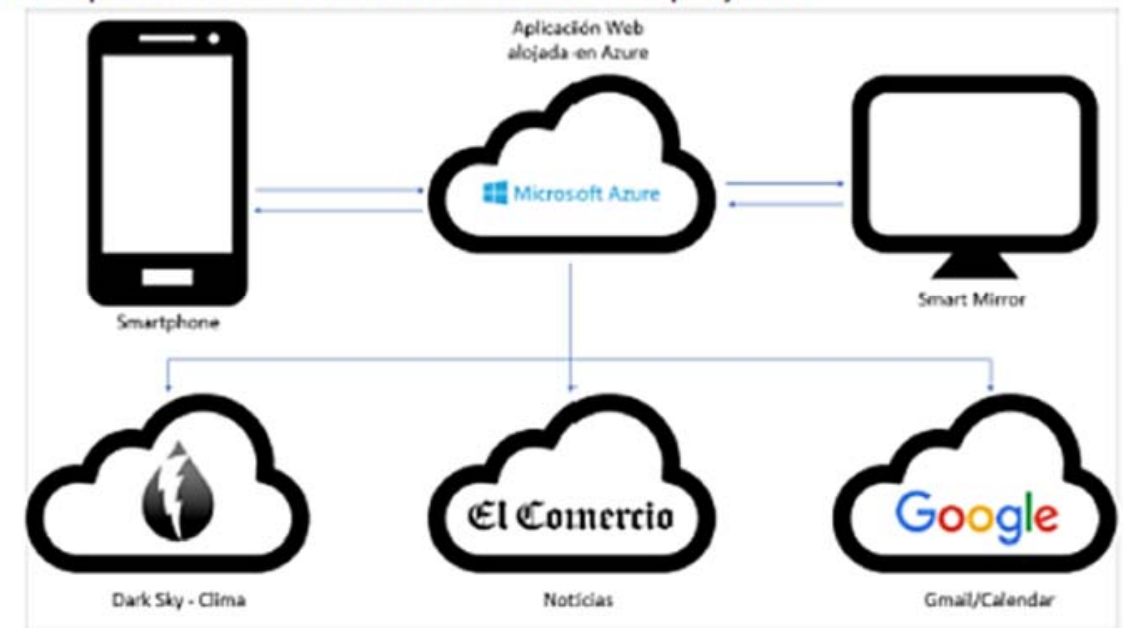

\section{Servidor}

El Proyecto Reflection está desarrollado utilizando el patrón MVC en el servidor con el fin de mantener un orden en el desarrollo y en los recursos utilizados. Solo se mencionarán las carpetas y archivos creados o donde se han realizado cambios, mas no aquellos autogenerados.

\subsection{Orden de Carpetas}

\section{- App_Data}

Dentro de esta carpeta tenemos dos carpetas vacias (Faces y Training), las cuales servirán para alojar recursos que se generan en tiempo de ejecución. Además de estas carpetas también se encuentran cuatro archivos XML los cuales son clasificadores utilizados por la librería EmguCV.

\section{- Content}

Aqui podemos encontrar el archivo cSS del proyecto, en el cual se encuentran todas las clases de estilo utilizadas en la interfaz del Smart Mirror.

\section{- Controllers}

En esta carpeta se encuentran todos los controladores del proyecto, los cuales son parte del patrón MVC utilizado.

- HomeController, contiene solo un método, el cual sirve para pasarle un model a la interfaz del espejo.

Figura 21. Instrucciones del software 1 Nota: Elaboración propia 
- PersonController, es una colección de servicios web utilizadas por la aplicación Android para tener control de la tabla Person de la base de datos MSSQL que se encuentra alojada en Azure.

- PhotoController, contiene servicios web para el uso de la aplicación móvil y de la interfaz del Smart Mirror. El método PostPhoto es utilizado por el móvil para registrar la foto de un usuario en la base de datos, mientras que Check sirve para que la interfaz del espejo obtenga todos los datos necesarios de un usuario que tengan que ser mostrados en la página principal, enviando una foto obtenida por la cámara web del Smart Mirror.

- WidgetsController, al igual que PersonController, en una colección de servicios utilizados por la aplicación móvil que sirven para poder controlar la tabla Widgets de la base de datos.

- Fonts

La carpeta fonts simplemente contiene las tipografías utilizadas por la interfaz del espejo.

- Helpers

Contiene una carpeta llamada Api que a su vez contiene diversas clases de ayuda para los diversos servicios web implementados.

- Images

En esta carpeta se encuentran las imágenes utilizadas por la interfaz del Smart Mirror.

- Models

Aqui podemos encontrar el modelo de la base de datos generado por Entity Framework 6 .

- Scripts

En la carpeta Scripts se encuentran todos los scripts hechos en el lenguaje JavaScript, incluyendo JQuery y demás scripts hechos específicamente para el proyecto.

- Utils

Esta carpeta contiene archivos utilitarios para el correcto funcionamiento del proyecto. DataUtils contiene clases equivalentes a respuestas en formato JSON, recibidas de servicios externos. En ServiceUtils existe una clase que contiene la lógica para poder obtener información de los servicios externos como Dark Sky o El Comercio.

- Views

Contiene las vistas del patron MVC. En este caso dentro de Views tenemos una carpeta con las vistas del controlador Home, es decir la vista proporcionada por el método Index.

\section{Aplicación Móvil}

La aplicación móvil registra al usuario y almacena las fotos en el servidor para que pueda hacer uso del Smart Mirror y esta organizado de la siguiente forma:

Figura 22. Instrucciones del software 2

Nota: Elaboración propia 


\subsection{Orden de Carpetas}

\section{- App}

Esta carpeta cuenta con 3 subcarpetas: manifests, java y res. En la primera de ellas se encuentra el AndroidManifest, en el cual se definen configuraciones necesarias para el funcionamiento del app.

La carpeta java cuenta con 3 paquetes:

- com.tdp.diego.tdp_02, dentro de esta carpeta se encuentran distribuidos los "Activities", las vistas y las clases para consumir los servicios web.

- com.tdp.diego.tdp_02 (androidTest), solo cuenta con la clase de test creada por defecto.

- com.tdp.diego.tdp_02 (test), cuenta con dos clases creadas por defecto para realizar las pruebas.

La carpeta res cuenta con 6 subcarpetas: drawable, layout, menu, mipmap, values y xml. Estas carpetas cuentan con diferentes componentes utilizadas en la interfaz gráfica de la aplicación, entre imágenes, configuraciones y valores predefinidos.

- Backend

Backend cuenta con 3 subcarpetas distribuidas de la misma manera que la carpeta app. En la carpeta manifests encontramos el AndroidManifest, en el cual se definen configuraciones que luego se utilizarán en la app, por lo general definir permisos para las funcionalidades a implementar. La carpeta java cuenta con una sola subcarpeta, esta a su vez cuenta con 3 carpetas:

- models, cuenta con la clase "User" en la que se definen los atributos y métodos para realizar la autenticación utilizando servicios externos.

- network, en esta carpeta encontramos dos clases: Constants y Google. En la primera de ellas se definen valores de constantes a utilizar en el desarrollo de la app. En la carpeta Google se desarrollan los métodos para realizar la autenticación con este proveedor.

- utils, cuenta con dos clases: Encoder y ParamsMensaje.

Finalmente, la carpeta res tiene dentro la carpeta values que a su vez contiene el archivo strings.xml.

- Gradle Scripts

En este caso, esta carpeta contiene diversos archivos, en los que se definen diversas configuraciones, utilizadas para la compilación del proyecto .

\section{NOTA:}

Se adjunta la arquitectura del servidor actual y la nueva arquitectura del servidor utilizando Azure Cognitive Services.

Figura 23. Instrucciones del software 3

Nota: Elaboración propia 


\section{Anexo 5: Guía de Despliegue}

\section{Introducción}

El siguiente manual describe los pasos necesarios para realizar el despliegue e instalación del sistema ISM (Implementación de un Smart Mirror con Raspberry Pi).

\section{Requisitos}

Para realizar un despliegue exitoso es necesario contar con lo siguiente:

- Un Smart TV LG 42LN5700

- Un vidrio reflejante de $120 \times 100$ centímetros.

- Una estructura metálica que logre soportar tanto al Smart TV como al vidrio reflejante.

- Una cámara web Logitech C920 HD Pro.

- Un CanaKit Raspberry Pi 3 Complete Starter Kit - 32GB Edition.

- Un mouse.

- Un teclado.

- Una cuenta de Microsoft Azure.

- Visual Studio 2017.

- SQL Server Management Studio.

- Conexión estable a internet.

\section{Construcción del Smart Mirror}

El Smart Mirror es el componente esencial del proyecto, por lo cual es lo primero que se debe construir. Es necesario elaborar un mueble metálico, para el cual se adjuntan los planos. 


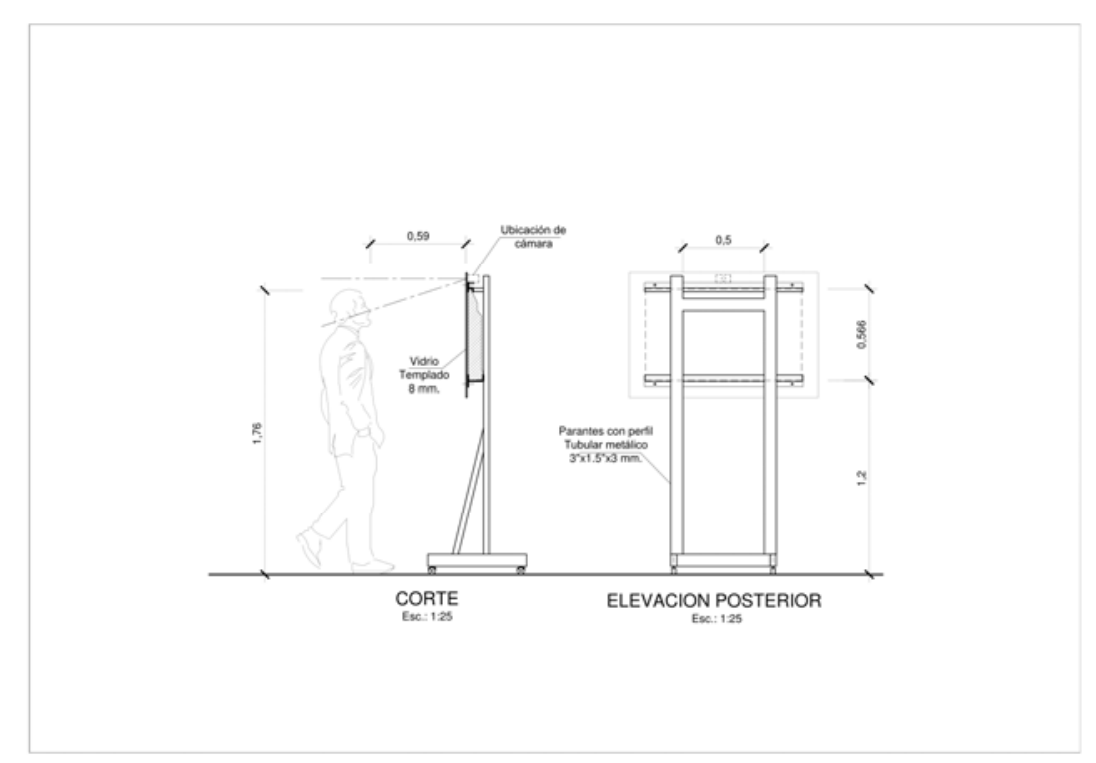

Figura 24. Planos del smart mirror 1 Nota: Elaboracion propia

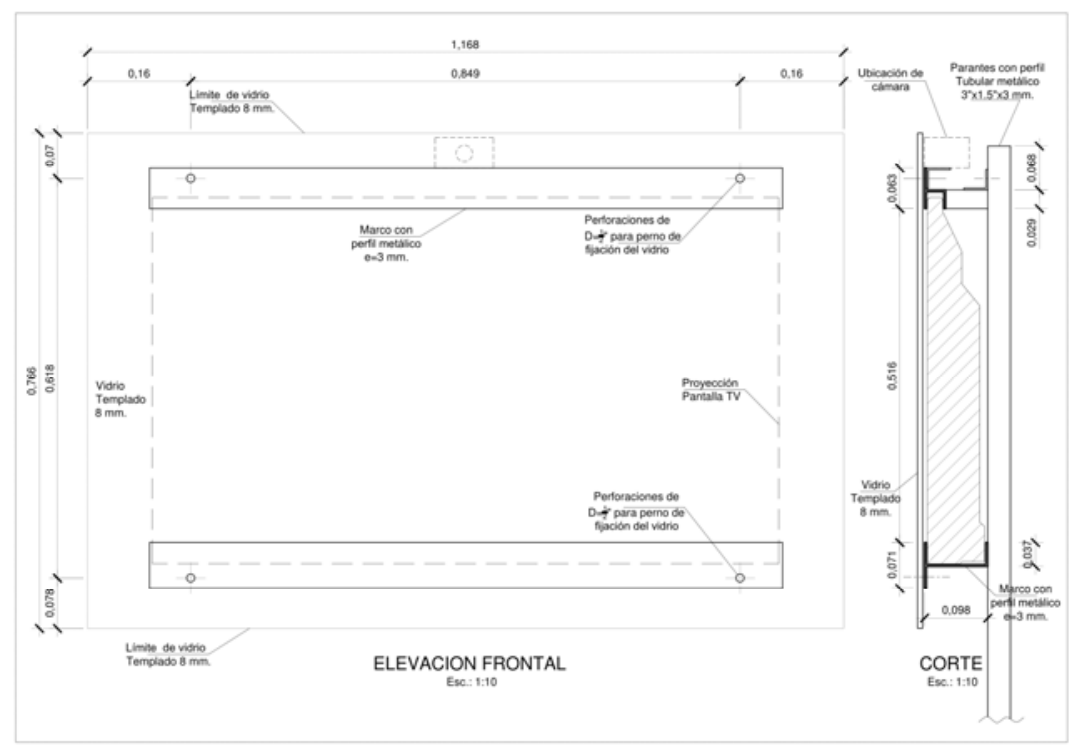

Figura 25. Planos del smart mirror 2

Nota: Elaboración propia 


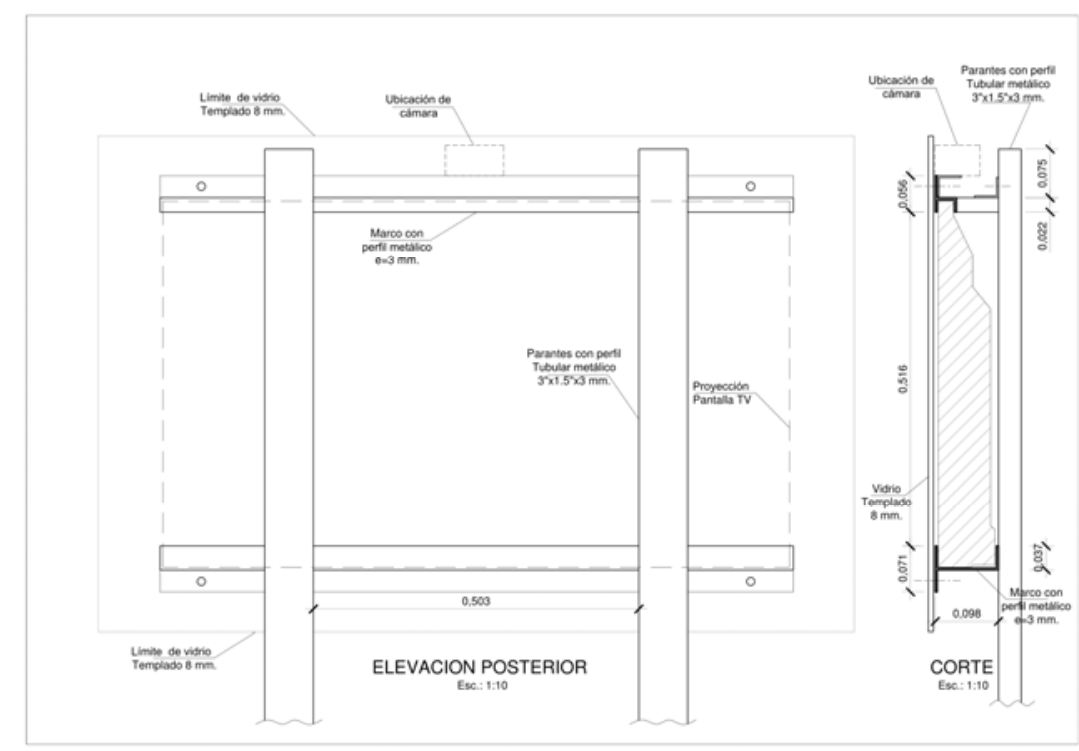

Figura 26. Planos del smart mirror 3

Fuente: Elaboración propia

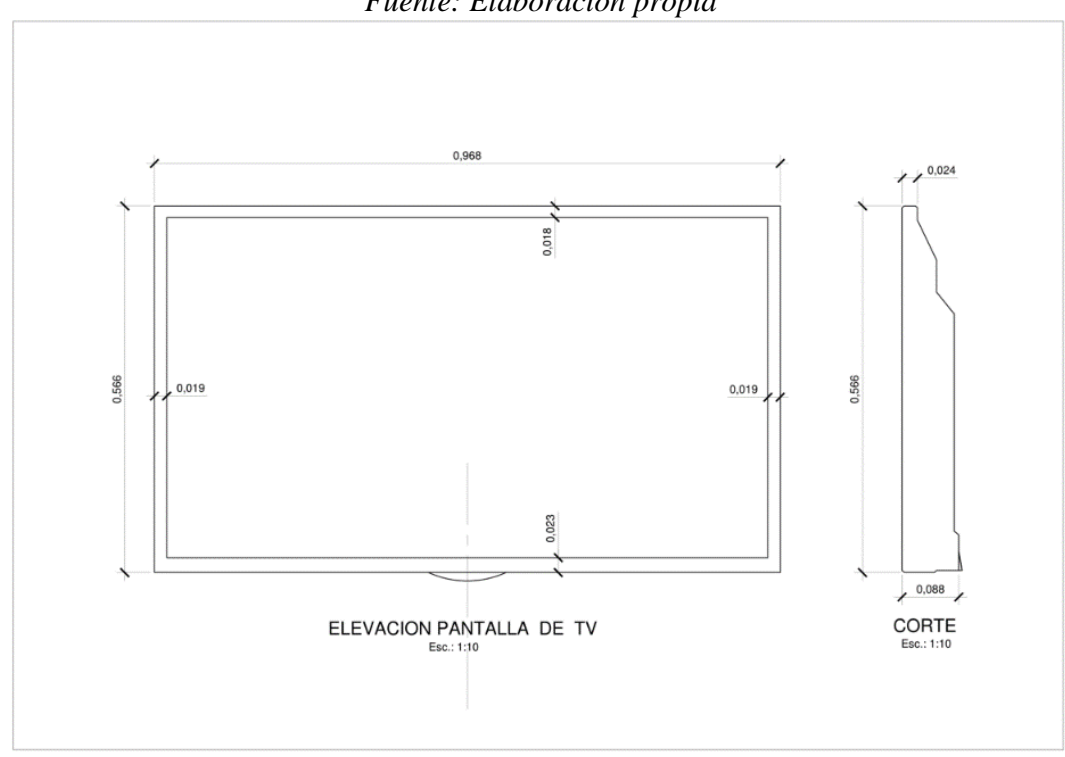

Figura 27. Planos del smart mirror 2

Fuente: Elaboración propia

Luego de lograr elaborar el mueble, hay que colocar el Smart TV dentro del mismo, seguido por el vidrio reflejante. Una vez asegurado el vidrio al mueble podemos seguir con el siguiente paso.

\section{Configuración del Raspberry Pi}

Esta sección explicará cómo configurar el Raspberry Pi en modo kiosco, el cual será necesario para mostrar únicamente información esencial en el espejo. 
Antes de comenzar a configurar el Raspberry es necesario darle un sistema operativo, el cual será instalado en la tarjeta miniSD que viene incluida dentro del CanaKit. Antes de comenzar a hacer esto, se recomienda colocar la placa dentro del case, que también viene incluido dentro del kit, para evitar que esta se maltrate. Una vez colocada la placa dentro del case podemos introducir la tarjeta miniSD en el espacio que se encuentra parte inferior del Raspberry. Una vez introducida la miniSD debemos colocar un mouse, un teclado, la cámara web y el Smart TV mediante el cable HDMI incluido. Por último, se debe conectar el cable de poder de la placa, para encender el Raspberry.

Cuando el Raspberry se encienda, mostrará una pantalla en la cual nos permitirá escoger diversos sistemas operativos, de los cuales debemos elegir Raspbian, la opción recomendada.

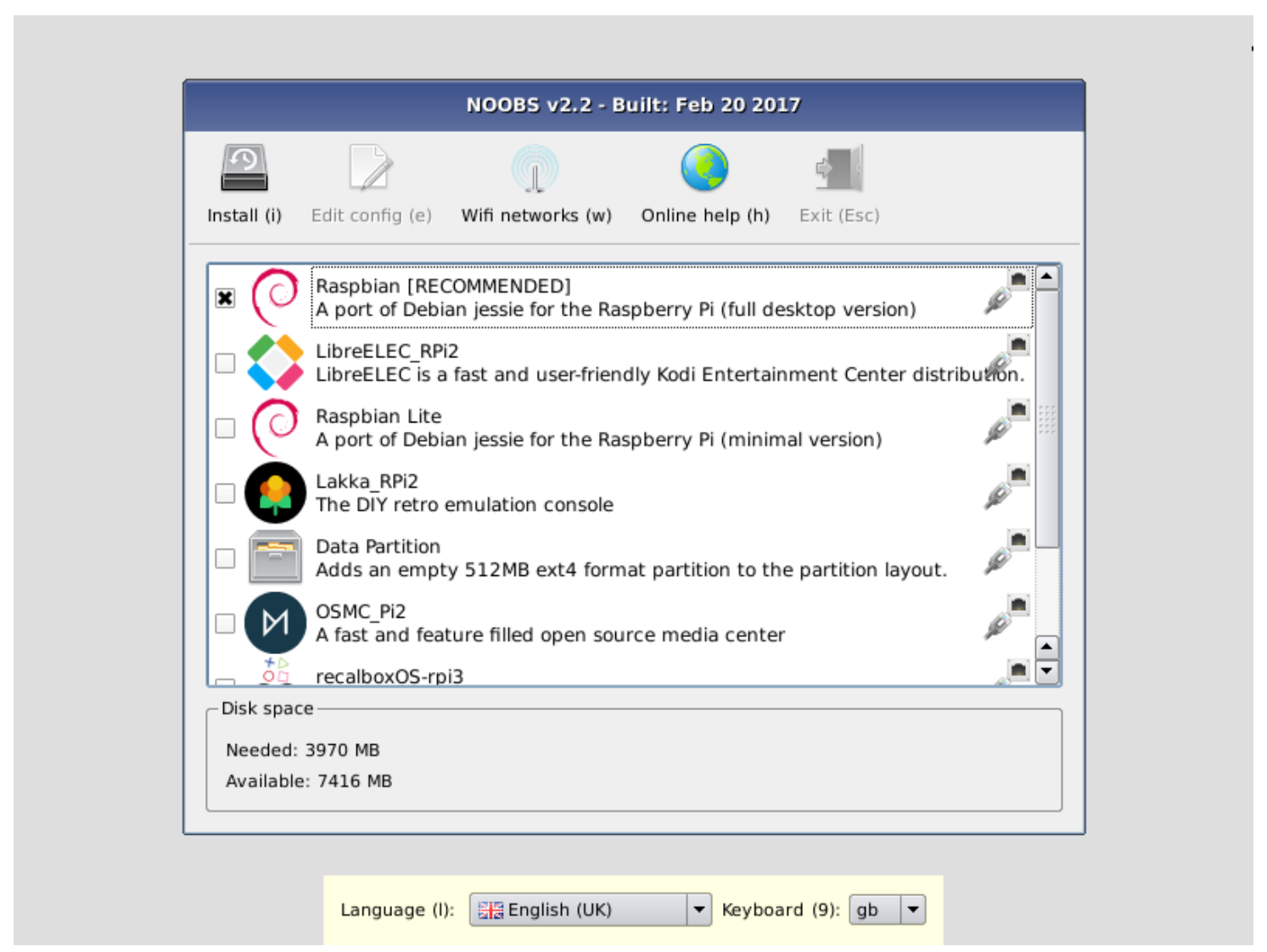

Figura 28. Configuración de Raspbian Nota: Elaboración propia

Luego de escoger la opción y darle Install, debemos esperar a que la instalación del sistema operativo termine. Al terminar debe verse el siguiente entorno visual: 


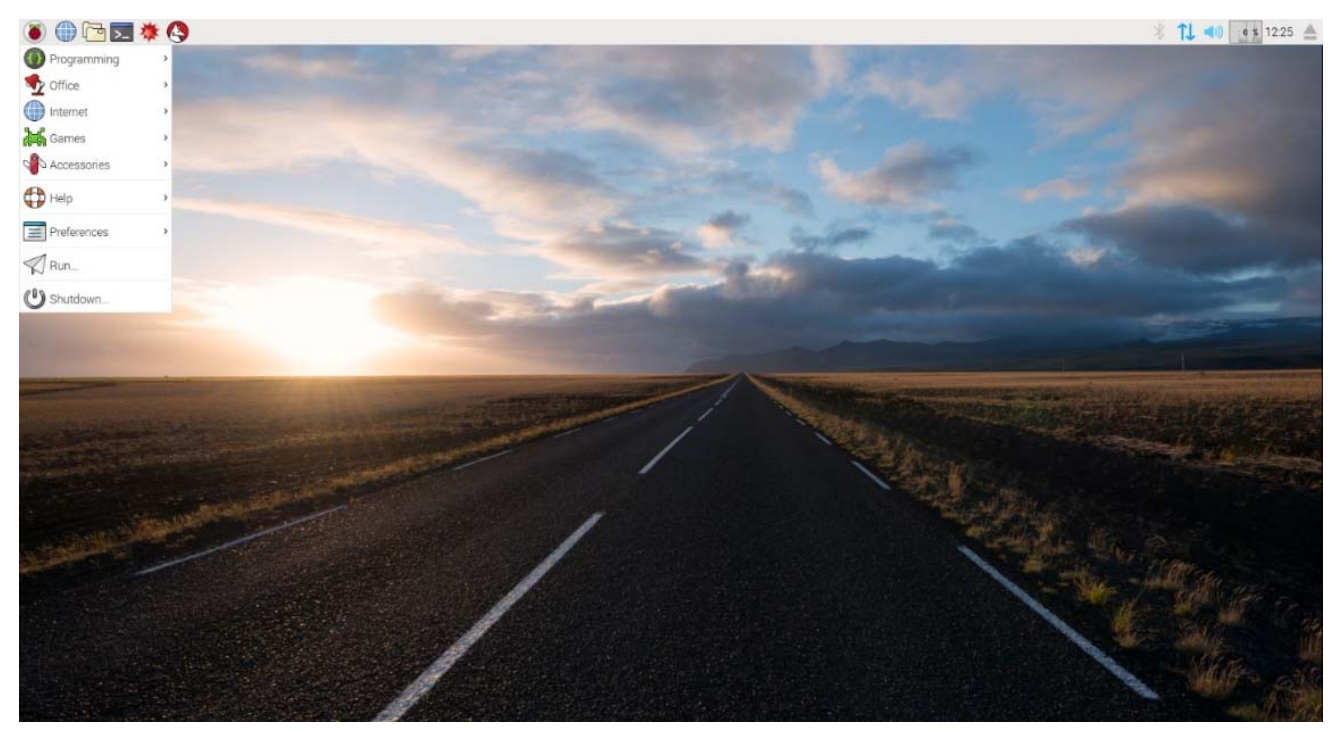

Figura 29. Pantalla principal de Raspbian Nota: Elaboración propia

Una vez que tenemos Raspbian a nuestra disposición, podemos comenzar con la configuración del modo quiosco. Abramos la terminal e introduzcamos el siguiente comando:

sudo apt-get install x11-xserver-utils unclutter

Una vez que terminen de instalar las aplicaciones solicitadas con el comando, debemos pasar a modificar el archivo de autostart. Ingresemos el siguiente comando para editar el archivo autostart:

sudo nano .config/lxsession/LXDE-pi/autostart

Al final del archivo abierto, añadir la siguiente línea:

@ chromium-browser-kiosk -incognito https://reflection-upc.azurewebsites.net

Esta servirá para que Chromium comience en modo quiosco y en incognito cuando se inicie el Raspberry. Es necesario recalcar que el URL presente varía dependiendo del nombre de la aplicación web creada en Azure.

Después de la última línea escrita en el archivo añadamos lo siguiente:
@xset s noblank
@xset s off
@xset -dpms 
@unclutter -idle 0.1 -root

Finalmente, para evitar que el Raspberry se suspenda usamos el comando:

sudo nano /etc/lightdm/lightdm.conf

Y editamos la línea que dice xserver-command de la siguiente manera:

Xserver-command $=\mathrm{X}-\mathrm{s} 0-\mathrm{dpms}$

Con esto habremos finalizado la configuración del Raspberry y estará listo para ser usado con el Smart Mirror.

\section{Creación de la base de datos}

Para crear la base de datos debemos ingresar a la página web https://portal.azure.com e iniciar sesión con nuestra cuenta Azure. Una vez que nos encontremos en el Dashboard podemos crear un nuevo recurso.

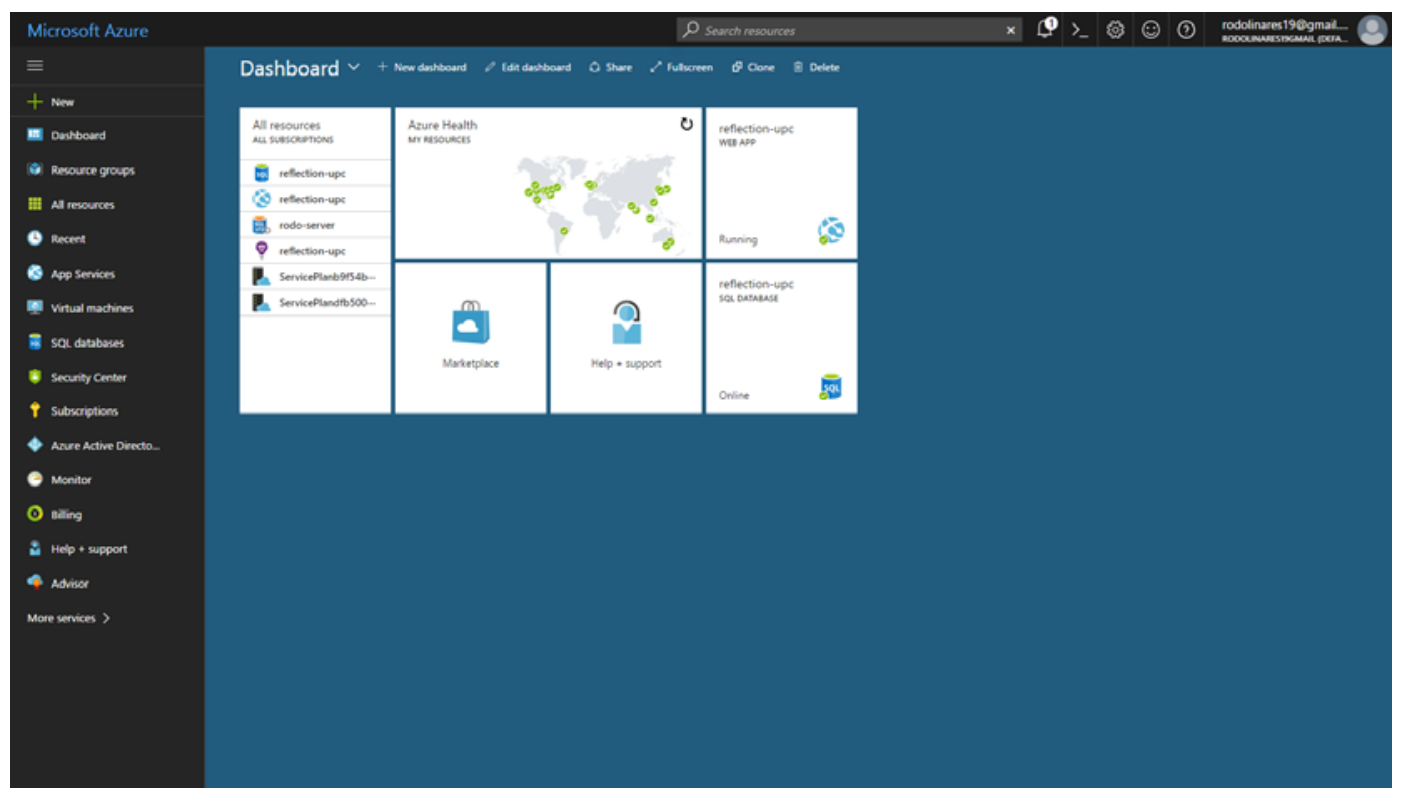

Figura 30. Dashboard Microsoft Azure

Nota: Elaboración propia

Primero debemos crear un servidor y ponerle un nombre, para lo cual entramos a la opción

New y en la barra de búsqueda escribimos server para luego escoger la opción SQL server (logical server) 


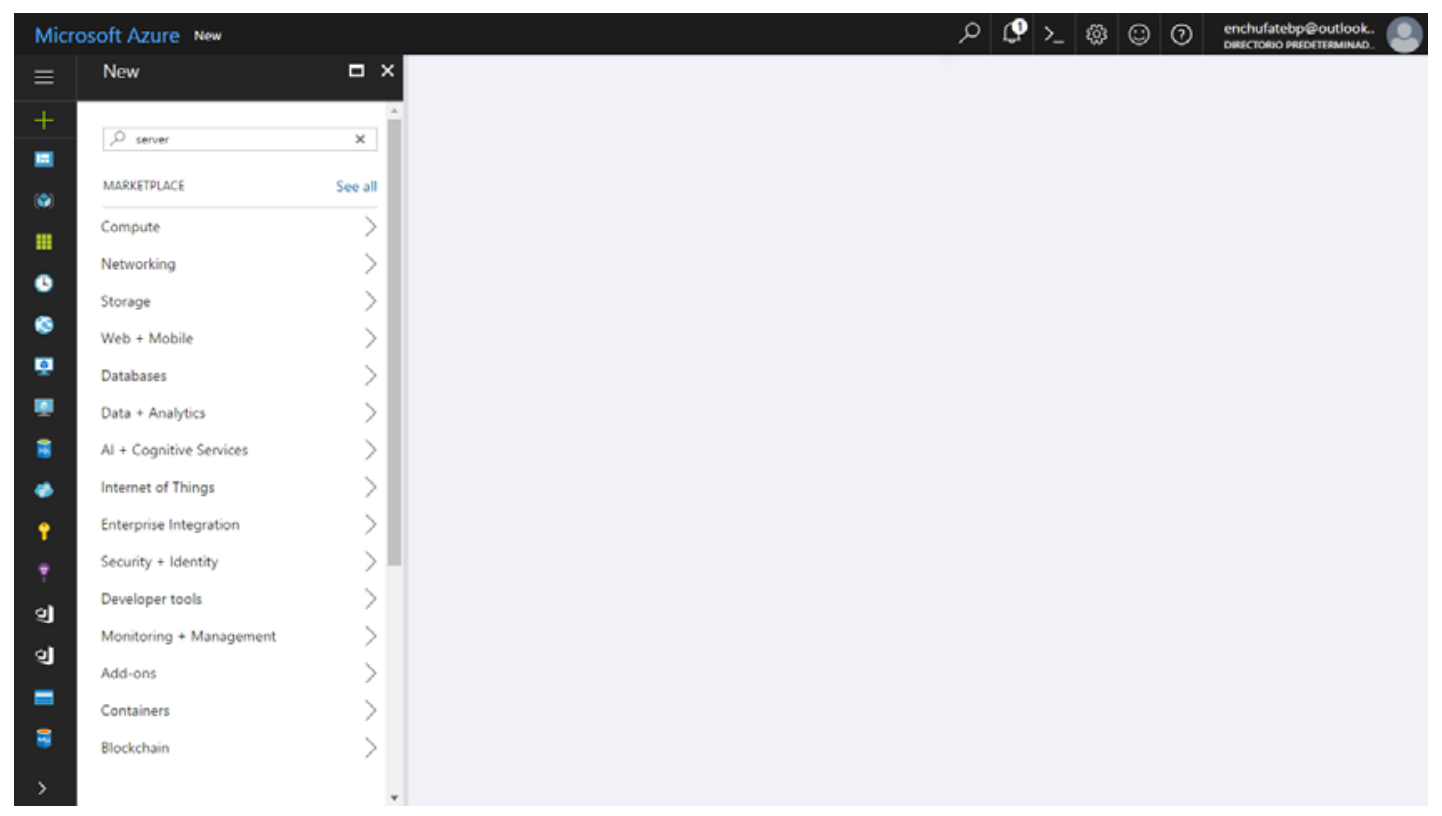

Figura 31. Panel de creación de Microsot Azure Nota: Elaboración propia

Después, seleccionamos la opción Create.

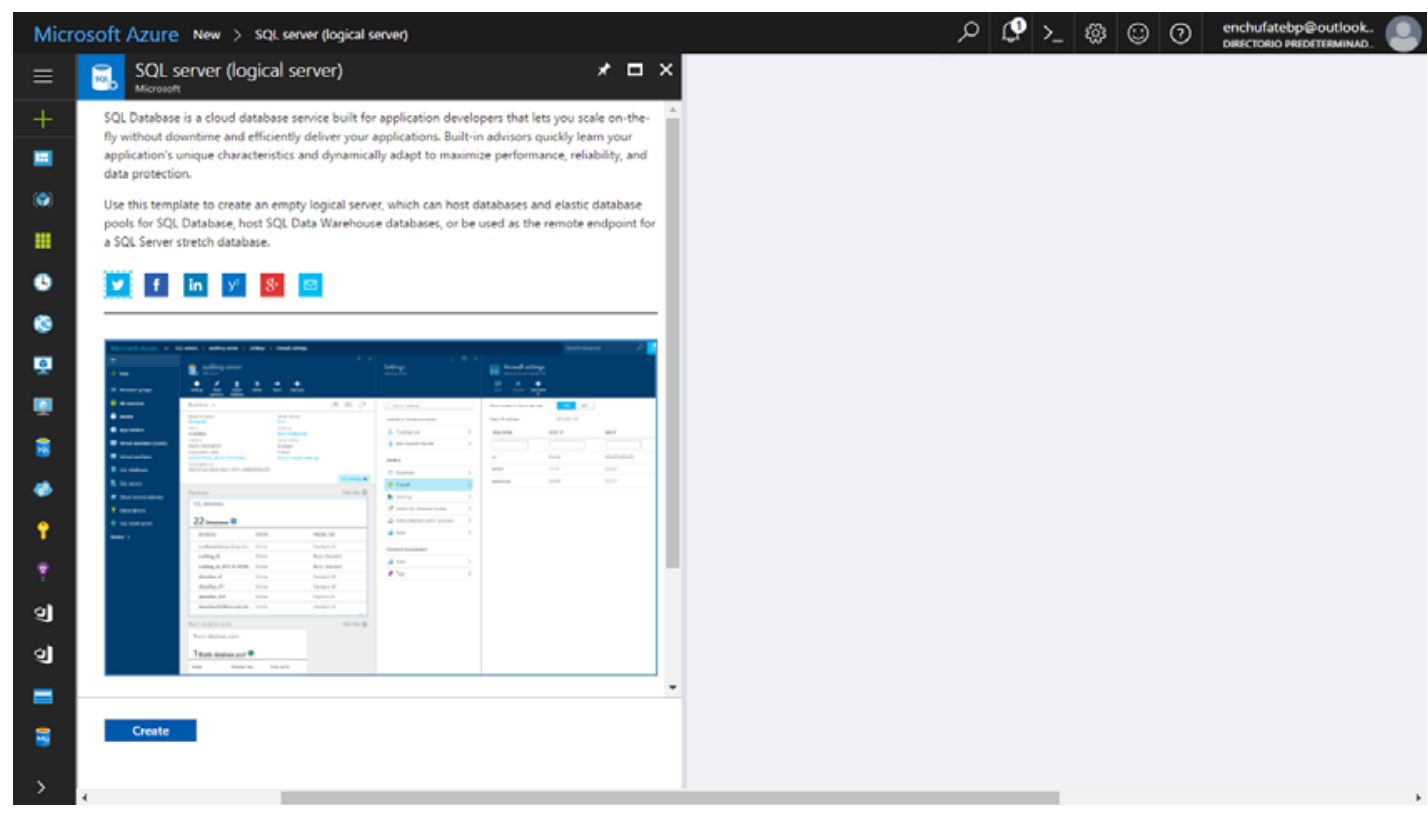

Figura 32. Panel de creación de servidor SQL server Nota: Elaboración propia

Acto seguido, tendremos que darle un nombre a la base de datos y escoger un nombre de usuario y contraseña para la cuenta de administrador del servidor, los cuales utilizaremos luego. 


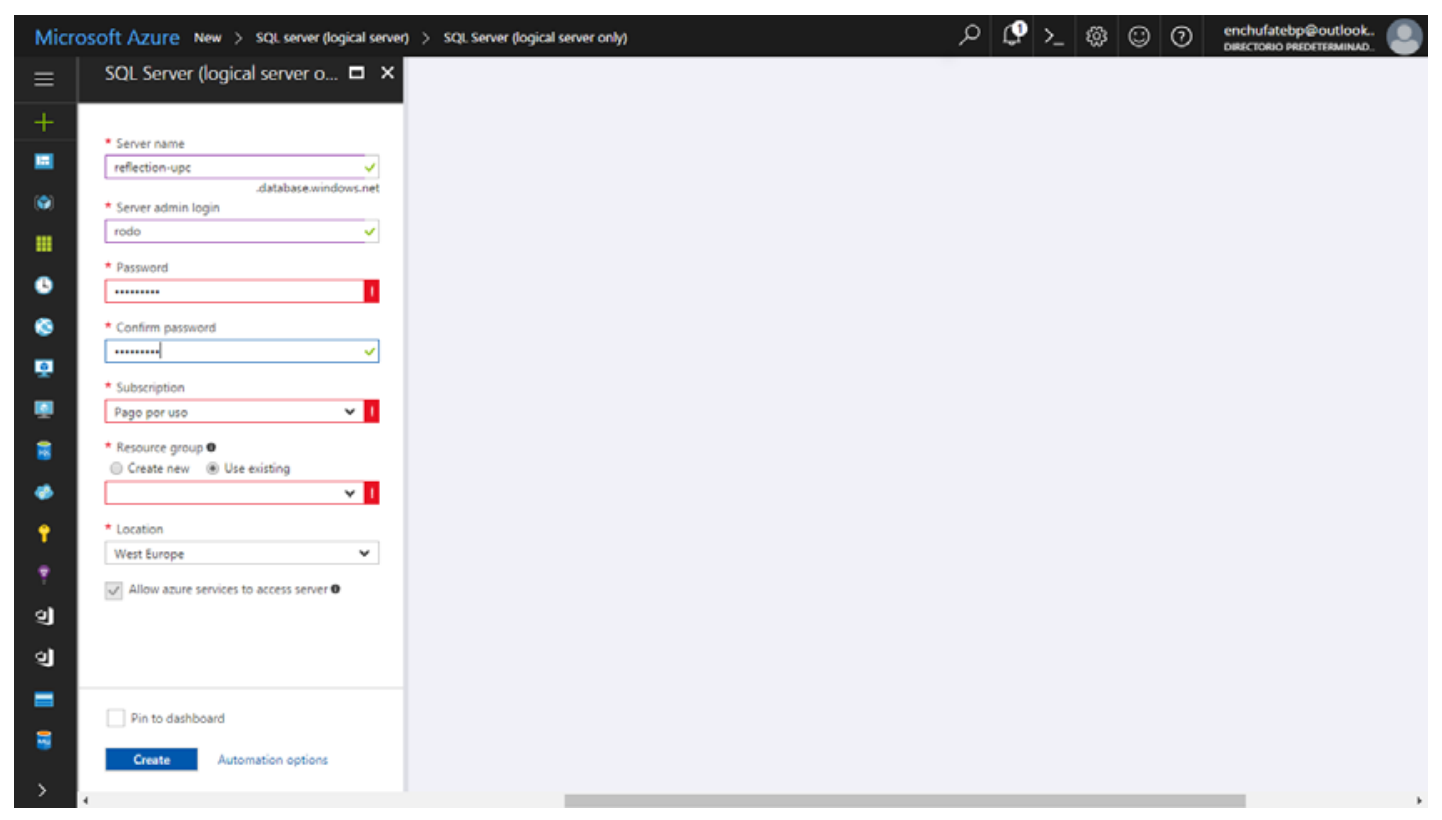

Figura 33. Configuración de servidor SQL Server Nota: Elaboración propia

Una vez que le hagamos click en Create debemos esperar un momento a que se cree el servidor. Una vez que esté listo nuestro servidor podremos crear nuestra base de datos, para lo cual nuevamente seleccionaremos la opción New, seguida de Databases y luego SQL Database.

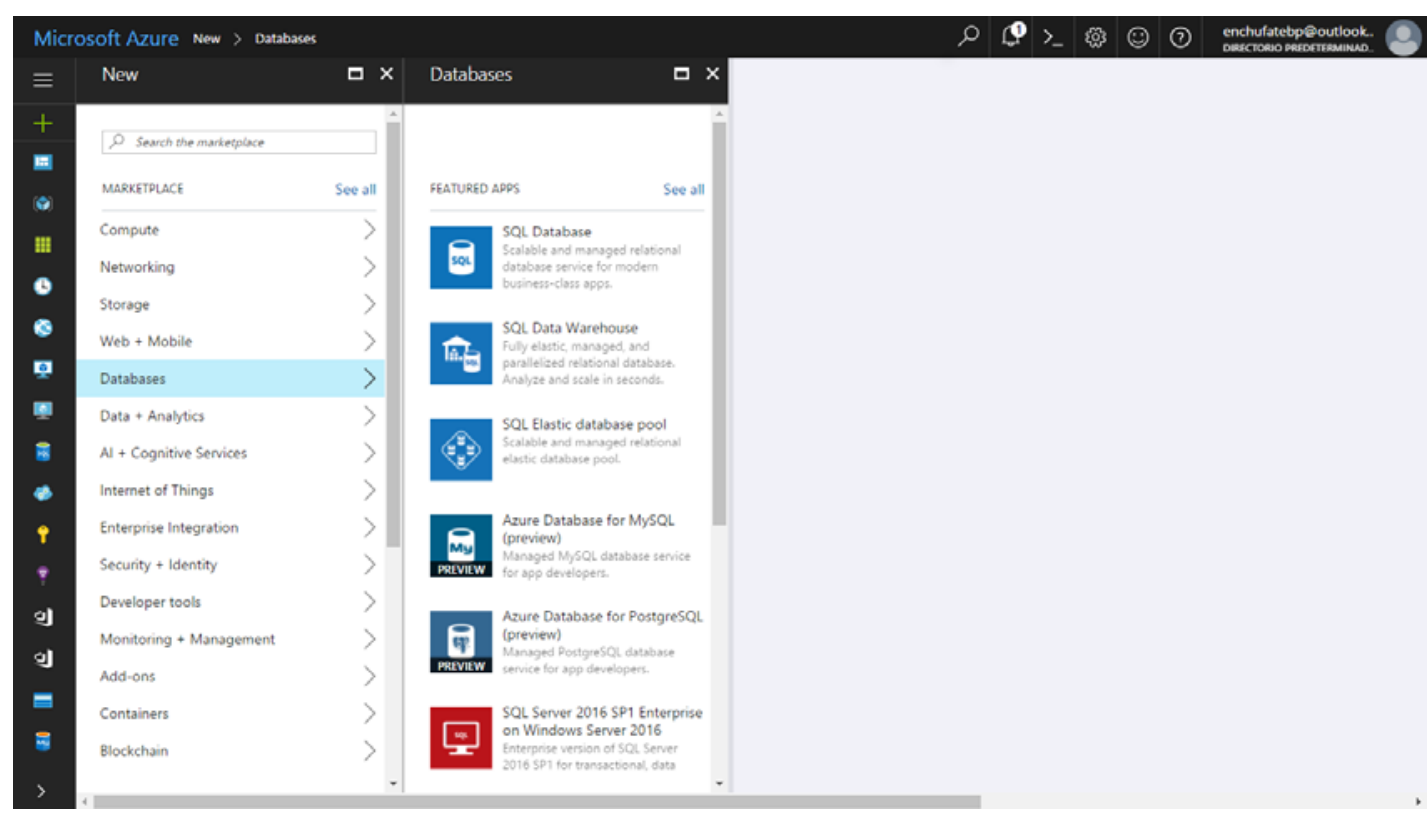

Figura 34. Panel de creación de base de datos Nota: Elaboración propia 
Ahora es necesario darle el nombre "reflection-upc" y asignarle un servidor a la base de datos que estamos creando. Asegurémonos que en Select source diga Blank database y que el Server sea el que creamos previamente.

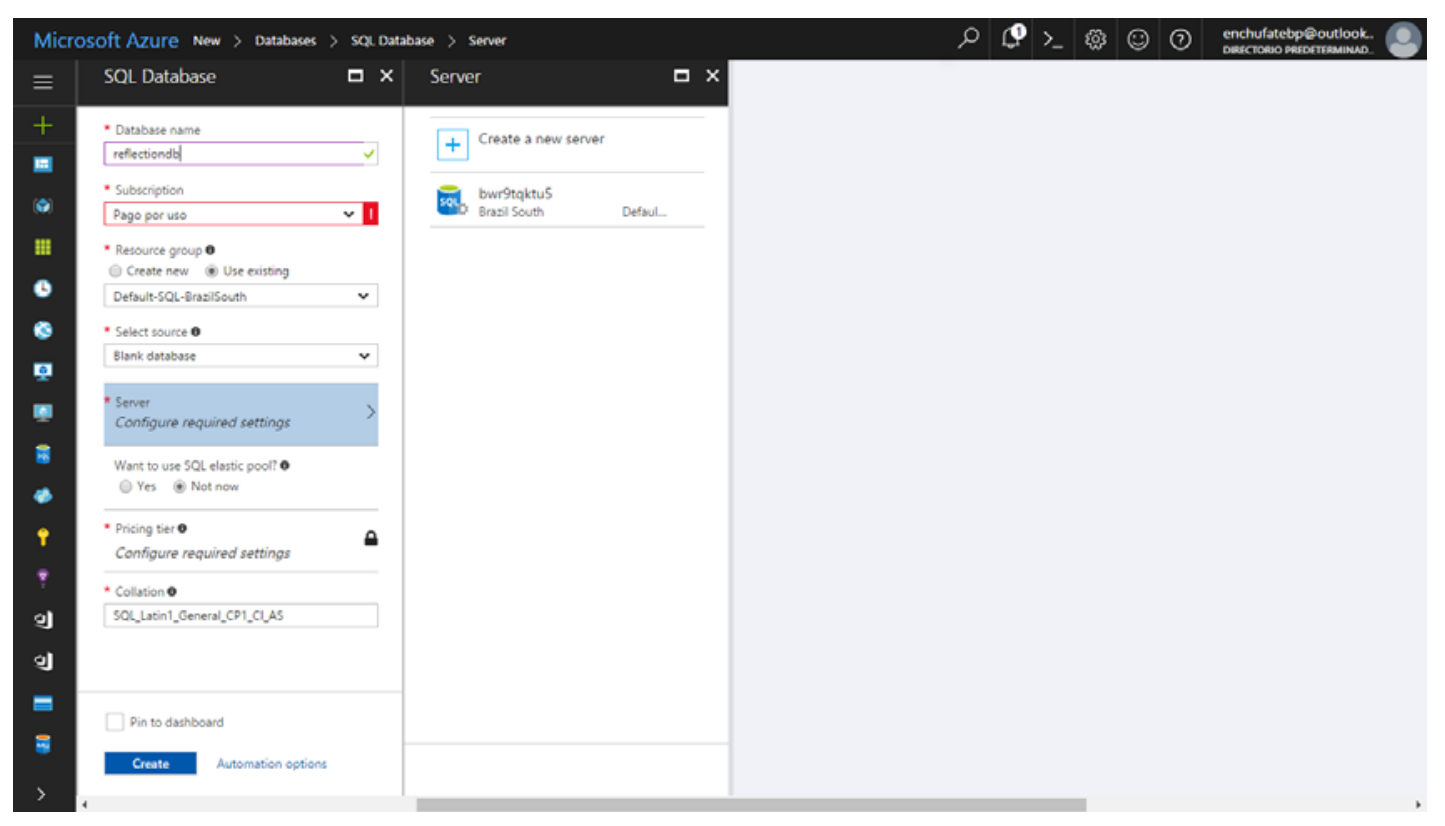

Figura 35. Panel de configuración de base de datos Nota: Elaboración propia

Al hacer click en Create debemos nuevamente esperar a que nuestro recurso se termine de generar. Cuando finalice seremos redirigidos a la siguiente ventana:

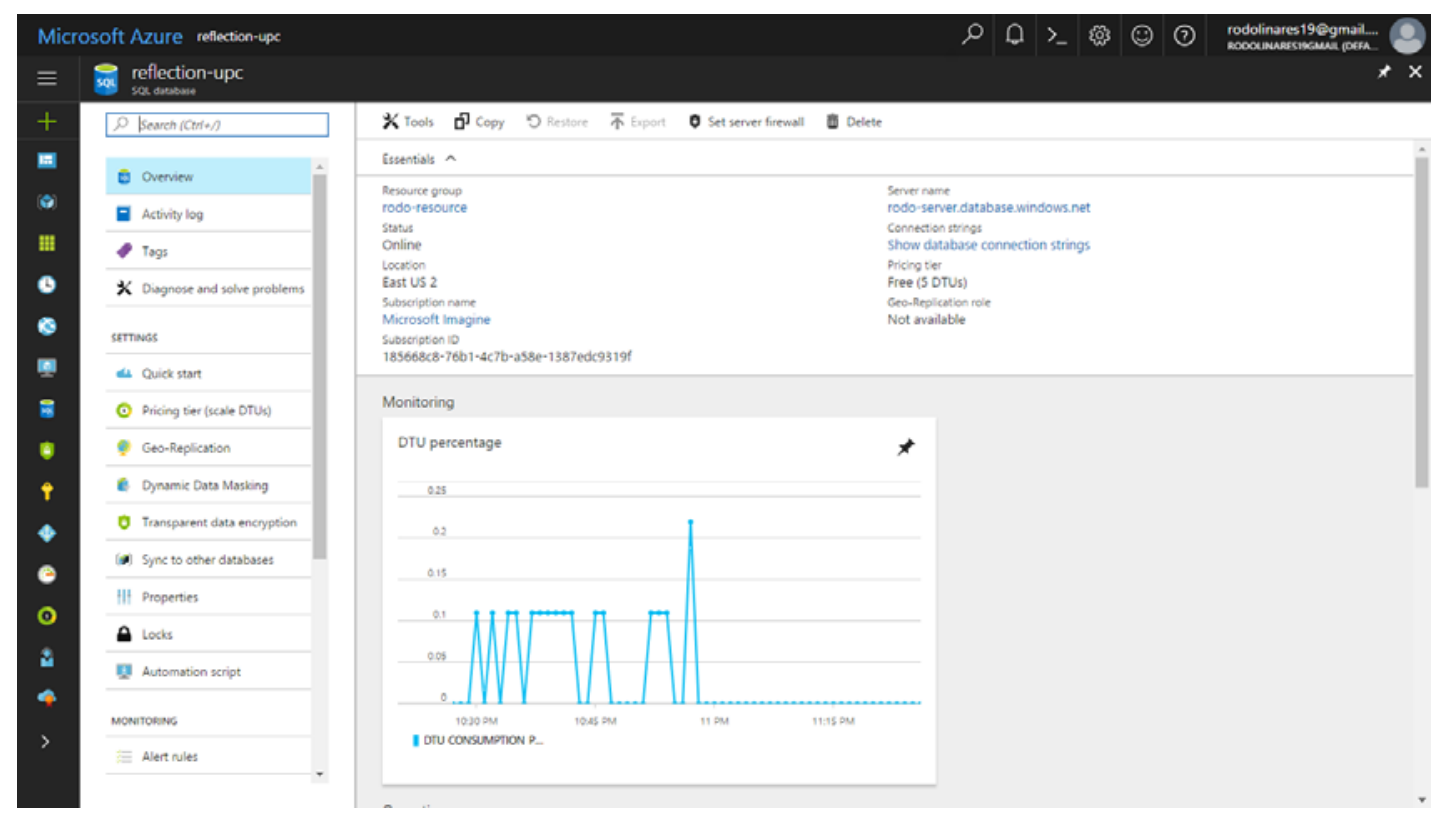

Figura 36. Panel de base de datos reflection-upc Microsoft Azure Nota: Elaboración propia 
Tomemos nota del nombre del servidor (Server name) pues lo necesitaremos para el siguiente paso, el cual será ingresar a nuestra base de datos y crear nuestras tablas.

Abramos Microsoft SQL Management Studio y utilicemos las credenciales del servidor que creamos previamente para poder ingresar.

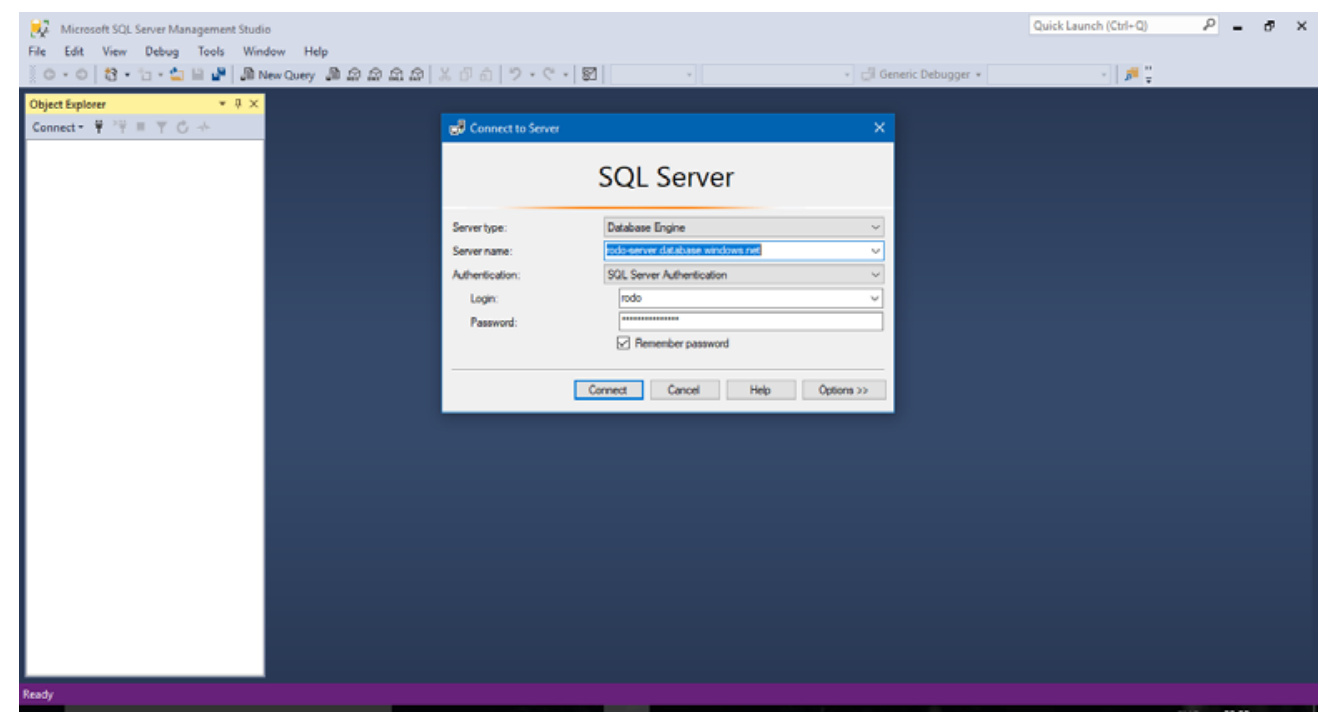

Figura 37. Pantalla de logueo de SQL Server Nota: Elaboración propia

Una vez que logremos ingresar a nuestro servidor vayamos al Object Explorer que se encuentra a la mano izquierda, despleguemos la carpeta Databases y hagamos click en reflection-upc. Ahora debemos encontrar el archivo reflection.sql que viene junto con este documento y hacerle doble click para poder abrirlo con SSMS (SQL Server Management Studio). Una vez abierto tendremos la siguiente pantalla:

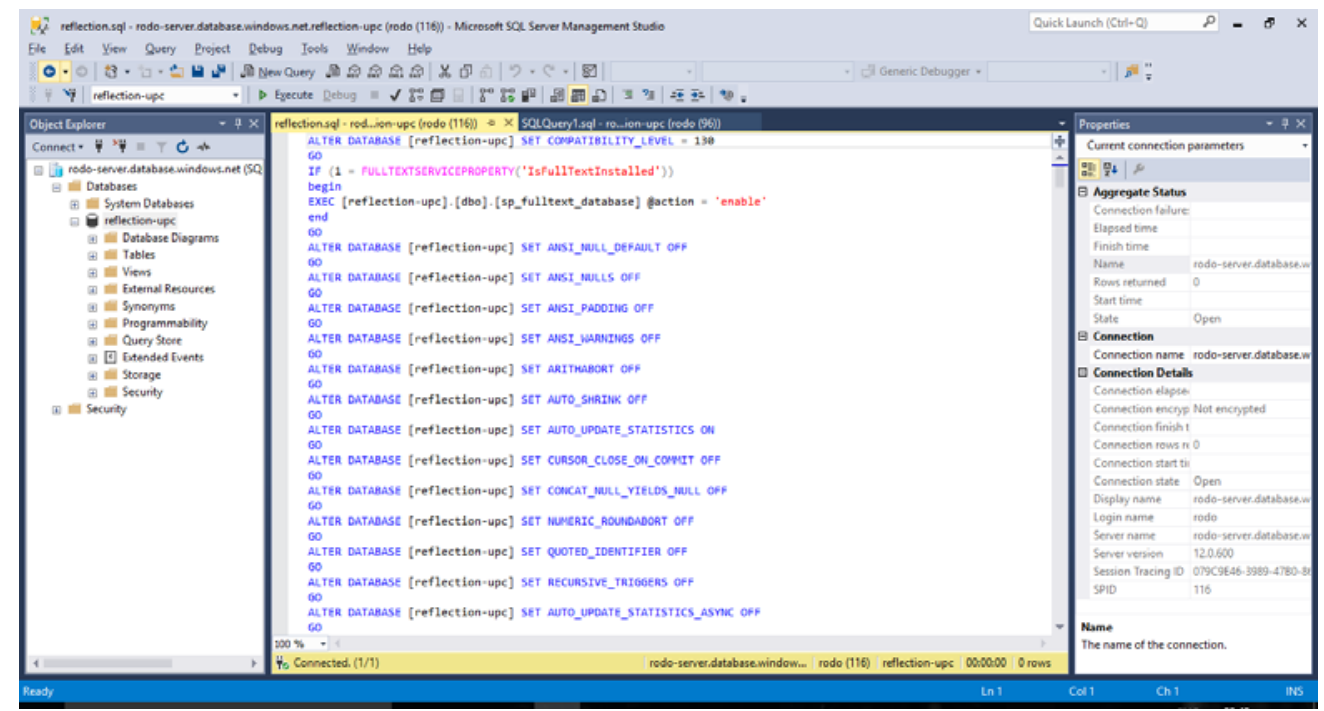

Figura 38. Ejecución de script en SQL Server Nota: Elaboración propia 
Al hacer click en la opción Execute nuestro script creará todas las tablas y relaciones necesarias para que funcione el sistema.

\section{Despliegue de la aplicación web}

Para poder desplegar nuestra aplicación web primero debemos ingresar a la página web https://portal.azure.com e iniciar sesión con nuestra cuenta Azure. Una vez que nos encontremos en el Dashboard podemos crear un nuevo recurso.

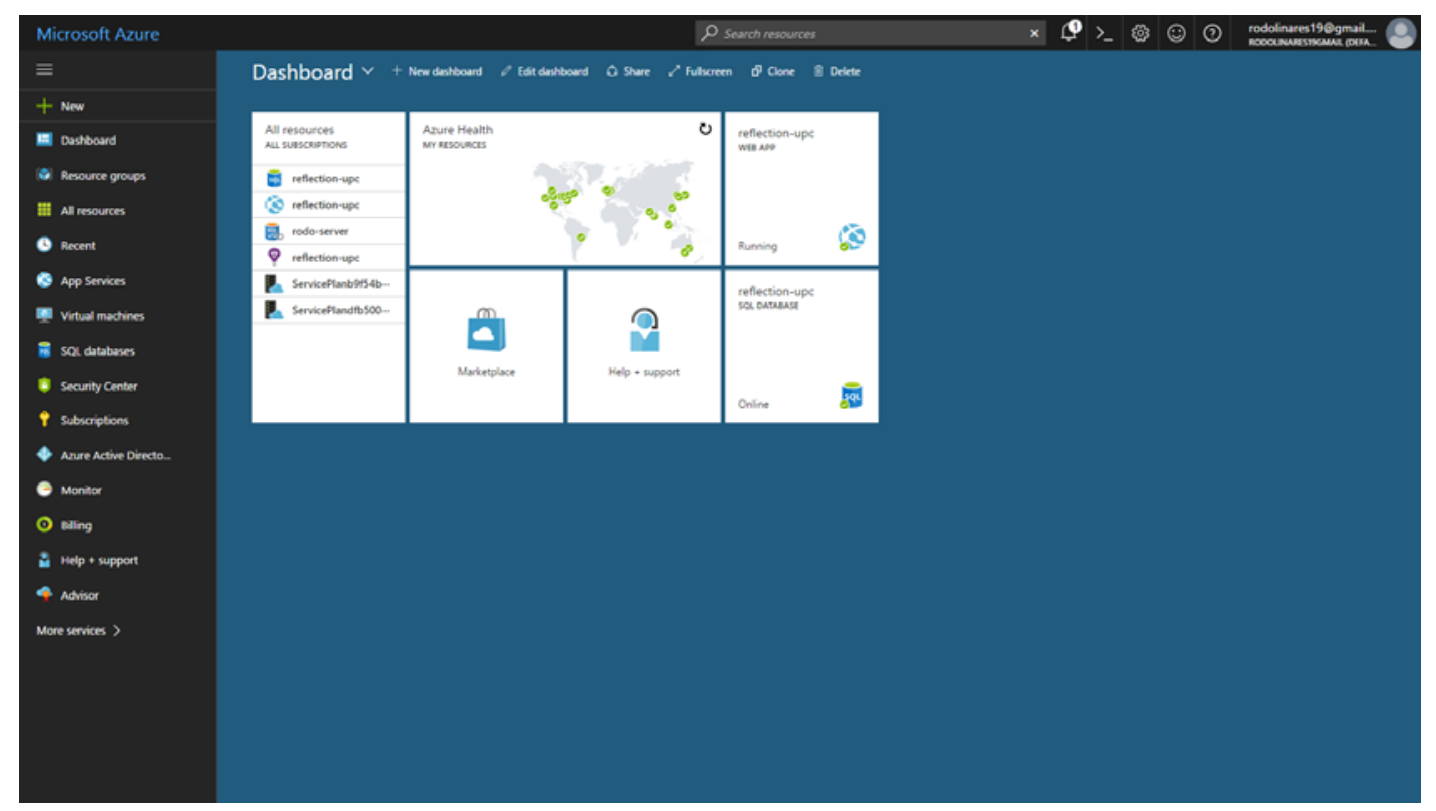

Figura 39. Dashboard Microsoft Azure
Nota: Elaboración propia

Al hacer click en New debería aparecer la siguiente ventana:

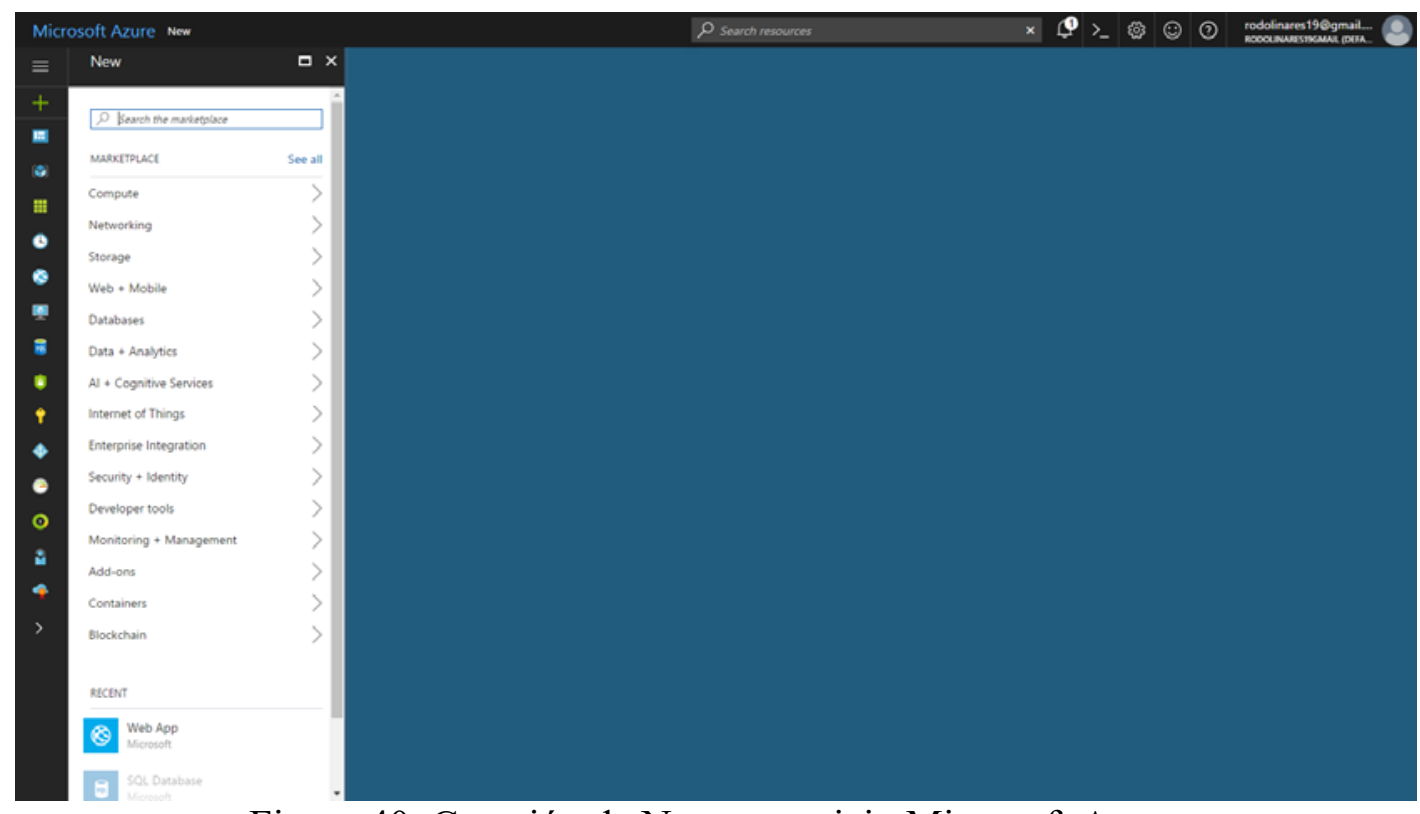

Figura 40. Creación de Nuevo servicio Microsoft Azure

Nota: Elaboración Propia 
Una vez aquí hagamos click en la opción Web + Mobile, seguido por Web App. Aparecerá la siguiente ventana:

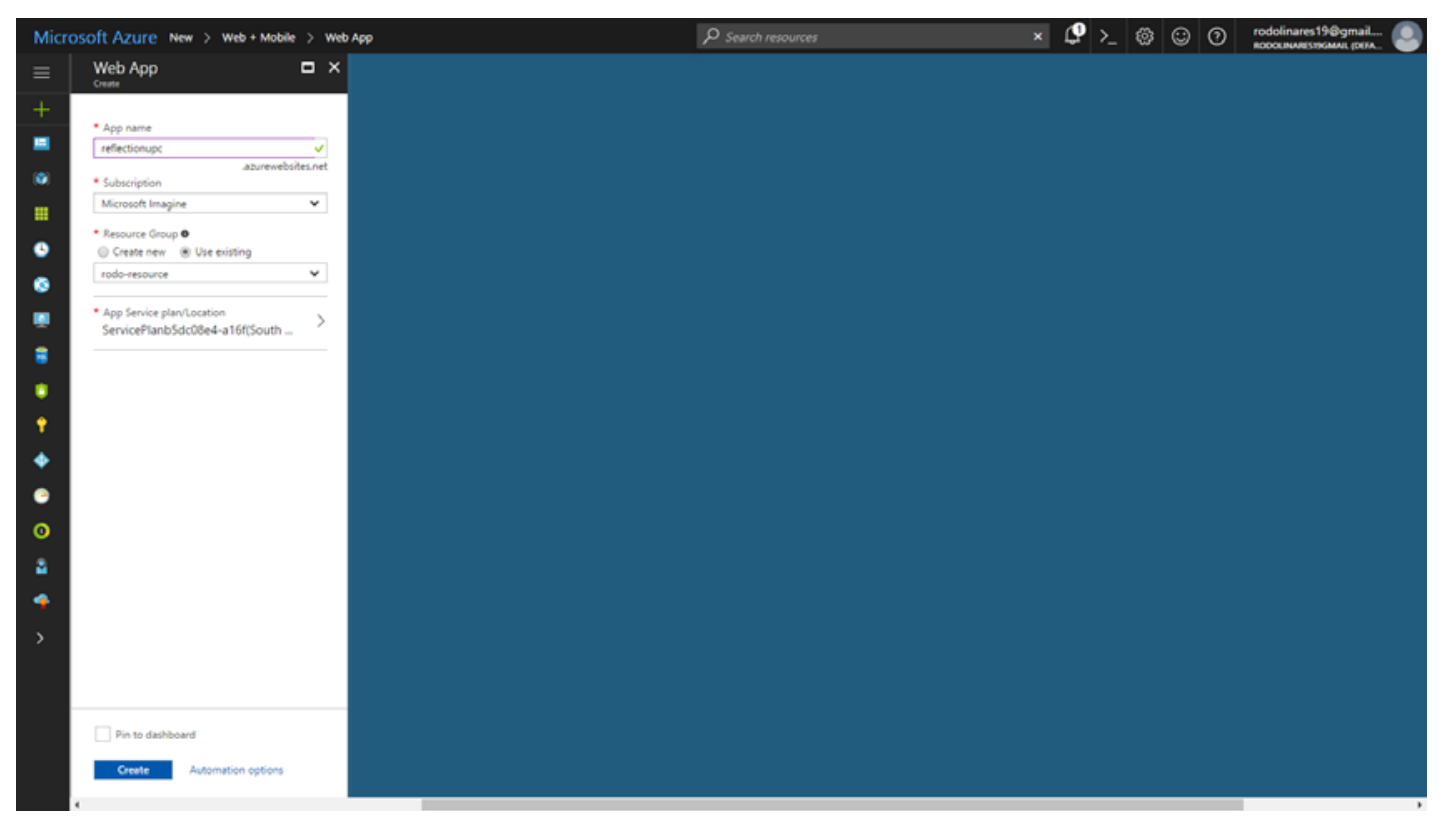

Figura 41. Creación de Web App

Fuente: Elaboración propia

Ahora debemos darle un nombre a la aplicación y escoger a que Resource Group pertenecerá. De preferencia también marcar la opción Pin to dashboard para contar con fácil acceso a la aplicación desde la pantalla principal de Azure. Hacemos click en Create y esperemos a que se cree la aplicación. Una vez creada, Azure debería redirigirnos a la página de la aplicación que acabamos de crear.

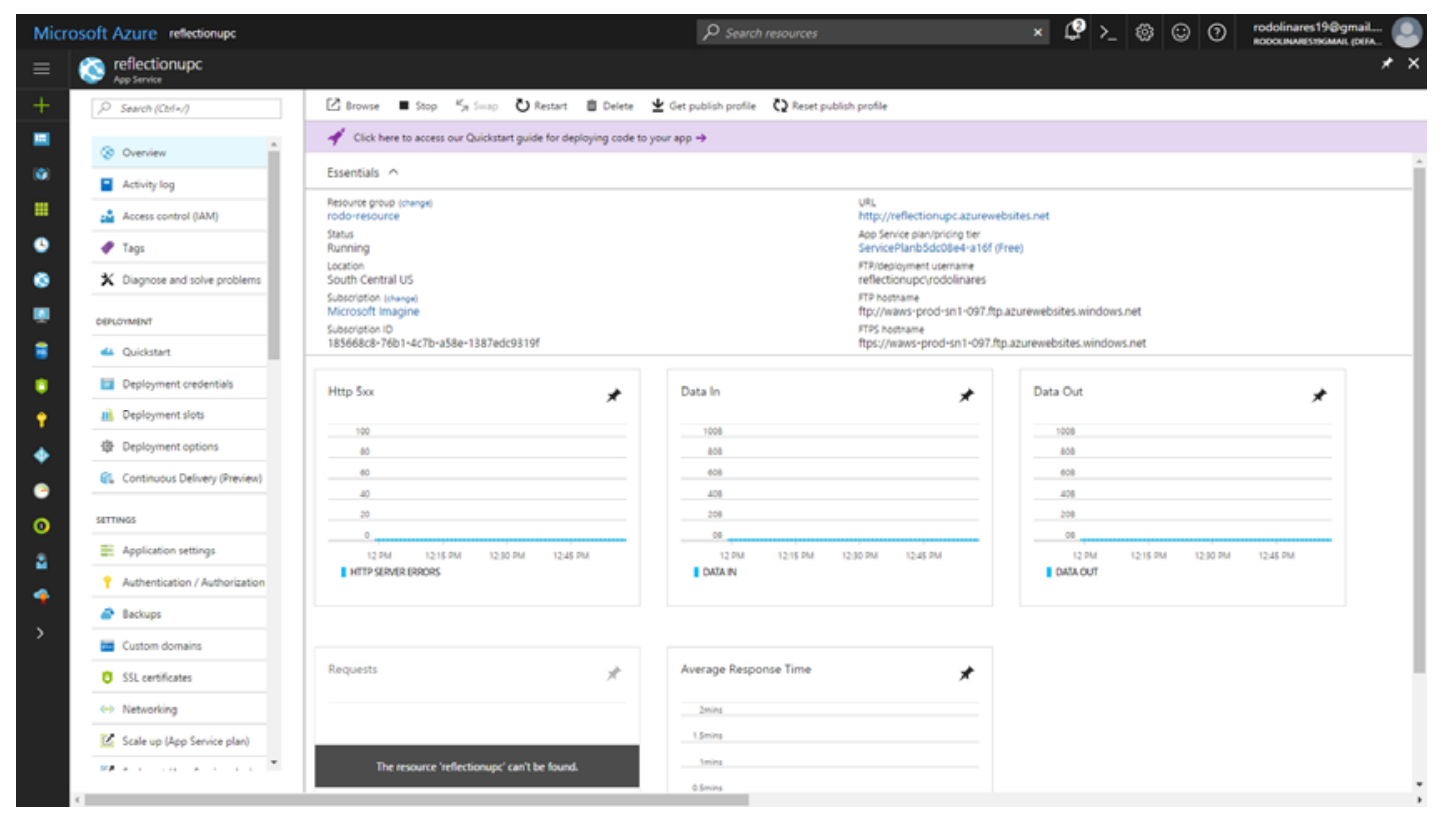

Figura 42. Configuración de web app

Nota: Elaboración propia 
En esta ventana debemos darle click a Get publish profile lo cual, a continuación, nos descargará un archivo, que servirá para publicar de manera sencilla nuestra aplicación web.

Nuestro siguiente paso será abrir la solución "ReflectionUPC" que se encuentra en la carpeta "reflection-upc" la cual viene junto con este documento. Una vez abierta la solución, abrimos el Solution Explorer y buscamos el archivo Web.config y nos dirigimos a la línea 88 del archivo. Aquí tendremos que cambiar data source, user id y password por los creados previamente en la sección anterior.

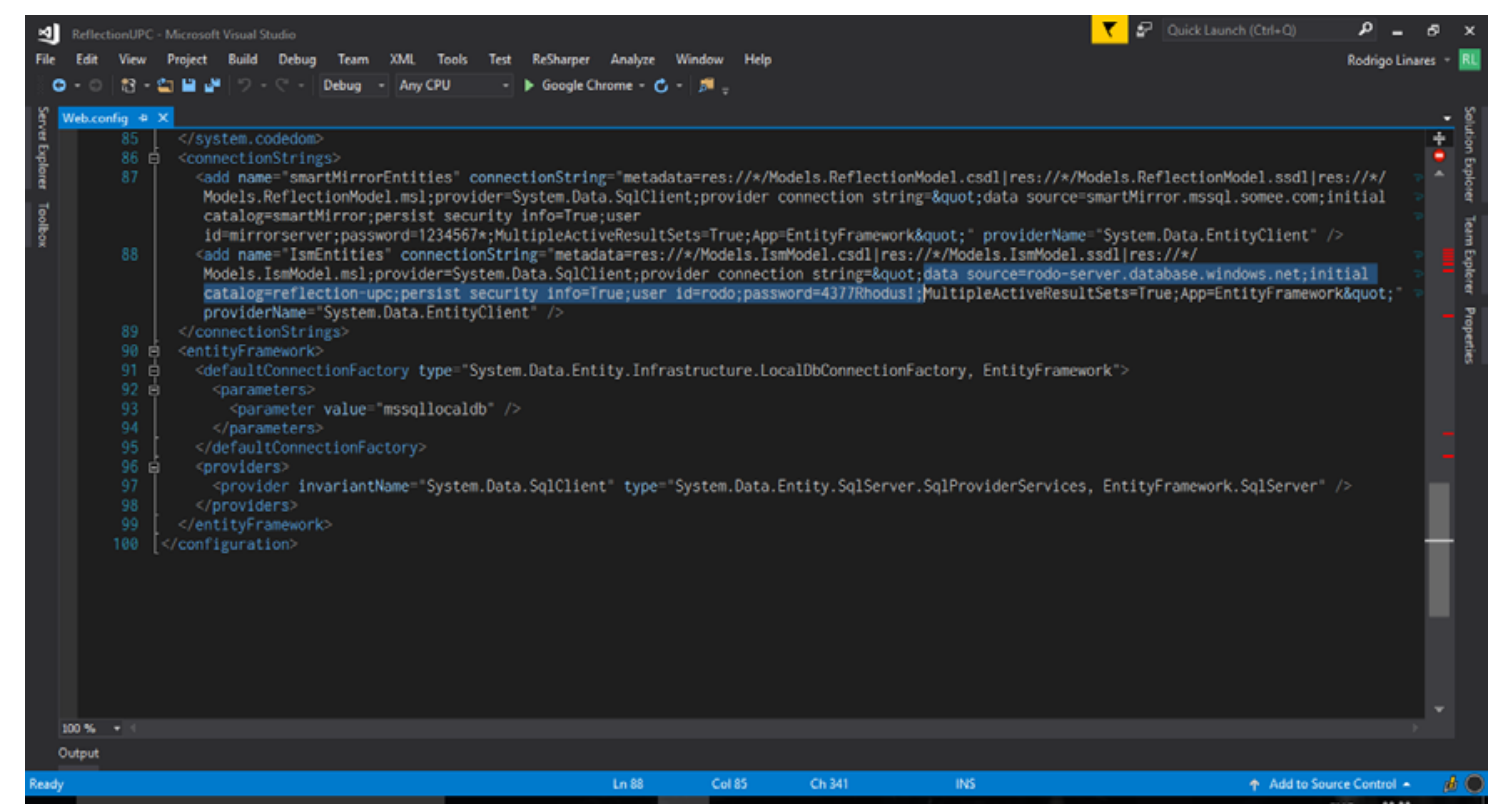

Figura 43. Modificación de cadena de conexión en Web.config Nota: Elaboración propia

Despues de hacer estos cambios, regresamos al Solution Explorer y hacemos click derecho en el proyecto ReflectionUPC y escogemos la opción Publish. Entre todas las opciones de publicación, debemos escoger Import y buscar el perfil de publicación descargado previamente. Luego de oprimir publish y esperar un momento, la aplicación web debe estar publicada en Azure. 


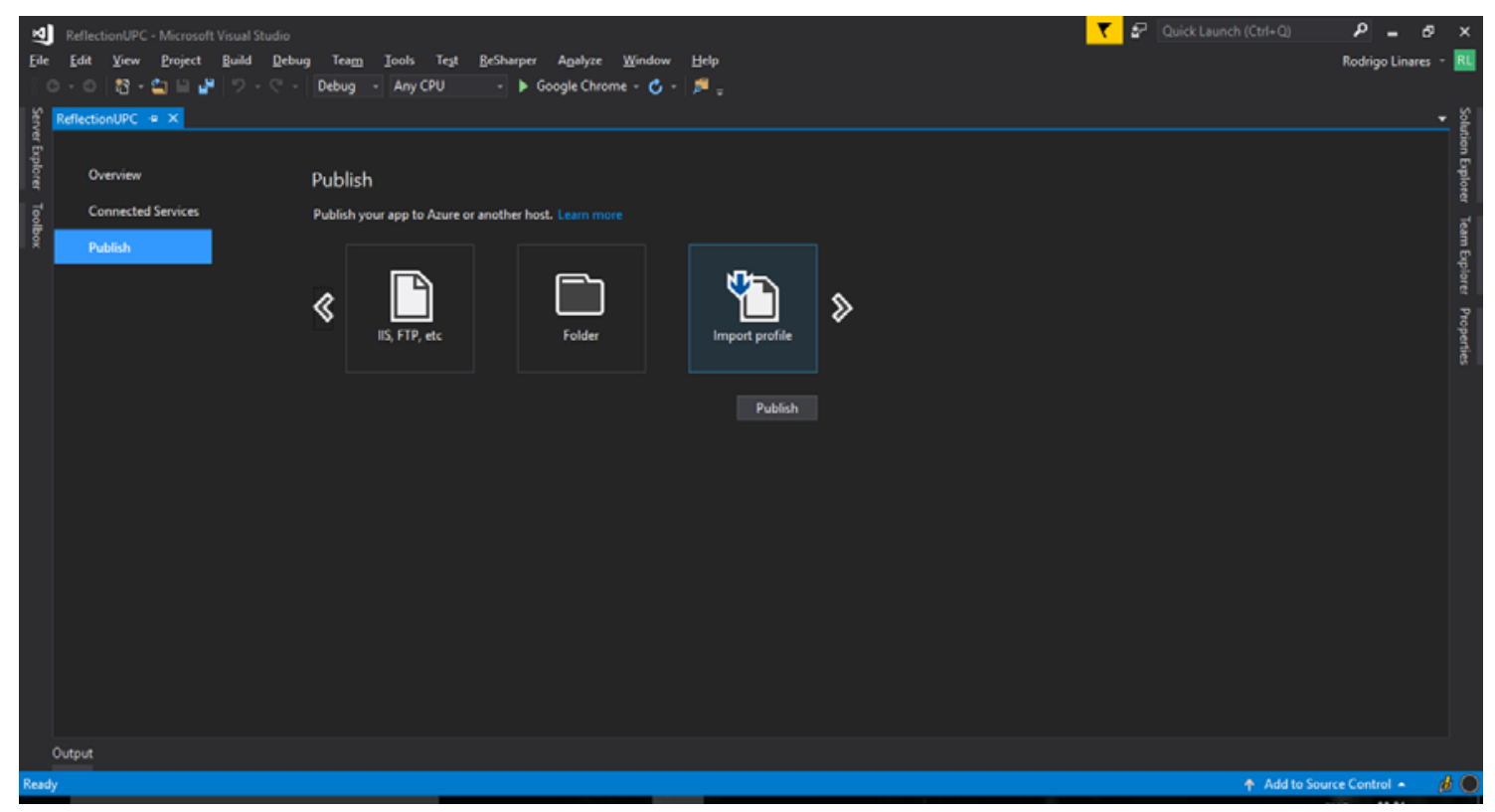

Figura 44. Publish de Web App

Nota: Elaboración propia

Una vez publicado el proyecto, debemos regresar a la página de la aplicación y activar el FTP, pues tendremos que subir las librerias EmguCV, las cuales no son publicadas por defecto. Va a ser necesario crear credenciales FTP por lo que se recomienda anotar las credenciales para su posterior uso.

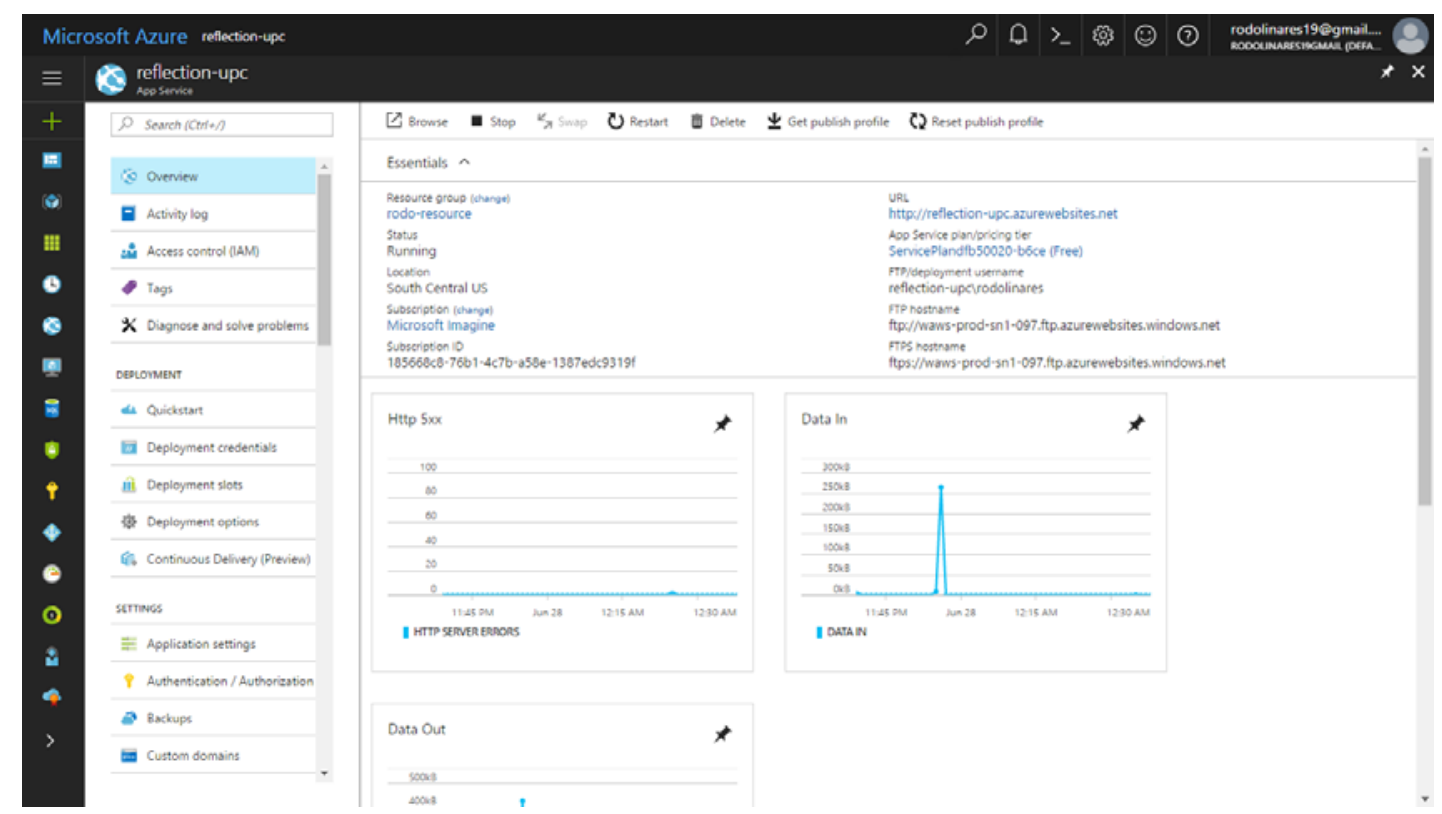

Figura 45. Dashboard reflection-upc

Nota: Elaboración propia

Una vez creadas las credenciales, abrimos una ventana del explorador de Windows y en la barra superior copiamos el FTP Hostname, ingresamos credenciales cuando nos las soliciten y navegamos a la carpeta bin como se muestra en la siguiente imagen: 


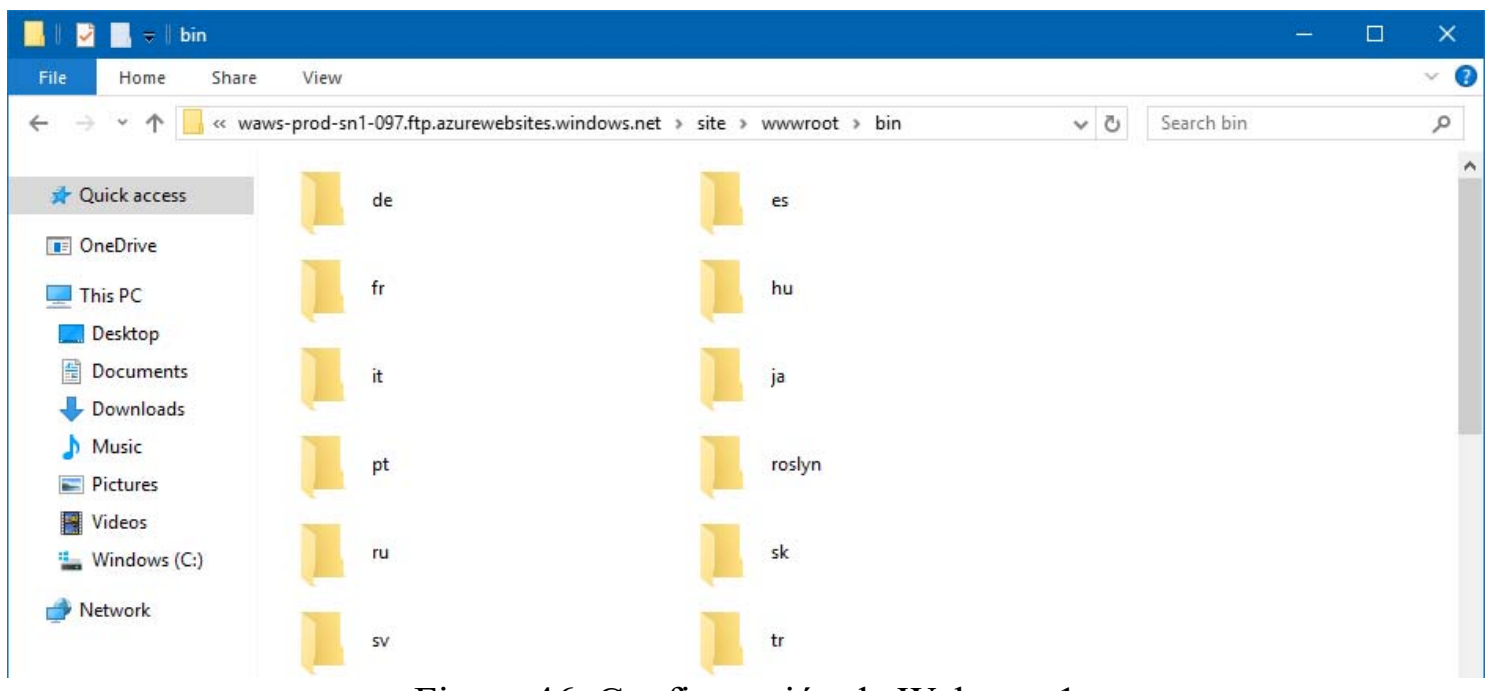

Figura 46. Configuración de Web app 1

Nota: Elaboración propia

Una vez aquí tendremos que copiar dos carpetas que se encuentran en la solución del sistema, también dentro de su propia carpeta bin.

\begin{tabular}{|c|c|c|c|c|c|}
\hline \multicolumn{5}{|l|}{ D $\mathbf{A}=$ bin } & \multirow{3}{*}{$\begin{array}{c}\square \quad \times \\
\\
0 \\
0\end{array}$} \\
\hline File Home Share & view & & & & \\
\hline \multicolumn{4}{|c|}{ 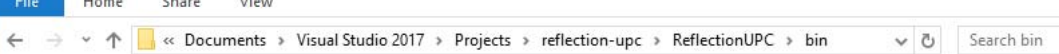 } & $\sim 0$ Search bin & \\
\hline \multirow[b]{2}{*}{ Quick access } & Name & Date modified & Type & Size & \\
\hline & de & 28-Jun-17 00:03 & File folder & & \\
\hline 国 OneDrive & Wes & 28-Jun-17 00:03 & File folder & & \\
\hline This PC & $\mathrm{fr}$ & 28-Jun-17 00:03 & File folder & & \\
\hline Desktop & hu & 28-Jun-17 00:03 & File folder & & \\
\hline Iric Documents & it & 28-Jun-17 00:03 & File folder & & \\
\hline Downloads & pt & $\begin{array}{l}\text { 28-Jun-1700:03 } \\
\text { 28-Jun-1700:03 }\end{array}$ & $\begin{array}{l}\text { File folder } \\
\text { Filefolder }\end{array}$ & & \\
\hline d) Music & roslyn & 28-Jun-1700:03 & File folder & & \\
\hline Pictures & $\mathrm{ru}$ & 28-Jun-17 00:03 & File folder & & \\
\hline 国 Videos & $\square \mathrm{sk}$ & 28-Jun-17 00:03 & File folder & & \\
\hline \multirow[t]{2}{*}{ \pm Windows (C:) } & $\square \mathrm{sv}$ & 28-Jun-17 00:03 & File folder & & \\
\hline & $\mathrm{tr}$ & 28-Jun-17 00:03 & File folder & & \\
\hline \multirow[t]{9}{*}{ Network } & $\times 64$ & 28-Jun-17 00:03 & File folder & & \\
\hline & $x 86$ & 28-Jun-17 00:03 & File folder & & \\
\hline & zh-cn & 28-Jun-17 00:03 & File folder & & \\
\hline & 2h-tw & 28-Jun-17 00:03 & File folder & & \\
\hline & 國 Emgu.Cv.ul.dll & 14-Jun-16 16:54 & Application ertens... & $115 \mathrm{~KB}$ & \\
\hline & Emgu.Cv.UI.GL.dll & 14-Jun-16 16:54 & Application extens.... & $27 \mathrm{~KB}$ & \\
\hline & Emgu.Cv.Ul.GL.xml & 14-Jun-16 16:54 & XML Document & $3 \mathrm{~KB}$ & \\
\hline & {[] Emgu.Cv.UI.xml } & 14-Jun-16 16:54 & XML Document & $34 \mathrm{~KB}$ & \\
\hline & Emgu.Cv.World.dll & 14-Jun-16 16:54 & Application ertens.... & $497 \mathrm{~KB}$ & \\
\hline 72 items 2 ittems selected & & & & & 相国 \\
\hline
\end{tabular}

Figura 47. Configuración de Web App 2

Nota: Elaboración propia 


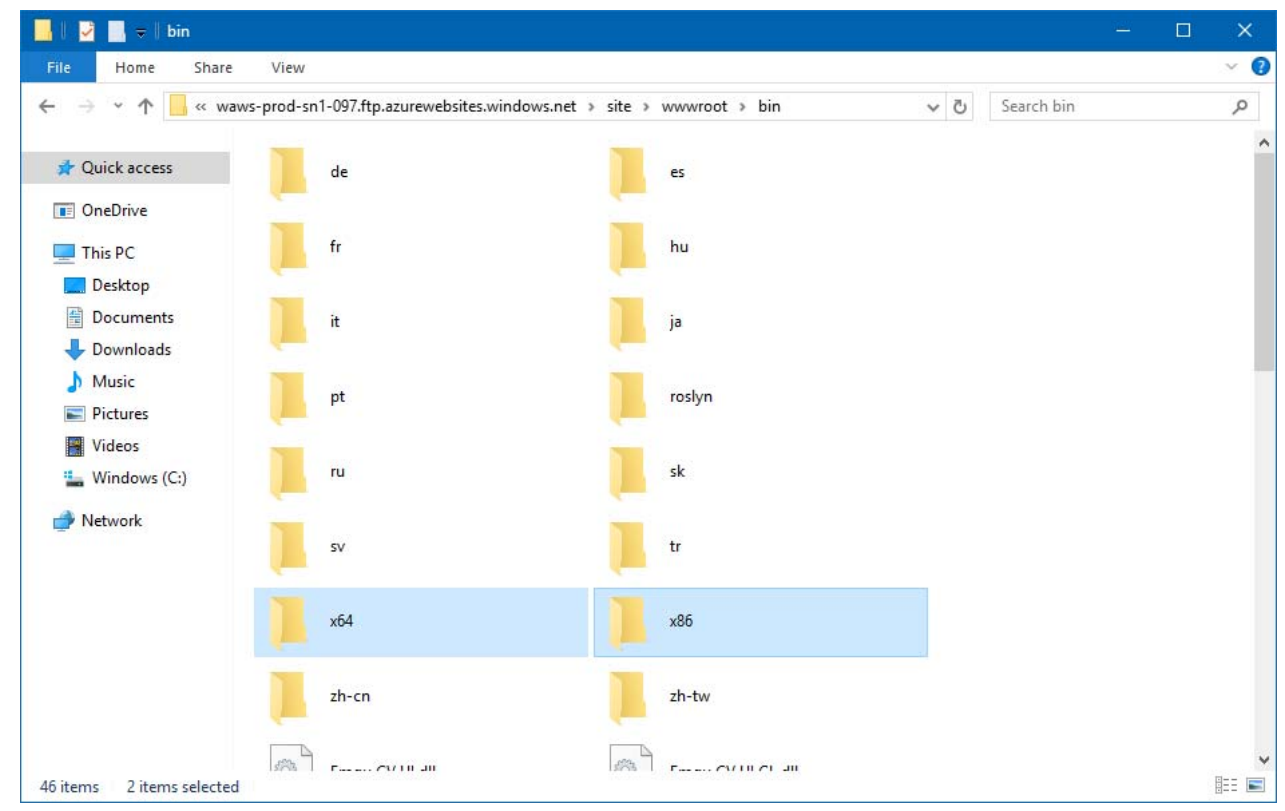

Figura 48. Configuración de Web App 3

Nota: Elaboración propia

Con esto habremos terminado la publicación de la aplicación web.

\section{Despliegue de la aplicación móvil}

Junto a este documento se añade un archivo con extensión apk el cual debe ser transferido e instalado a un teléfono Android versión 6 (Marshmallow). Una vez instalada la aplicación, estará listo para utilizar la aplicación. 


\section{Anexo 6: Manual de Identidad Reflection}

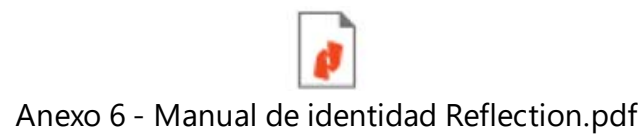




\section{Anexo 7: User Persona}

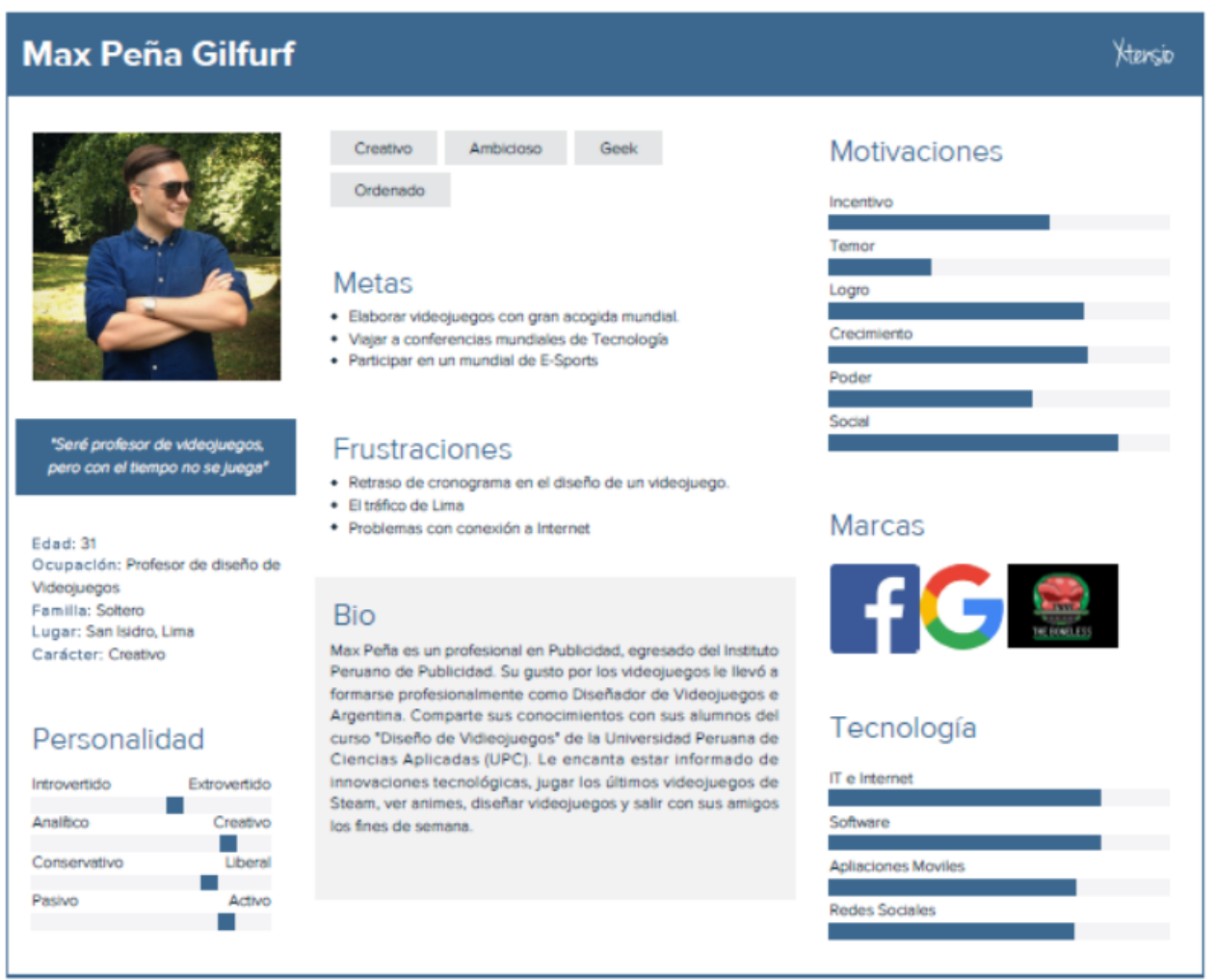

Figura 49. Usuario $\mathrm{N}^{\circ} 1$

Nota: Elaboración propia

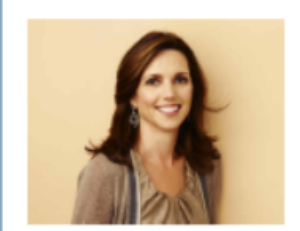

Un Iider es aquel que conoce of "Un ider es aquel que conoce of
camina, va par el camino y muestats
ef comino"

\section{Edad: 35}

Ocupaclón: Jefa de Proyectos

Familla: Casada

Lugar: San Luis, Lima

Carbcter: Liderazgo

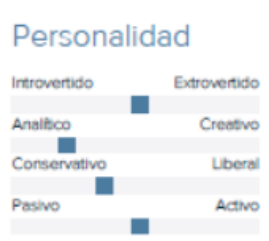

\section{Ordenade Ambicosa Prosdiva}

Independiente

\section{Metas}

- Escalar laboraimente en la consultora donde traboja - Vajar en un tour por Europa y Asia junto a su esposo

Frustraciones

- Poco compromiso de algunos miembros de equipo de

proyecto

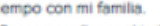

Bio

Deidid Doza professional en ingeniería de Sistemas egresada de ia Universidad San Martin de Porres con estudios de postgrado en la Universidad Pertuana de Cencias Aplicadas (UPC), Madre de famitia de dos hijos de edades de 5 y 8 a ros Generamente. deja sus cosas istas un dira antes para compartir el desayuno con su familia. Considera como "sagrado" el tempo que demora en alistarse porque cuida mucho de su imagen personal. Sin embargo, le gustaria mantenerse mas informada de los acontecmientos actuales que sucede en el mundo.
Motivaciones

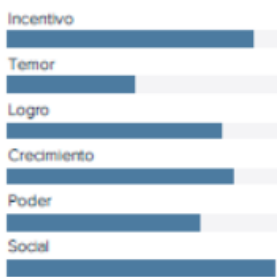

Marcas

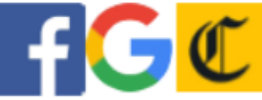

Tecnología

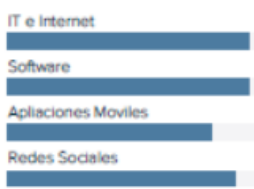

Figura 50. Usuario $\mathrm{N}^{\circ} 2$

Nota: Elaboración propia 


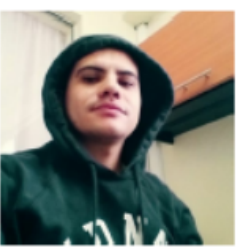

Za folografio es ba histong que no coloco en postobras"

Edad: 27

Ocupación: Edtor de imsgenes

Familla: Casado

Lugar: San Juan de Luniganctio.

Cardcter: Extrovertico

Personalidad

Introvertido Extroventido

Analitoo

Conservativo

a

Crestivo

Pasivo

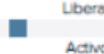

- Activo
Aventurero Creatvo Ambicoso

Apasionado

Metas

- Ser un forograforeconocido a rivel mundial

- Capactarse en herramientas de edicón y técricas de fotografa

Alore mi proplo estudio de fotografa

Frustraciones

- No cortar con los programas de edidón por temas de licenci

Poca velocidad de irternet para descargar herramientas de

edión

- No conseguir el ángulo o encuadre deseado

Bio

Jorge Torres es un aficionado a la Fotografia, Trabaja en ung gencia publicitaria donde brinda servicios de edición de otografia. Sin embargo, le gustaría involuctarse mas en ins sesiones como fotógrafo principal Thene 1 año de casado y una bebe de 3 meses Le encanta pasar tiempo con su familia $y$ atesorar esos momentos en la cofmara
Motivaciones

Incentvo

Temor

Logro

Creamierto

Poder

Socidel

Socd

Marcas

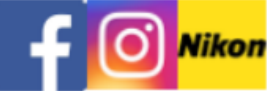

Tecnología

IT e internet

Sotrine

Sothware

Aplisciones Moviles

acossoges

Redes Sociales

Figura 51. Usuario $\mathrm{N}^{\circ} 3$

Nota: Elaboración propia 
Anexo 8: Informe - ESTADO DEL ARTE

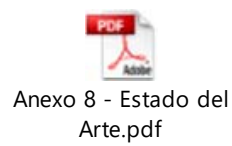


Anexo 9: Informe - ARBOL / PAPER

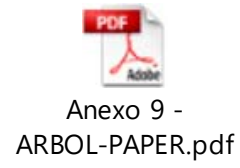




\section{Anexo 10: Informe - ALGORITMO DE MACHINE LEARNING}

\section{INTRODUCCIÓN}

Este informe detalla el proceso de la implementación del algoritmo de Machine Learning que se utilizó en el proyecto Smart Mirror. Desde la investigación de dataset similares para utilización y recopilación de datos, como las pruebas de rendimientos del dataset para la elaboración del modelo predictivo a implementar en la funcionalidad de visualización de noticias.

\section{DATASET}

Es una colección de datos que son usados para entrenar y probar un nuevo sistema en desarrollo. Conforme los sistemas reales trabajen en los datos, es necesario validar y verificar su comportamiento con extensos conjuntos de datos antes de su implementación. Además, los conjuntos de datos de alta calidad se han vuelto fundamentales para capacitar a estas aplicaciones para que funcionen con un nivel aceptable de precisión. En el campo de la recomendación de noticias, todavía hay pocos conjuntos de datos disponibles, y muchos se sienten obligados a utilizar conjuntos de datos no nuevos para probar sus algoritmos para recomendación de noticias.

Para nuestro proyecto se tuvo la necesidad de elaborar un dataset con el objetivo de obtener información de las categorías de noticias que interesan a una persona según su perfil.

Para obtener información recurrimos a la recolección de datos utilizando como técnica las entrevistas y encuestas que realizamos a una cantidad de personas, cuya cantidad de muestra se realizó calculando el total de la cantidad de valores que puede tomar un atributo.

\subsection{Definición de las variables de Investigación}

Se definen a partir de la hipótesis de investigación, pues se establece de forma clara y operativa las variables que son causa y efecto.

Hipótesis: ¿Cuáles son las categorías de noticias que son de interés de acuerdo a características de personas que estén en el rango de edad de 18 a 40 años de la ciudad de Lima?

A. Por su posición en una Hipótesis o Relación de Dependencia

- Variable independiente: Categorías de Noticias.

- Variable dependiente: Perfil de personas

B. Por su naturaleza

- Variables Cuantitativas: Edad

- Variables Cualitativas: Categoría de noticias, Sexo, Estado Civil, Ocupación, Residencia, Sector socioeconómico. 
C. Descripción de variables

$\underline{\text { Variable edad }}$

\begin{tabular}{|l|l|}
\hline Denominación & Edad \\
\hline Tipo & Independiente \\
\hline Naturaleza & Cuantitativa \\
\hline Medición & De razón \\
\hline Indicador & Fecha de Nacimiento \\
\hline Unidad de Medida & Años \\
\hline Instrumento & Encuesta \\
\hline Dimensión & Biológica \\
\hline Definición operacional & \\
\hline Definición conceptual & $\begin{array}{l}\text { Tiempo que ha vivido una } \\
\text { persona. }\end{array}$ \\
\hline
\end{tabular}

Tabla 8. Descripción de la variable edad Fuente: Elaboración Propia

$\underline{\text { Variable Sexo }}$

\begin{tabular}{|l|l|}
\hline Denominación & Sexo \\
\hline Tipo & Independiente \\
\hline Naturaleza & Cualitativa \\
\hline Medición & Nominal \\
\hline Indicador & Identidad Sexual \\
\hline Unidad de Medida & Cantidad de Mujeres y Hombres \\
\hline Instrumento & Encuesta \\
\hline Dimensión & Biológica \\
\hline Definición operacional & Masculino/Femenino \\
\hline Definición conceptual & $\begin{array}{l}\text { Característica natura o biológica } \\
\text { del ser humano. }\end{array}$ \\
\hline
\end{tabular}

Tabla 9. Descripción de la variable sexo Fuente: Elaboración Propia

$\underline{\text { Variable Estado Civil }}$

\begin{tabular}{|l|l|}
\hline Denominación & Estado civil \\
\hline Tipo & Independiente \\
\hline Naturaleza & Cualitativa \\
\hline Medición & Nominal \\
\hline Indicador & Partida de Matrimonio \\
\hline Unidad de Medida & Cantidad de acuerdo a su condición \\
\hline Instrumento & Encuesta \\
\hline Dimensión & Social \\
\hline Definición operacional & Soltero/Casado/Viudo/Divorciado \\
\hline Definición conceptual & $\begin{array}{l}\text { Condición de unión social de una } \\
\text { pareja. }\end{array}$ \\
\hline
\end{tabular}

Tabla 10. Descripción de la variable estado civil Fuente: Elaboración Propia 
Variable Ocupación

\begin{tabular}{|l|l|}
\hline Denominación & Ocupación \\
\hline Tipo & Independiente \\
\hline Naturaleza & Cualitativa \\
\hline Medición & Nominal \\
\hline Indicador & Sector Laboral \\
\hline Unidad de Medida & Condición laboral \\
\hline Instrumento & Encuesta \\
\hline Dimensión & Social \\
\hline Definición operacional & Estudiante/Trabajador/Ambos \\
\hline Definición conceptual & Actividad o trabajo \\
\hline
\end{tabular}

Tabla 11. Descripción de la variable ocupación

Fuente: Elaboración Propia

$\underline{\text { Variable Residencia }}$

\begin{tabular}{|l|l|}
\hline Denominación & Residencia \\
\hline Tipo & Independiente \\
\hline Naturaleza & Cualitativa \\
\hline Indicaón & Nominal \\
\hline Unidad de Medida & Domicilio \\
\hline Instrumento & $\begin{array}{l}\text { Cantidad de personas residentes } \\
\text { por distrito de Lima }\end{array}$ \\
\hline Dimensión & Encuesta \\
\hline Definición operacional & Ubicación demográfica \\
\hline Definición conceptual & $\begin{array}{l}\text { Lugar o domicilio en el que una } \\
\text { persona reside }\end{array}$ \\
\hline
\end{tabular}

Tabla 12. Descripción de la variable residencia Fuente: Elaboración Propia

$\underline{\text { Variable Sector Socioeconómico }}$

\begin{tabular}{|l|l|}
\hline Denominación & Sector Socioeconómica \\
\hline Tipo & Independiente \\
\hline Naturaleza & Cualitativa \\
\hline Medición & Nominal \\
\hline Indicador & Economía por persona \\
\hline Unidad de Medida & Cantidad de ingreso mensual \\
\hline Instrumento & Encuesta \\
\hline Dimensión & Social \\
\hline Definición operacional & A/B/C/D/E \\
\hline Definición conceptual & $\begin{array}{l}\text { Medida económica y } \\
\text { sociológica de una persona. }\end{array}$ \\
\hline
\end{tabular}

Tabla 13. Descripción de la variable sector socioeconómico Fuente: Elaboración Propia 
Asimismo, durante la investigación de la obtención de datos se utilizó como referencias datasets similares cuya información es utilizada en sistemas de recomendación:

- Netflix Dataset: El servicio de alquiler de películas online más grande del mundo anunció un concurso para mejorar su servicio de recomendación de películas, para el cual publicó su conjunto de datos entre los años 1999 y 2005. El cual contiene las siguientes características:

\begin{tabular}{|l|l|}
\hline Atributos & Valores \\
\hline Característica del Dataset & Multivariable \\
\hline $\begin{array}{l}\text { Característica de los } \\
\text { atributos }\end{array}$ & Enteros \\
\hline Tareas asociadas & Clustering, Sistema de recomendación \\
\hline Cantidad de instancias & 100480507 \\
\hline Cantidad de Atributos & 17770 \\
\hline ¿Existe valores nulos? & $\mathrm{Si}$ \\
\hline Área & $\mathrm{N} / \mathrm{A}$ \\
\hline
\end{tabular}

Tabla 14. Características de dataset Netflix

Fuente: http://academictorrents.com/details/9b13183dc4d60676b773c9e2cd6de5e5542cee9a

\begin{tabular}{|l|l|}
\hline Atributos & Valores \\
\hline MovieID & $\begin{array}{l}\text { Se asignó arbitrariamente un número } \\
\text { entero único en el intervalo de 1-17770 }\end{array}$ \\
\hline CustomerID & $\begin{array}{l}\text { Se asignó arbitrariamente un número } \\
\text { entero único en el intervalo de 1- } \\
2649429\end{array}$ \\
\hline Rating & $\begin{array}{l}\text { Número de estrellas asignadas a una } \\
\text { película por un cliente; Un número } \\
\text { entero de 1 a 5. }\end{array}$ \\
\hline Title & $\begin{array}{l}\text { Título de la película que se encuentra en } \\
\text { Netflix }\end{array}$ \\
\hline YearOfRelease & $\begin{array}{l}\text { Año de la película que fue estrenada } \\
\text { entre los años 1890-2005. }\end{array}$ \\
\hline Date & $\begin{array}{l}\text { Año en el que fue calificado por el } \\
\text { usuario }\end{array}$ \\
\hline NetflixID & $\begin{array}{l}\text { ID de una película como se utiliza } \\
\text { actualmente en la API de desarrollador } \\
\text { de Netflix }\end{array}$ \\
\hline
\end{tabular}

Tabla 15. Atributos de dataset Netflix

Fuente: http://academictorrents.com/details/9b13183dc4d60676b773c9e2cd6de5e5542cee9a

- MovieLens Dataset: Es un proyecto de la Universidad de Minnesota, dirigido por GroupLens Research Group. Existe tres conjuntos de datos de diferentes tamaños que se han elaborado en diferentes periodos de tiempo. Los conjuntos de datos contienen información demográfica de los usuarios como edad, sexo, ocupación, código postal. 


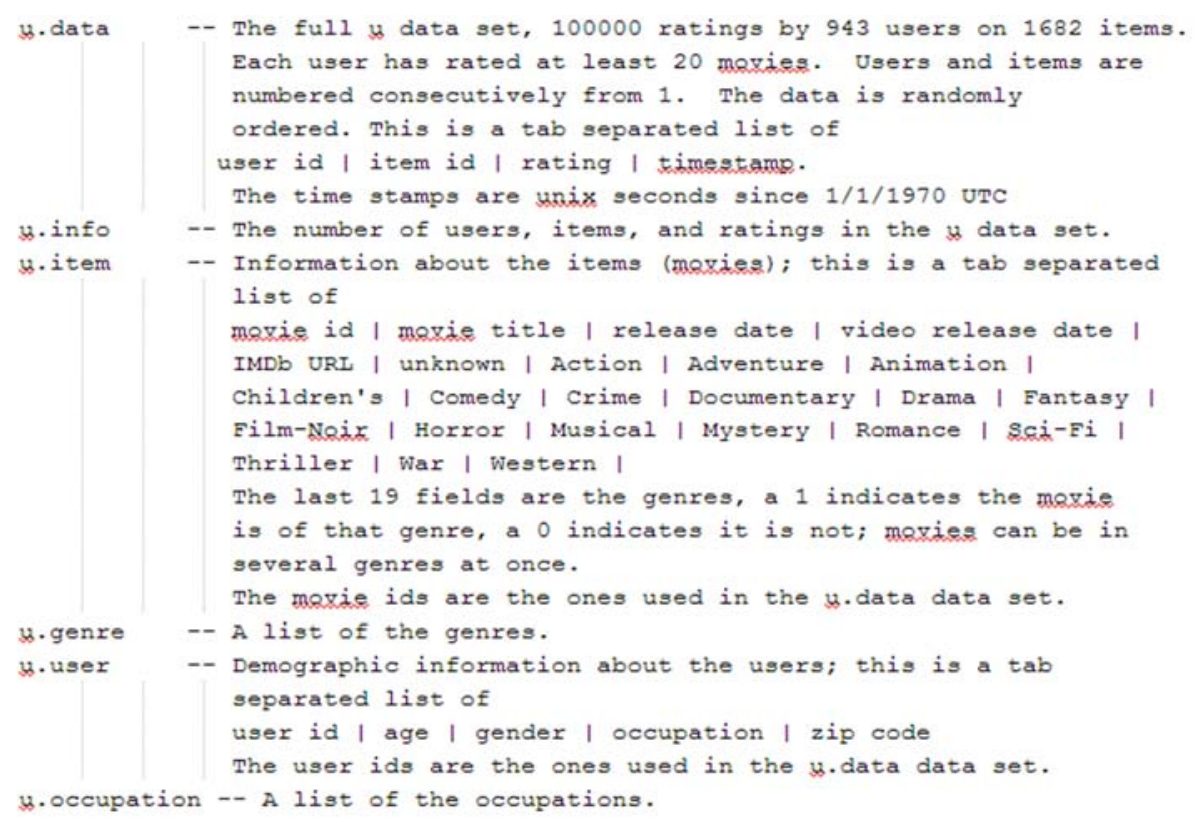

Figura 52. Estructura de Dataset

Fuente: https://grouplens.org/datasets/movielens/

De tal forma, se concluyó que nuestro instrumento principal para la extracción de datos serían encuestas elaboradas con Google Forms y los datos a extraer son: edad, sexo, estado civil, residencia, ocupación, sector socioeconómico. Posteriormente, se calculó la cantidad de instancias que se debe obtener según el estudio de muestreo estratificado o el cálculo total de los valores que puede tomar cada atributo.

\subsection{Muestreo Estratificado}

El muestreo estratificado es una técnica de muestreo probabilístico en donde el investigador divide toda la población en diferentes subgrupos o estratos. Luego, selecciona aleatoriamente a los sujetos finales de los diferentes estratos en forma proporcional. En base a esta teoría los estratos para la encuesta a realizar serán muestras de los alumnos de cada carrera de la UPC presentes en la sede de Monterrico.

2.2.1. Obtención del tamaño de muestra

Podemos considerar 3 métodos para distribuir el tamaño de la muestra entre los estratos:

- Proporcionalmente al tamaño de cada estrato, es decir, si tomamos el estrato j-esimo de tamaño $\mathrm{N}-\mathrm{j}$, entonces una muestra de dicho estrato será de tamaño:

$$
n \cdot\left(N_{j} / N\right)
$$

Siendo $\mathrm{N}$ el total de la población y n el tamaño de la muestra.

- Proporcionalmente a la variabilidad de la característica que estamos considerando en cada estrato. Por ejemplo, si conocemos que la varianza en la altura de los alumnos es de $15 \mathrm{~cm}$ y en las 
alumnas es de $5 \mathrm{~cm}$, la proporción de los alumnos es 3 a 1 y la muestra deber guardar esa proporción.

- Se asigna el mismo tamaño a cada estrato. Como consecuencia se favorece a los estratos más pequeños y se perjudica a los grandes en cuanto a precisión.

\subsection{Obtención de datos por cantidad de atributos y valores}

Se definió la cantidad de atributos y la cantidad de valores de cada atributo, para luego proceder a multiplicarlos y obtener el mínimo tamaño de la muestra que se debe obtener a partir de la encuesta. En la siguiente tabla se describe los atributos y sus valores:

\begin{tabular}{|c|c|c|}
\hline Input atributos & Valor & $\begin{array}{c}\text { Valor } \\
\text { cuantificado }\end{array}$ \\
\hline \multirow{2}{*}{ Género } & Masculino & 1 \\
\hline \multirow{2}{*}{ Edad } & Femenino & 2 \\
\hline Ocupación & {$[18 ; 35]$} & 1 \\
\hline \multirow{5}{*}{ Área } & Estudiante & 1 \\
\hline \multirow{5}{*}{} & Trabajador & 2 \\
\hline & Ambos & 3 \\
\hline & Adm. Hotelera & 1 \\
\hline & Arquitectura & 2 \\
\hline & Artes Contemporáneas & 3 \\
\hline & Ciencias de la Salud & 4 \\
\hline & Comunicaciones & 5 \\
\hline & Derecho & 6 \\
\hline & Diseño & 7 \\
\hline & Economía & 8 \\
\hline & Educación & 9 \\
\hline & Ingeniería - Informática & 10 \\
\hline & Negocios & 11 \\
\hline & Psicología & 12 \\
\hline
\end{tabular}

Tabla 16. Atributos finales del Dataset

En donde: Fuente: Elaboración propia

$$
\begin{aligned}
\operatorname{Muesta}(\mathrm{N}) & =2 \times 1 \times 3 \times 12 \\
& =72 \text { instancias }
\end{aligned}
$$

Por último, se decidió tener como objetivo una muestra mínima de 72 instancias con cuatro atributos descartando algunos que se tenía en la versión inicial, pues dado el poco tiempo que teníamos para obtener la data decidimos trabajar con lo necesario , logrando tener un total de 98 instancias en el archivo final de extensión .arff . 


\subsection{Pre-procesamiento de Datos}

2.4.1. Definición de la estructura del dataset

Este proceso fue muy iterativo, se realizaron diversas encuestas con el fin de encontrar la estructura correcta que nos ayude a construir el dataset que nuestro modelo predictivo utilizaría. Inicialmente la encuesta contaba con 9 preguntas, luego de obtener alrededor de 40 instancias, se realizaron pruebas con Weka; con estas pruebas notamos que el dataset no respondía a las necesidades que demandaría el modelo y al caso de estudio al cuál buscábamos aplicarlo.

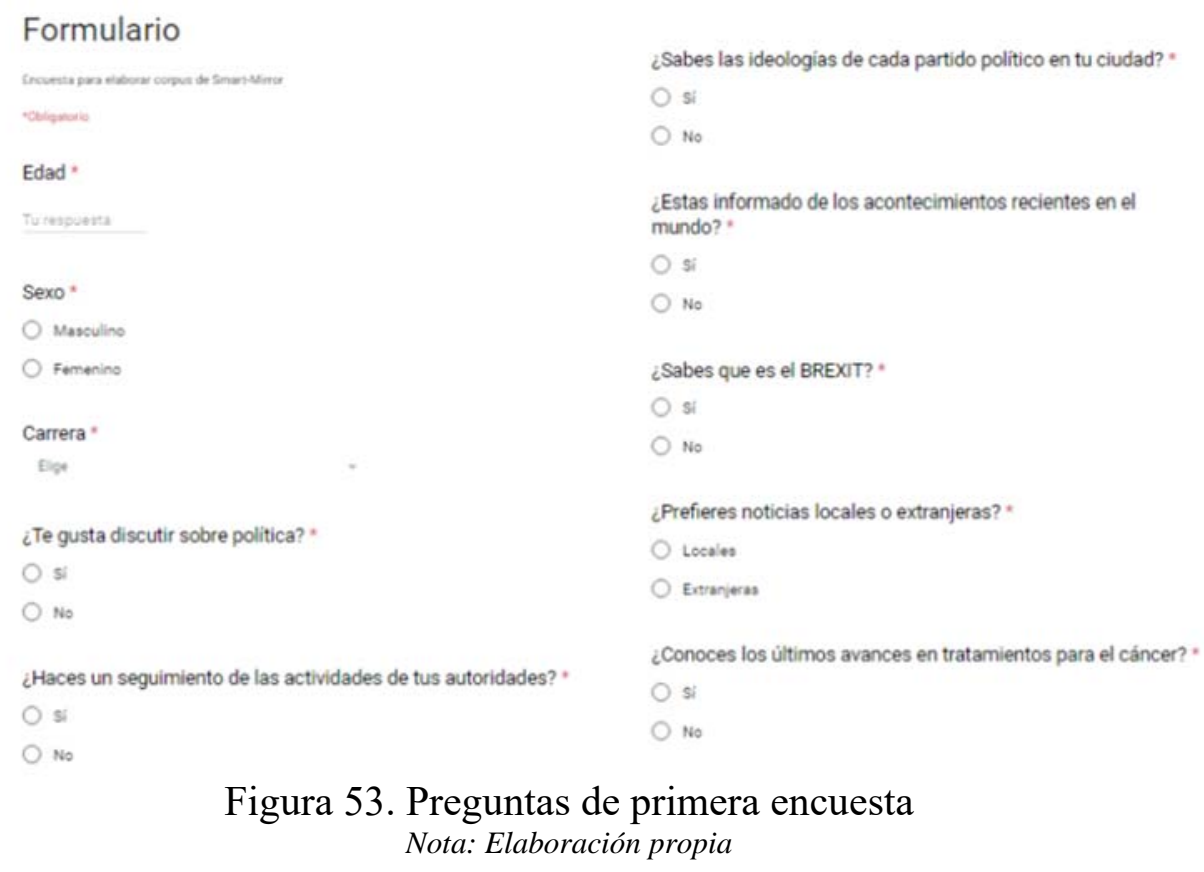

En la siguiente encuesta, se redujo el número de preguntas, pero cada una de estas preguntas podía tomar gran cantidad de diversos valores, lo cual no era favorable para el modelo. Además, en esta encuesta la pregunta acerca del área de interés del usuario podía ser respondido con más de un tema lo cual generaba gran dispersión. Esto fue confirmado realizando pruebas con Weka, los resultados obtenidos eran demasiado bajos. Con la prueba del algoritmo de Naive Bayes se obtuvo: (9.5238\%) con percentage split y $(12.6761 \%)$ con cross validation. 


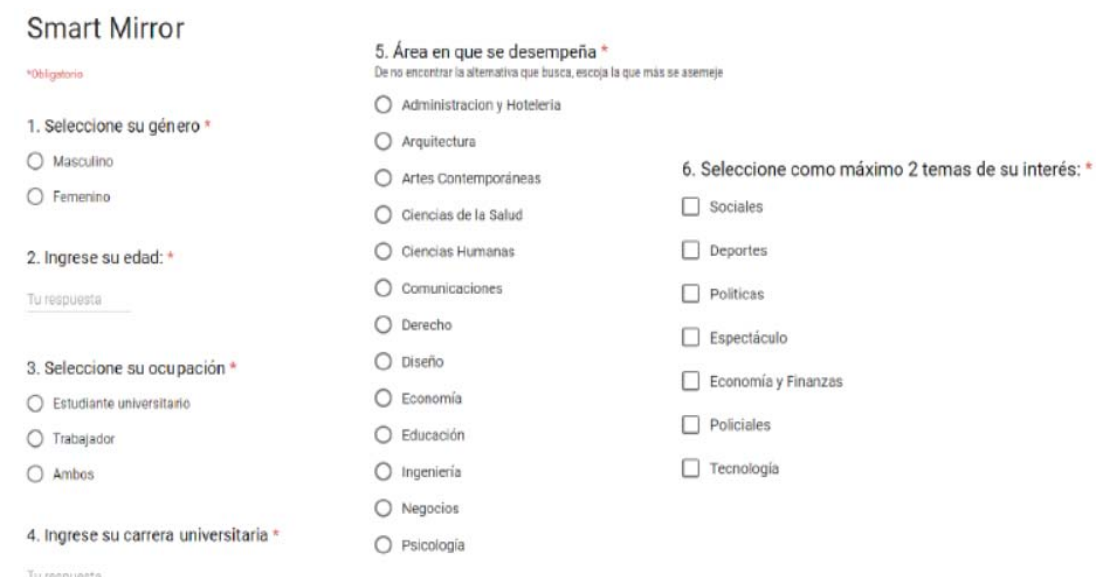

Figura 54. Preguntas de segunda encuesta Fuente: Elaboración propia

Finalmente, se creó otra encuesta, la cual cuenta con 5 preguntas, y la pregunta acerca del área de interés del usuario podía tomar un valor único. A partir de esta encuesta se generó el dataset utilizado.

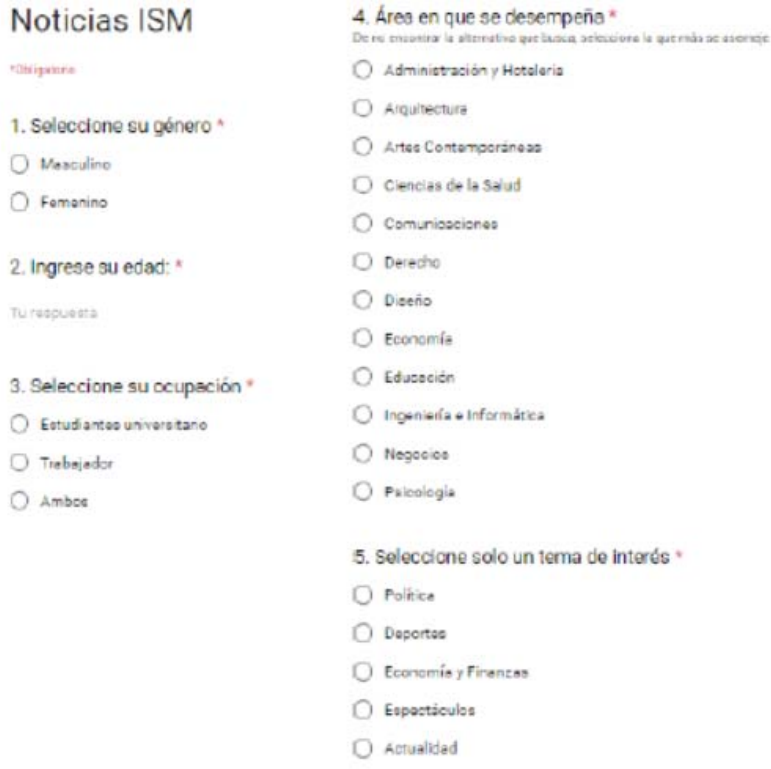

Figura 55. Preguntas de tercera encuesta Fuente: Elaboración propia

\subsubsection{Limpieza de datos}

El proceso de recolección de información trae consigo la obtención de datos de todo tipo, por lo general gran parte de dichos datos tienen que ser descartados debido a que cuentan con valores atípicos o incompletos. En este caso, luego de haber culminado la etapa de recolección (con encuestas), comenzamos la etapa de depuración de información incompleta. En este caso, se utilizó Excel para eliminar las instancias que contaban con valores nulos o vacíos. 


\section{EXPERIMENTACIÓN}

Luego de obtener las instancias a partir de la encuesta se procedió a evaluar tres diferentes algoritmos de clasificación. Estos algoritmos son:

- Multilayer Perceptron (MP)

- Naive Bayes (NB)

- $\mathrm{J} 48$

Además se usaron los siguientes métodos de evaluación:

- Cross Validation (CV)

- Percentage Split (PS)

\begin{tabular}{|l|l|l|}
\hline Algoritmo de clasificación & Método & Instancias clasificadas \\
\hline Naive Bayes & CV (10) & $58.16 \%$ \\
\hline Naive Bayes & PS (70\%) & $62.07 \%$ \\
\hline Multilayer Perceptron & CV (10) & $56.12 \%$ \\
\hline Multilayer Perceptron & PS (70\%) & $51.72 \%$ \\
\hline J48 & CV(10) & $55.10 \%$ \\
\hline J48 & PS (70\%) & $55.17 \%$ \\
\hline
\end{tabular}

Tabla 17. Comparación de porcentajes de instancias correctamente clasificadas

Fuente: Elaboración Propia

En el primer caso comparamos los porcentajes de instancias correctamente clasificadas para conocer la eficiencia de cada algoritmo. Debido a la cantidad de instancias y el modelo de los datos, se verificó que el algoritmo de Naive Bayes, utilizando percentage split, presenta los mejores resultados con un $62.07 \%$.

3.1 Matriz de confusión

- Naive Bayes CV (10)

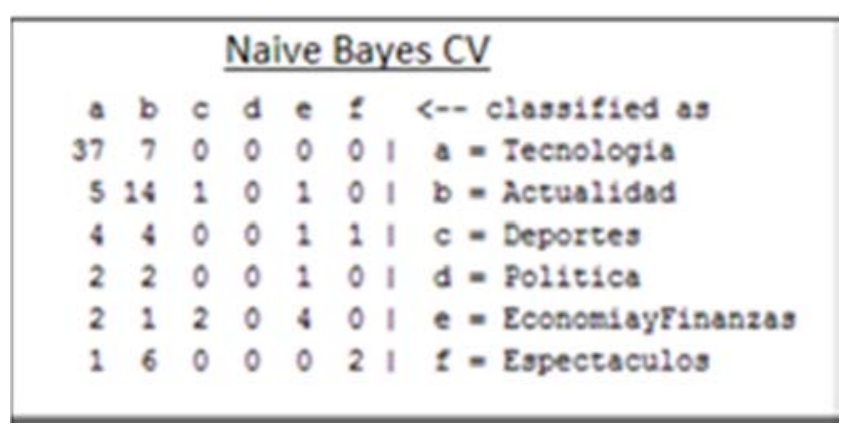

Figura 56. Matriz de confusión usando Naive Bayes con Cross Validation Nota: Elaboración propia 
- Naive Bayes PS (70\%)

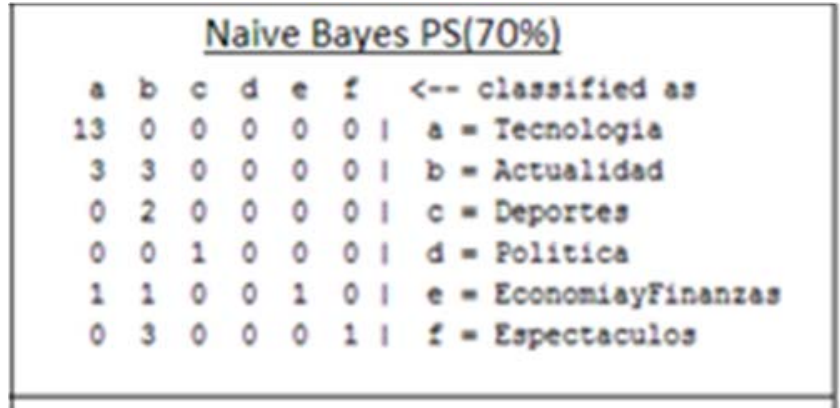

Figura 57. Matriz de confusión usando Naive Bayes con 70 Percentage Split Nota: Elaboración propia

- Multilayer Perceptron CV(10)

\begin{tabular}{|c|c|c|c|c|c|c|}
\hline \multicolumn{7}{|c|}{ Multilayer Perceptron CV (10) } \\
\hline a & b & e & d & e & 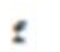 & <- claggified ag \\
\hline 23 & 0 & 0 & 0 & 0 & 01 & a - Tecnologia \\
\hline 3 & 3 & 0 & 0 & 0 & 01 & b $=$ Actualidad \\
\hline 0 & 2 & 0 & 0 & 0 & 01 & $c=$ Deportes \\
\hline 0 & 0 & 2 & 0 & 0 & 01 & d = Politica \\
\hline 1 & 1 & 0 & 0 & 1 & 01 & e - Econoniayfinanzag \\
\hline 0 & 3 & 0 & 0 & 0 & 11 & : - Espectaculos \\
\hline
\end{tabular}

Figura 58. Matriz de confusión usando Multilayer Perceptron con Cross Validation Nota: Elaboración propia

- Multilayer Perceptron PS (70\%)

\begin{tabular}{|c|c|c|c|c|c|c|}
\hline \multicolumn{7}{|c|}{ Multilayer Perceptron PS (70\%) } \\
\hline a & $b$ & c & d & e & & <- clasgitied as \\
\hline 10 & 0 & 2 & 0 & 1 & 01 & a - Tecnologia \\
\hline 1 & 2 & 2 & 0 & 0 & 21 & b $=$ Actualidad \\
\hline 0 & 2 & 0 & 0 & 0 & 01 & c - Deportes \\
\hline 0 & 0 & 2 & 0 & 0 & 01 & $d=$ Politica \\
\hline 0 & 0 & 2 & 0 & 2 & 01 & $e=$ Economiayrinanzas \\
\hline 0 & 3 & 0 & 0 & 0 & 11 & I = Escectaculos \\
\hline
\end{tabular}

Figura 59. Matriz de confusión usando Multilayer Perceptron, 70 Percentage Split

Nota: Elaboración propia 
- J48 CV (10)

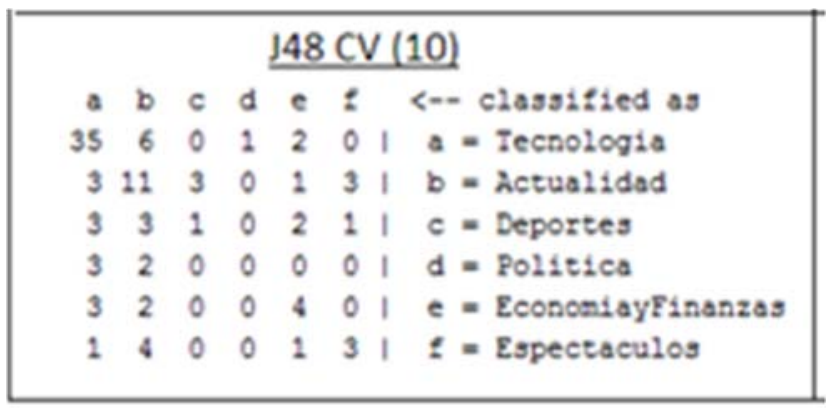

Figura 60. Matriz de confusión usando J48 con Cross Validation Nota: Elaboración propia

- J48 PS (70\%)

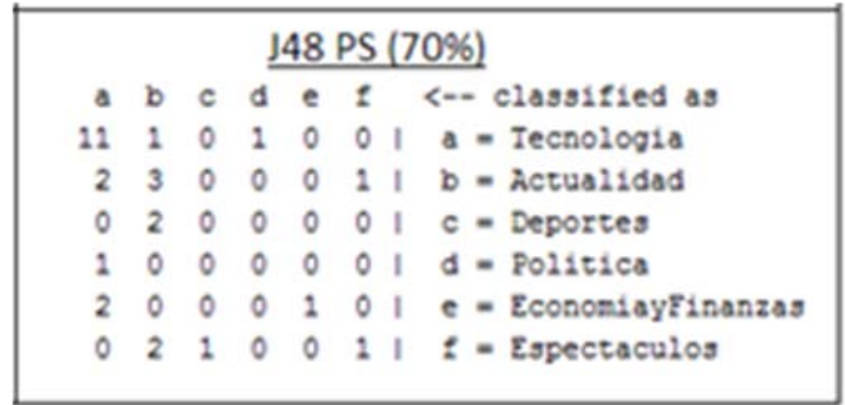

Figura 61. Matriz de confusión usando J48, 70 Percentage Split Nota: Elaboración propia

3.2 Área debajo de la curva ROC:

\begin{tabular}{|c|c|c|c|c|c|c|c|}
\hline Algoritmo & Tecnología & Actualidad & Deportes & Política & Economía & Espectáculos & Promedio \\
\hline $\begin{array}{ll}\mathrm{NB} & (\mathrm{CV} \\
10) & \end{array}$ & 0.838 & 0.794 & 0.610 & 0.415 & 0.792 & 0.708 & 0.768 \\
\hline $\begin{array}{l}\text { NB } \quad \text { (PS } \\
70 \%)\end{array}$ & 0.959 & 0.710 & 0.704 & 0.500 & 0.891 & 0.770 & 0.841 \\
\hline $\begin{array}{ll}\mathrm{MP} & (\mathrm{CV} \\
10) & \end{array}$ & 0.840 & 0.728 & 0.695 & 0.452 & 0.769 & 0.667 & 0.759 \\
\hline $\begin{array}{ll}\mathrm{MP} & (\mathrm{PS} \\
70 \%) & \end{array}$ & 0.925 & 0.630 & 0.185 & 0.500 & 0.814 & 0.390 & 0.713 \\
\hline $\begin{array}{ll}\mathrm{J} 48 & (\mathrm{CV} \\
10) & \end{array}$ & 0.727 & 0.647 & 0.530 & 0.342 & 0.801 & 0.511 & 0.657 \\
\hline $\begin{array}{ll}\mathrm{J} 48 & (\mathrm{PS} \\
70 \%) & \end{array}$ & 0.834 & 0.692 & 0.148 & 0.696 & 0.821 & 0.380 & 0.689 \\
\hline
\end{tabular}

Figura 62. Comparación por área debajo de la curva de los algoritmos de clasificación y método.

Nota: Elaboración Propia

Para el análisis de la curva ROC observamos que Naive Bayes obtiene un mayor promedio (0.841) utilizando percentage split. Al entrar en detalle, vemos que el 
valor más bajo del área debajo de la curva ROC es el de política con un 0.5. Esto se debe principalmente a los pocos datos que se tienen de este valor.

\section{IMPLEMENTACIÓN}

Finalmente el código principalmente consiste en leer el dataset mediante IDE Netbeans con el API de Weka, el cual genera un archivo de texto plano con el modelo resultante, el cual es enviado al servidor del espejo, que se encuentra en .NET, para ser leído y generar la predicción de la categoría, cuyo resultado es enviado a la funcionalidad de mostrar noticia a partir del RSS del diario local Perú 21.

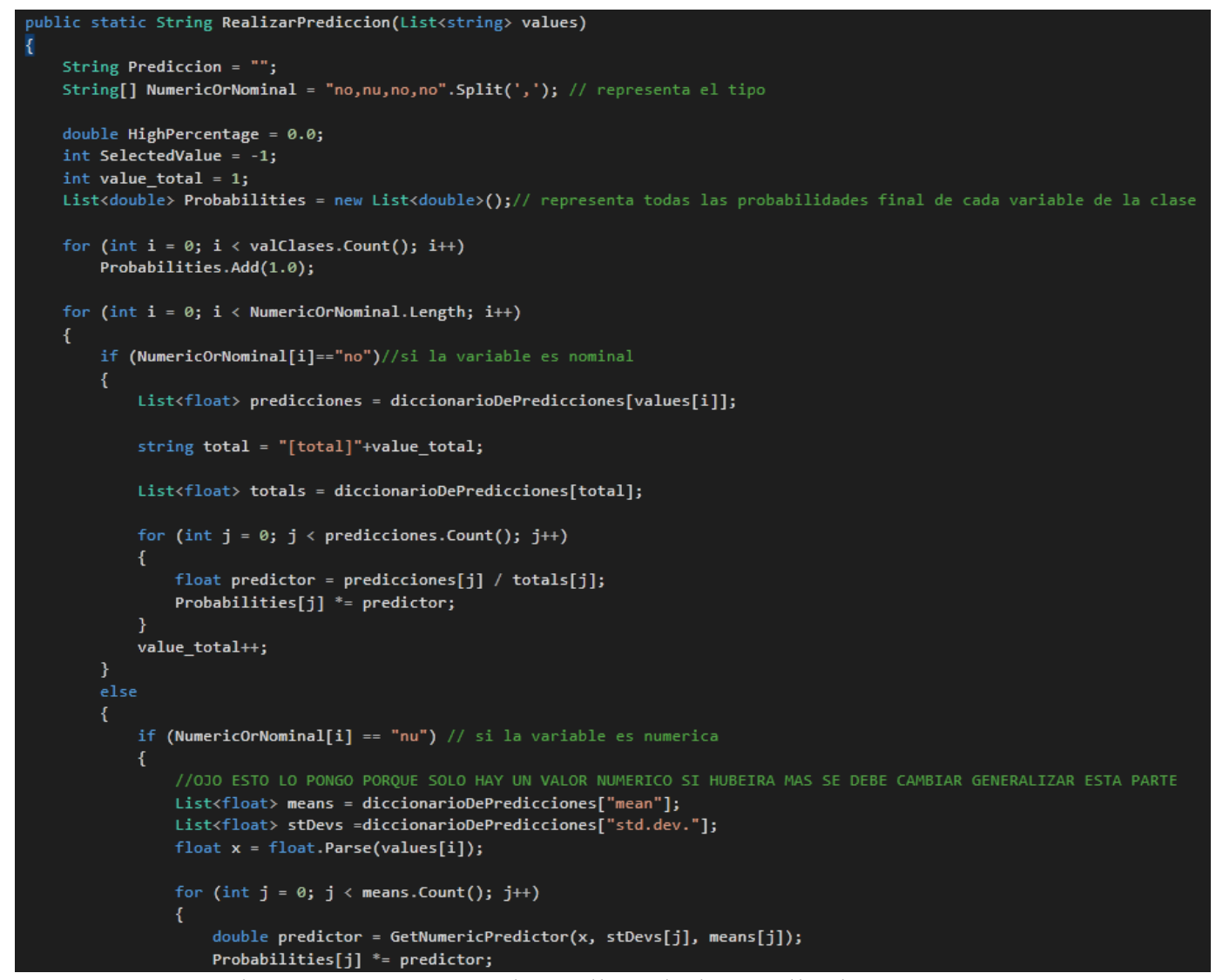

Figura 63. Captura de código de la predicción Nota: Elaboración propia

\section{CONCLUSIONES}

- Dada la escasez de datasets para la recomendación de noticias, se procedió a elaborar propio dataset.

- Se utilizó encuestas como técnica de obtención de datos.

- La cantidad de instancias se definió según la cantidad de atributos y valores que puede tomar cada uno de ellos.

- La encuesta fue realizada a losalumnos de cada carrera de la UPC presentes en la sede de Monterrico. 
- Se definió los atributos del dataset según modelos de dataset de sistemas de recomendación de películas.

- Conforme recopilamos información de las encuestas, descartamos atributos que no aportaban información relevante al dataset, quedando finalmente los atributos de edad, sexo, ocupación,área y como class la categoría de noticia a predecir.

- Se implementó el algoritmo de clasificación Naive Bayes con el método de evaluación de Cross Validation. 